Rationale and Preliminary Plan for Federal Research for Construction and Building

Subcommittee on Construction and Building

Civilian Industrial Technology Committee

National Science and Technology Council

Richard N. Wright, Co-Chair

Arthur H. Rosenfeld, Co-Chair

Andrew J. Fowell, Secretariat

QC

100

.456

N0.5536

1994 


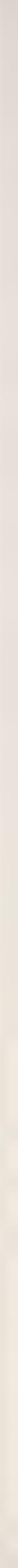




\section{Rationale and Preliminary Plan for Federal Research for Construction and Building}

Subcommittee on Construction and Building Civilian Industrial Technology Committee National Science and Technology Council

Richard N. Wright, Co-Chair Arthur H. Rosenfeld, Co-Chair Andrew J. Fowell, Secretariat

November 1994
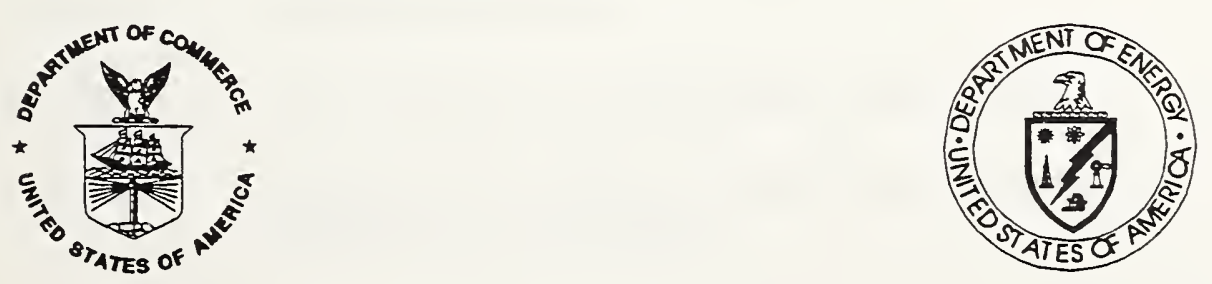

U.S. Department of Commerce

Ronald H. Brown, Secretary Technology Administration

Mary L. Good, Under Secretary for Technology National Institute of Standards and Technology Arati A. Prabhakar, Director
U.S. Department of Energy Hazel R. O'Leary, Secretary Energy Efficiency and Renewable Energy Christine A. Ervine, Assistant Secretary 

RATIONALE AND PRELIMINARY PLAN FOR FEDERAL RESEARCH FOR CONSTRUCTION AND BUILDING

CONTENTS

EXECUTIVE SUMMARY . . . . . . . . . . . . . . . . . . . . . . . . iii

INTRODUCTION . . . . . . . . . . . . . . . . . . . . . . . . . . . 1

R\&D PLAN FOR MEETING CONSTRUCTION AND BUILDING GOALS . . . . . . . . . . . 6

Research, Education and Removal of Barrier . . . . . . . . . . . . . 6

Roadmaps for Reaching the $C \& B$ Goals and Removal of Barriers to

Innovation . . . . . . . . . . . . . . . . . . . . . . . . . . 8

Goal $1-50 \%$ reduction in delivery time . . . . . . . . . . . . . . . 9

Goal 2- 50\% reduction in operation, maintenance and energy costs . . 10

Goal 3-30\% increase in productivity and comfort . . . . . . . . . . 12

Goal 4-50\% fewer occupant related illness and injuries . . . . . . . 13

Goal 5- 50\% less waste and pollution . . . . . . . . . . . . . . 14

Goal 6-50\% more durability and flexibility . . . . . . . . . . . . . 15

Goal 7-50\% reduction in job related illnesses and injuries . . . 16

Removal of Barriers. . . . . . . . . . . . . . . . . . . . . 17

Timeline for Construction and Building R\&D Program . . . . . . . . 18

PLAN FOR DEPLOYMENT . . . . . . . . . . . . . . . . . . . . . . . . 20

BUDGET PRIORITIES . . . . . . . . . . . . . . . . . . . . . . . . . 23

ACKNOWLEDGMENTS . . . . . . . . . . . . . . . . . . . . . . . . . . . . . 27

REFERENCES . . . . . . . . . . . . . . . . . . . . . . . 28

TABLE 1 PARTICIPATING AGENCIES . . . . . . . . . . . . . . . . . . . . . . . 1

TABLE 2 FEDERAL CONSTRUCTION RD\&D BUDGET SUMMARY . . . . . . . . . . . 23

TABLE 3 ADEQUACY OF RED . . . . . . . . . . . . . . . . . . . . . . . . 25

FIGURE 1 LIFE CYCLE OF CONSTRUCTED FACILITIES . . . . . . . . . . . . . . 2

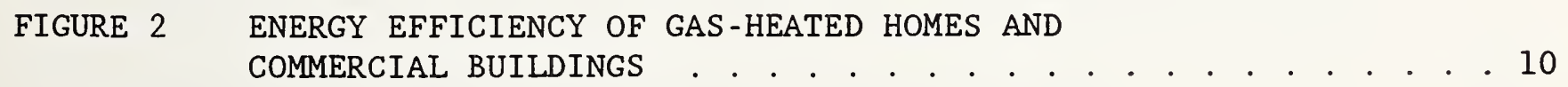


APPENDIX 1 CONSTRUCTION INDUSTRY WHITEPAPER . . . . . . . . . . . . . . . 29

APPENDIX 2 R\&D ROADMAPS FOR MEETING SUBCOMMITTEE GOALS . . . . . . . . . 45

Goal 1- 50\% reduction in delivery time . . . . . . . . . . . . 45

Goal 2-50\% reduction in operation,

maintenance and energy costs . . . . . . . . . . . . . . . 52

Goal 3-30\% increase in productivity and comfort . . . . . . . 58

Goal 4-50\% fewer occupant related illness and injuries . . . 61

Goal 5-50\% less waste and pollution . . . . . . . . . . . 67

Goal 6-50\% more durability and flexibility . . . . . . . . 70

Goal 7-50\% reduction in construction work

illnesses and injuries . . . . . . . . . . . . . . . 73

Removal of Barriers . . . . . . . . . . . . . . . 79

APPENDIX 3 DEPLOYMENT PLANS AND OPPORTUNITIES . . . . . . . . . . . . . . 83

Demonstration Projects Nearing Completion . . . . . . . . . . 83

Demonstration Projects Planned for FY95 and FY96 . . . . . . . 86

Technologies Ready for Deployment . . . . . . . . . . . 90

APPENDIX 4 AGENCIES' PROGRAM SUMMARIES . . . . . . . . . . . . . . . . . 99

Department of Agriculture (FPL) . . . . . . . . . . . . . . . 99

Department of Commerce (NIST) . . . . . . . . . . . 101

Department of Defense . . . . . . . . . . . . . 103

Department of Energy . . . . . . . . . . . . . . . 105

Department of Health and Human Services (NIOSH) . . . . . 109

Department of Housing and Urban Development . . . . . . . . 111

Department of Interior (U.S. Bureau of Mines) . . . . . . . 115

Department of Transportation . . . . . . . . . . . . 116

General Services Administration . . . . . . . . . . . . 118

Environmental Protection Agency . . . . . . . . . . . . 120

National Aeronautics and Space Administration . . . . . . 126

National Science Foundation . . . . . . . . . . . . 129 


\section{EXECUTIVE SUMMARY}

The National Science and Technology Council (NSTC), a cabinet-level group charged with setting federal technology policy, coordinates R\&D strategies across a broad cross-section of public and private interests. It has established nine research and development committees, including the Committee on Civilian Industrial Technology (CCIT), to collaborate with the private sector in developing a comprehensive national technology policy. The purpose of CCIT is to enhance the international competitiveness of U.S. industry through federal technology policies and programs. The Subcommittee on Construction and Building (C\&B) of CCIT coordinates and defines priorities for Federal research, development and deployment related to the industries that produce, operate and maintain constructed facilities, including buildings and infrastructure.

The Administration, in the OMB/OSTP memorandum of May 6, 1994, has assigned priority for research and development to Construction and Building for the FY 1996 budget.

Construction is one of the Nation's largest industries and a critical asset for enhancing the international competitiveness of U.S. industry. In 1993, new construction put in place amounted to $\$ 470$ billion, $8 \%$ of the GDP, and provided employment for 6 million persons. Constructed facilities shelter and support most human activities. Their quality affects the competitiveness of U.S. industry, the safety and quality of life of the people, and environmental quality. For U.S. industries to compete internationally, their technologies must be superior and their production facilities must be more cost effective than their competitors'.

However, construction has declined since 1966 from $12 \%$ of GDP to its present $8 \%$ (Japan's is 16\%). Public and private construction R\&D is less than $0.5 \%$ of annual sales compared to $3.8 \%$ for all industry. The U.S. will fall further behind in technology and competitiveness unless actions are taken to change present trends.

The vision for the construction and building industries is:

- High quality constructed facilities support the competitiveness of U.S. industry and everyone's quality of life.

- U.S. industry leads in quality and economy in the global market for construction products and services.

- The construction industry and constructed facilities are energy efficient, environmentally benign, safe and healthful, properly responsive to human needs, and sustainable in use of resources.

- Natural and manmade hazards do not cause disasters.

- Intelligent renewal, a process that cost effectively uses limited economic, material, and human resources, is applied to rebuilding America. 
$C \& B$ has studied research priorities expressed by the construction industry in industry fora and in proposals for the Advanced Technology Program of the Department of Commerce. Two priority thrusts; better constructed facilities and health and safety of the construction workforce, were defined for focus of research, development and deployment (RD\&D) in the construction and building area for the FY 1996 budget. The goals for the C\&B Program are:

\section{Better Constructed Facilities}

- $50 \%$ reduction in delivery time

- $50 \%$ reduction in operation, maintenance and energy costs

- $30 \%$ increase in productivity and comfort

- $50 \%$ fewer occupant related illnesses and injuries

- $50 \%$ less waste and pollution

- $50 \%$ more durability and flexibility

\section{Health and Safety of Construction Workforce}

- $50 \%$ reduction in construction work illnesses and injuries

Long delivery time, waste and pollution, and construction work illness and injury contribute substantially to the cost of construction. Achievement of the above goals reduce construction cost and make housing more affordable through reduction in initial cost and life cycle cost. The baseline for measuring progress against the goals will be today's business practices. The $C \& B$ program plans to make technologies and practices capable of achieving the goals under these thrusts available for general use in the construction industry by 2003 .

The C\&B program and goals were reviewed with a focus group of industry leaders convened on April 5, 1994, by the Civil Engineering Research Foundation. The response of the focus group is described in the Construction Industry Whitepaper "Innovation in the U.S. Construction Industry: An Essential Component for America's Economic Prosperity and Well Being." The white paper is an industry perspective of methods and means that, if jointly supported and implemented by the public and private sector, promise to transform the construction sector into the high technology/high skill sector America requires. Construction industry leaders strongly endorsed the goals established by $C \& B$. The industry leaders urged expanded dialogue and the immediate initiation of actions. $C \& B^{\prime} s$ partnership with industry is being developed further through a "White House Construction Industry Workshop on National Construction Goals" to be held in Washington, D.C., in December 1994. Participants in the workshop will include representatives from design, construction, equipment materials, finance, insurance, owners, codes, etc., and will come from all sectors of the construction and building industry: residential, commercial, industrial, institutional and public works. The 
purpose of the workshop, which is being organized by the Civil Engineering Research Foundation, is to provide an industry perspective on the proposed construction goals and develop a platform from which an appropriate industry implementation plan can emerge. Output from this workshop will also be used to refine this preliminary plan for Federal research for construction and building.

Seven areas of technology have been identified as those that will contribute most to achieving the goals:

1. Information and Decision Technologies

2. Automation in Design, Construction and Operation

3. High Performance Materials, Components, and Systems

4. Environmental Quality

5. Risk Reduction Technologies

6. Performance Standards System

7. Human Factors

Objectives have been developed to meet needs for each of these technologies. For each objective, an assessment of the adequacy of current Federal R\&D funding has been made. Planned Federal RD\&D expenditures are focused on achieving the goals of the C\&B program. FY 94 programs, planned future programs and currently unfunded programs are listed.

Improved technologies alone are not sufficient for improvement of the life cycle quality of constructed facilities and enhancement of the competitiveness of U.S. industry. The improved products and services must be successful in the marketplace and become the ruling technologies in construction practice.

In a number of studies, industry has identified the following major nontechnical barriers:

1. Lack of leadership

2. Regulatory barriers

3. Liability

4. Adversarial relations in construction projects

5. Financial disincentives for innovation

Objectives for removal of these non-technical barriers have been developed.

Showcase and demonstration projects are an early and continuing emphasis for the $C \& B$ program. They remove much of the risk of innovation by bringing owners, designers, manufacturers and builders in a team effort to show the benefits of advanced technologies and practices. General implementation is enhanced by visible, successful demonstration projects. Important current and early (FY 1995-1996) demonstration projects are defined in the program and technologies available for future demonstrations are cited. 


\title{
INTRODUCTION
}

The National Science and Technology Council (NSTC), a cabinet-level group charged with setting federal technology policy, coordinates R\&D strategies across a broad cross-section of public and private interests. It has established nine research and development committees, including the Committee on Civilian Industrial Technology (CCIT), to collaborate with the private sector in developing a comprehensive national technology policy. The purpose of CCIT is to enhance the international competitiveness of U.S. industry through federal technology policies and programs. The Subcommittee on Construction and Building (C\&B) of CCIT coordinates and defines priorities for Federal research, development and deployment related to the industries that produce, operate and maintain constructed facilities, including buildings and infrastructure.

The mission of $C \& B$ is to enhance the competitiveness of U.S. industry, public safety and environmental quality through research and development, in cooperation with U.S. industry, labor, and academia, for improvement of the life cycle performance of constructed facilities. C\&B will address Administration goals to:

- Forge partnerships with industry to strengthen America's industrial competitiveness and create jobs.

- Make environmental protection and energy efficiency fully consistent with other business objectives.

Agencies participating in $C \& B$ are listed in Table 1. They include agencies with responsibilities: as owners and operators of constructed facilities, for assistance or regulation for constructed facilities and construction, and for research.

TABLE 1

\section{PARTICIPATING AGENCIES}

\author{
Department of Agriculture (Forest Products Laboratory) \\ Department of Commerce, Co-chair (NIST) \\ Department of Defense \\ Department of Energy, Co-chair \\ Department of Health and Human Services (National Institute for \\ Occupational Safety and Health) \\ Department of Housing and Urban Development \\ Department of Interior \\ Department of Labor (Occupational Safety and Health Administration) \\ Department of Transportation \\ Department of Veterans Affairs \\ Environmental Protection Agency \\ General Services Administration \\ National Aeronautics and Space Administration \\ National Science Foundation
}


Construction is one of the Nation's largest industries and a critical asset for enhancing the international competitiveness of U.S. industry. In 1993, new construction put in place amounted to $\$ 470$ billion, $8 \%$ of the GDP, and provided employment for 6 million persons. The breakdown of new construction put in place in 1993 is: residential 44\%; commercial, institutional and industrial 28\%; public works 28\%). (When renovation is included, construction probably amounts to about $\$ 800$ billion annually, $13 \%$ of GDP, and 10 million jobs.) Constructed facilities shelter and support most human activities. Their quality affects the competitiveness of U.S. industry, the safety and quality of life of the people, and environmental quality. For U.S. industries to compete internationally, their technologies must be superior and their production facilities must be more cost effective than their competitors'. Moreover, the quality of construction strongly affects the wealth of the Nation; over five-eighths of the Nation's fixed reproducible wealth is invested in constructed facilities.

Construction includes the whole life of the project: initial planning and programming, design, manufacturing and site construction, occupancy and maintenance, condition assessment, retrofit and renovation or removal. Figure 1 shows the life cycle of constructed facilities and the industries

\section{Life Cycle of Constructed Facilities}

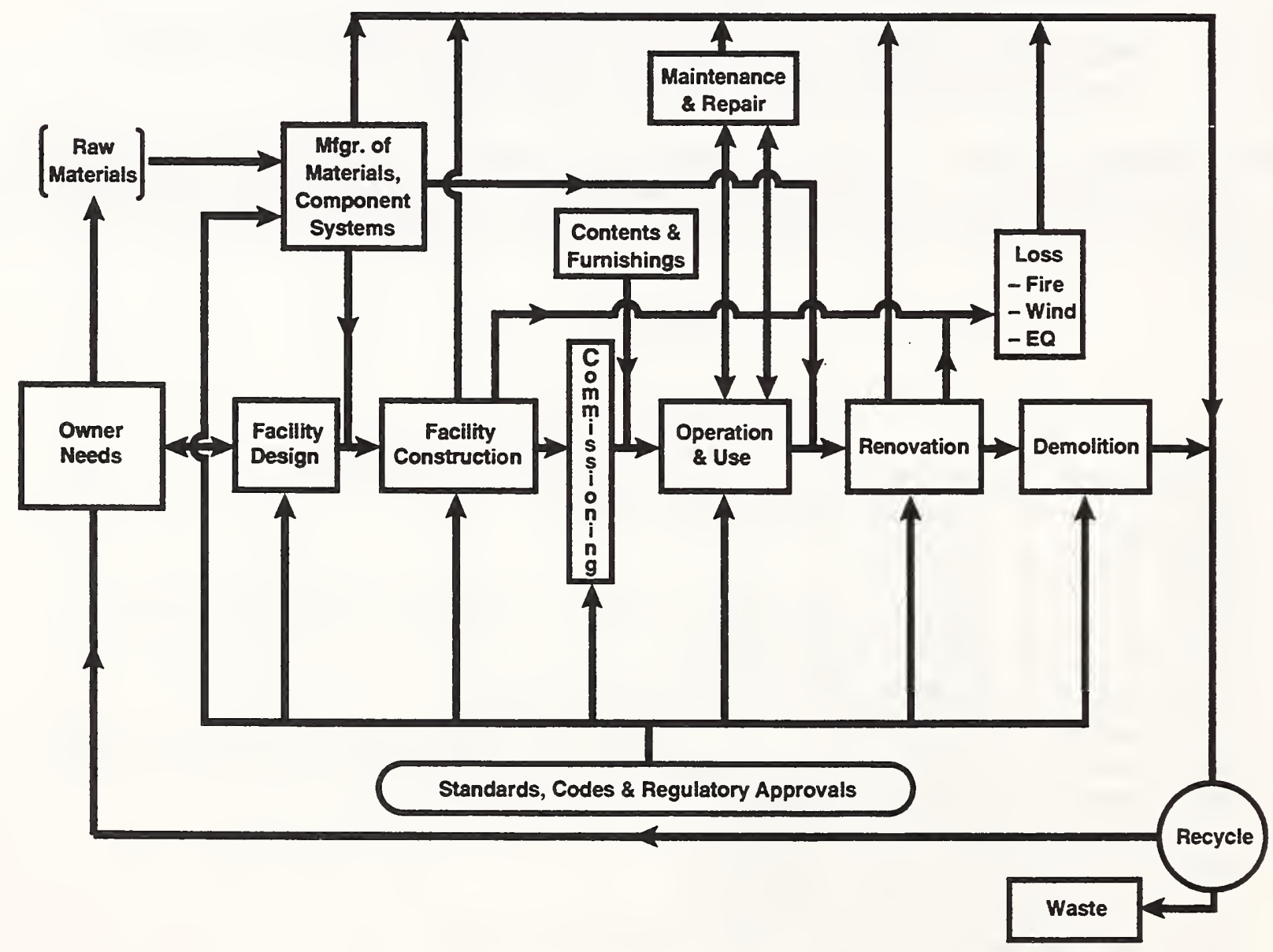

Figure 1 
involved in it. This whole life viewpoint is necessary to give realistic attention to values and costs of constructed facilities. For instance, for an office building, the annual operating cost, including salaries of occupants, roughly equals the initial construction cost. The primary value comes from the productivity of the occupants, which depends on the capability of the building to meet user needs throughout its useful life.

The average level of new construction put in place over the last decade has been $8 \%$ of the GNP which is down from the $11.9 \%$ attained in 1966 . In contrast, Japan's is about $16 \%$ of GNP. The effects of the low U.S. investment are seen in the condition of U.S. constructed civil infrastructure systems: according to the National Council on Public Works Improvement "the quality of America's infrastructure today is barely adequate to meet current requirements and insufficient to meet the demands of future economic growth." Effects also are seen on the productive capabilities of commerce and industry: according to David Aschauer "the decline in infrastructure investment can explain half or more of the productivity decline in the U.S."

Technical leadership is essential to competitiveness of the U.S. construction industry. A survey of leading U.S. and foreign design and construction firms, published in Cost Engineering, obtained their views of international leadership in construction technologies. Nineteen areas of construction technology were considered; the U.S. was assessed by the respondents to lead in just four, be even in one and to trail in fourteen. Specific instances of foreign leadership were cited in innovative materials, tunneling, underground piping, robotics and earthquake engineering.

Comparisons of U.S. and foreign construction research, development and application efforts indicate the U.S. will fall further behind in technology and competitiveness unless actions are taken to change present trends. U.S. research support for construction technology is very limited compared to other nations and industries. A 1993 study by the Civil Engineering Research Foundation indicates that construction R\&D is only $0.5 \%$ of construction value. Private sector R\&D for construction focuses on product development from which research investments can be recouped in the marketplace. Most technology development work by design and construction firms is expensed to specific projects rather than reported as research and development, but these efforts are much smaller than the $1 \%$ of gross income reported by Japanese designconstruction firms [1], [2].

The vision for the construction and building industries is:

- High quality constructed facilities support the competitiveness of U.S. industry and everyone's quality of life.

- U.S. industry leads in quality and economy in the global market for construction products and services.

- The construction industry and constructed facilities are energy efficient, environmentally benign, safe and healthful, properly responsive to human needs, and sustainable in use of resources. 
- Natural and manmade hazards do not cause disasters.

- Intelligent renewal, a process that cost effectively uses limited economic, material, and human resources, is applied to rebuilding America.

$C \& B$ has studied research priorities expressed by the construction industry in industry fora and in proposals for the Advanced Technology Program of the Department of Commerce. Two priority thrusts; better constructed facilities and health and safety of the construction workforce, were defined for focus of research, development and deployment (RD\&D) in the construction and building area for FY 1996. The C\&B program plans to make technologies and practices capable of achieving the goals under these thrusts available for general use in the construction industry by 2003. The goals for the C\&B Program are:

\section{Better Constructed Facilities}

- $50 \%$ reduction in delivery time

- $50 \%$ reduction in operation, maintenance and energy costs

- $30 \%$ increase in productivity and comfort

- 50\% fewer occupant related illnesses and injuries

- $50 \%$ less waste and pollution

- $50 \%$ more durability and flexibility

\section{Health and Safety of Construction Workforce}

- $50 \%$ reduction in construction work illnesses and injuries

Long delivery time, waste and pollution, and construction work illness and injury contribute substantially to the cost of construction. Achievement of the above goals reduce construction cost and make housing more affordable through reduction in initial cost and life cycle cost. The baseline for measuring progress against the goals will be today's business practices.

Continuous improvement is taking place in the private sector through partnering and team building (TQM) efforts.[4] For example, safety programs for Construction Industry Institute member companies using "best practices" have reduced their lost workday cost incident rate from 1.76 in 1989 to 1.09 in 1992. Whereas, over the same period the national average reported by OSHA was 6.8 in 1989 and 5.8 in 1992. Also, there is tremendous potential for increasing productivity by reducing administrative delays. Poor management accounts for $30 \%$ of worker downtime.

The C\&B program and goals were reviewed with a focus group of industry leaders convened on April 5, 1994, by the Civil Engineering Research Foundation (CERF). The response of the focus group is described in the Construction 
Industry Whitepaper "Innovation in the U.S. Construction Industry: An Essential Component for America's Economic Prosperity and Well Being." The white paper (Appendix 1) is an industry perspective of methods and means that, if jointly supported and implemented by the public and private sector, promise to transform the construction sector into the high technology/high skill sector America requires. Construction industry leaders strongly endorsed the goals established by $C \& B$. The industry leaders urged expanded dialogue and the immediate initiation of actions. C\&B's partnership with industry is being developed further through a "White House Construction Industry Workshop on National Construction Goals" to be held in Washington, D.C., in December 1994. Participants in the workshop will include representatives from design, construction, equipment materials, finance, insurance, owners, codes, etc., and will come from all sectors of the construction and building industry: residential, commercial, industrial, institutional and public works. The purpose of the workshop, which is being organized by the Civil Engineering Research Foundation, is to provide an industry perspective on the proposed construction goals and develop a platform from which an appropriate industry implementation plan can emerge. Output from this workshop will also be used to refine this preliminary plan for Federal research for construction and building.

The Administration, in the OMB/OSTP memorandum of May 6, 1994, has assigned priority for research and development to Construction and Building for the FY 1996 budget as "Activities that support the residential/commercial building construction industry and its suppliers in the development of advanced technologies aimed at increasing the productivity of construction, improving product quality (including energy efficiency and improved indoor air quality), use of renewable resources, and increased worker health and safety."

Program milestones for development and deployment of innovative technologies are chosen to achieve prompt benefits and accelerating progress towards the goals:

\section{Better Constructed Facilities}

Identify and evaluate current innovative building technologies, encourage their use and demonstration in currently planned building projects, and plan implementation of successful technologies. (1995)

Synthesize advanced technologies addressing the program goals from available knowledge, and define specific research objectives. (1996)

Demonstrate research based, advanced technologies which realize the program goals. (1996-2001)

Implement standards making successful advanced technologies normal practice. (2003)

Health and Safety of Construction Workers 
Identify gaps in national surveillance systems for hazards, illness, and injury and develop needed new systems (1995)

Identify construction practices of those companies with low injury records, incorporate and highlight such practices in currently planned building demonstration projects, and plan their general implementation. (1995)

Identify advanced state-of-the-art, safe, cost-effective construction practices, and define specific research objectives. (1996)

Develop national and international coalitions to foster exchange of safety and health information, to identify successful interventions and to encourage their adoption. (1995-1999)

Implement new, research-based standards for construction practices. (2000)

The following sections of the report describe the RD\&D plan for FY 1996 and beyond for providing the knowledge needed to achieve the C\&B goals, the deployment activities for FY 1995 and 1996 that will test and showcase advanced technologies available for contributing to the goals. The program herein described will be further developed and elaborated with industry, and draw appropriately on the capabilities and resources of industry and government to conduct and implement the RD\&D needed to meet $C \& B$ goals.

R\&D PLAN FOR MEETING CONSTRUCTION AND BUILDING GOALS

\section{Research. Education and Removal of Barriers}

Research to improve construction technologies, education to bring the technologies to practice, and the removal of non-technical barriers to implementation of advanced technologies are needed to achieve the C\&B goals.

Seven areas of technology will be developed to achieve the goals:

1. Information and Decision Technologies

Integrated data bases and information systems

Knowledge systems as successors to standards and books

Integrated project information systems

Construction management technologies

Collaborative decision making environments

Post-occupancy evaluation systems

2. Automation in Design, Construction and Operation

Simulation and visualization

Computer-aided design

Computer-integrated construction

Advanced sensors

Construction robotics

Building automation systems 
Computer-aided facilities management

3. High Performance Materials, Components, and Systems

Advanced materials

Advanced components

Whole building systems

Connections

Mechanisms, models and data for life cycle performance

Assessment and quality assurance technologies

Renewal engineering

Recycling and reuse

Functional flexibility

4. Environmental Quality

Energy conservation

Indoor air quality

Remediation of contaminated construction sites

Sustainable development (ecological quality, conservation of raw materials, etc.)

5. Risk Reduction Technologies

Fire protection

Toxic exposures

Earthquake risk reduction

Wind risk reduction

Other hazards

6. Performance Standards System

Performance standards for products and processes

Test methods and data for life cycle performance

Conformance assessment system

7. Human Factors

Cognitive processes and uses of information

Physiology

Ergonomics

Environmental and person-machine interactions

Team building and workforce efficiency

Education and training are required for implementers of the technologies (designers, manufacturers and fabricators, regulators, construction workforce, operators and maintainers, and users). Educational materials and curricula will be required for each area of technology and each category of users. In some instances, research on educational methods may be needed for selected technologies and users.

Improved technologies alone are not sufficient for improvement of the life cycle quality of constructed facilities and enhancement of the competitiveness of U.S. industry. The improved products and services must be successful in the marketplace and become the ruling technologies in construction practice. In a number of studies, industry has identified the following major nontechnical barriers to beneficial innovations: 
1. Lack of leadership

Policy makers in industry and government do not give priority to quality of constructed facilities consistent with their importance to the economy and quality of life. An important symptom of this lack of leadership is the overemphasis on first cost of construction with failure to recognize life cycle benefits possible from improved functionality, efficiency and durability.

2. Regulatory barriers

Individual projects often are severely delayed by a large number of uncoordinated and sometimes conflicting regulatory requirements. Delay raises costs and leaves the need for the facility unfulfilled during the delay. The introduction of innovative products and services to the marketplace is made more expensive and delayed by the need to get approvals from many local jurisdictions.

3. Liability

Innovators and users of innovations face potentially large liability from real or imputed failures of products to perform over the service life as the customer or other injured party expected.

4. Adversarial relations in construction projects

Participants in each project for a constructed facility (owners, users, designers, manufacturers, constructors, regulators, etc.) often take adversarial positions rather than partnership to achieve project objectives.

5. Financial disincentives for innovation

Industry and government have underinvested in construction R\&D as compared to other industrial sectors. The large number of design and construction firms and the mobility of their workforces make trade secrets infeasible and patent enforcement difficult. Regulatory barriers noted above slow returns on investments in innovation. The overemphasis on first cost, noted above, is a barrier to products and services requiring increased first cost to achieve reduced life cycle cost. Education and training are required for successful use of an innovation; the innovator often is required to provide the education and training.

\section{Roadmaps for Reaching the $C \& B$ Goals and Removal of Barriers to Innovation}

Each of the seven areas of technology, the education and training and the barrier removal activities contribute to each of the goals. A roadmap is outlined below for each goal and for barrier removal. Educational efforts are considered to be implicit in the technical and barrier removal objectives. The projects of $C \& B$ agencies related to these roadmap outlines are given in Appendix 2. 
Roadmap for Goal 1. $50 \%$ Reduction in Delivery Time

Background:

Reduction in the time from the decision to construct a new facility to its readiness for service is vital to industrial competitiveness and project cost reduction. During the initial programming, design, procurement, construction and checkout/startup process, the need of the client for the facility is not being met; needs evolve over time so a facility long in delivery may be uncompetitive when it is finished; and the investments in producing the facility cannot be recouped until the facility is operational. The need for reduction in time to project completion is often stronger in the case of renovations and repairs of existing facilities because of interruption of ongoing business. Owners, users, designers and constructors are among the groups calling for technologies and practices reducing delivery time.

Objectives:

1. Provide information systems to enable instantaneous controlled distribution and exchange of information and communication of needs for information, and decision-support systems that replicate a complete project cycle from project needs assessment through engineering, construction and operations studies.

2. Provide automation in techniques for understanding users' needs, project planning and management, design, manufacturing, materials handling and placement, quality assurance, regulatory review and inspection, and automatic exchange of information among project participants to reduce time for design, construction and commissioning activities and support, to the extent feasible, parallel activities.

3. Develop and implement cost-effective high performance construction materials, components and systems, promoting reduction in project delivery time. Technologies promoting reduction in project delivery time include: materials and components that rapidly can be procured, fabricated, delivered and installed; systems and components supportive of ready reconfiguration to support changing requirements; and sensing, assessment and quality assurance technologies providing real time evaluation of properties relative to those specified.

4. Provide technologies for the prompt environmental assessment of a project site and rapid abatement of environmental hazards.

5. Develop and implement technologies for reduction of risks that natural and manmade hazards will slow project delivery by damaging project documentation, the project site or the incomplete constructed facility.

6. Provide an internationally-recognized performance standards system that supports rapid acceptance of the project design and construction by regulatory authorities, and supports rapid acceptance of design, 
construction, review, inspection, commissioning, and other innovations capable of speeding project delivery.

7. Develop and apply knowledge of how cognitive processes, physiology, ergonomics, human interactions with equipment and environment, and inter-personal and inter-group relations affect performance of project personnel and equipment and relations with persons and organizations affecting project approval to develop practices improving project qualities and accelerating project delivery.

Roadmap for Goal 2: $50 \%$ Reduction in Operation, Maintenance and Energy Costs

Background:

Operation and maintenance costs over the life of the facility usually exceed its first cost and may do so on an annualized cost basis. To the extent that prices for energy, water, sewage, waste, communications, taxes, insurance, plant services, etc., represent costs to society in terms of resource consumption, operation and maintenance costs also reflect the environmental qualities of the constructed facility. Therefore, reductions in operation and maintenance and energy costs benefit the general public as well as the owners and users of the facility.

Figure 2 presents evidence that at least the energy part of our Goal 2 (50\% reduction in buildings designed in 2003) is a reasonable extrapolation of the

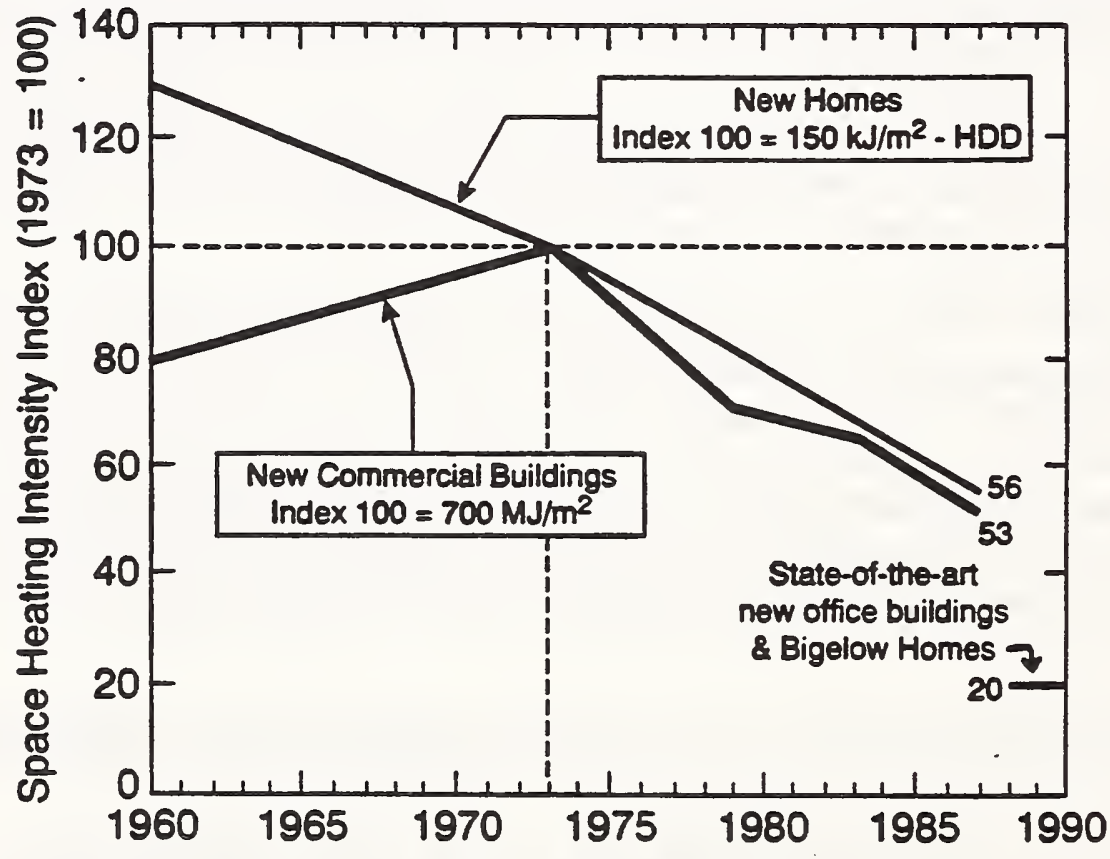

Source: Source for now homes and now commercial bulidings: U.S. DOE, Eneroy Conservation Trends, DOERPE-0092, 9/89, fios 19 and 21. Source for large now office buildings: ASHRAE SP 41. PNL Report 4870-18, 10/83. Source for Bigotow Homes: BECA 1991 Annual Report. Building Energy Data Group, LBL, 1991.

Figure 2. Energy efficiency of gas-heated homes and commercial buildings (units are kilojoules (kj) of gas per square meter of floor area $\left(\mathrm{m}^{2}\right)$ ) [4] 
$50 \%$ saving in new building heating intensity (gas use per sq. ft. of floor area) which took place in the 13 years starting in 1973, when energy prices were high and rising. The same 50\% saving was achieved for space cooling, lighting, many household appliances, and new buildings and homes overall. In these 13 years we learned to build cost-effective "energy showplace" buildings and homes which saved not $50 \%$, but $80 \%$. These showplaces are still rare, but in the next decade, new policies and new more affordable technology should make them widespread. Productivity of occupants is related to their comfort.

Objectives:

1. Provide information systems and decision-support systems that provide real-time information on users' needs, the operating condition of the facility and support for cost-effective, proactive operations and maintenance decisions by owners, operators and maintainers.

2. Provide automation in techniques for understanding users' needs, facilities operations and management, condition assessment and adaptive control to support high quality operations and minimize waste in operations and maintenance.

3. Develop and implement cost-effective high performance construction materials, components and systems where high performance denotes qualities for efficiency in operations and maintenance such as: damage tolerance, durability and resistance to soiling, energy efficiency, low emissions of pollutants, and systems, components and materials that are self-assessing and/or are readily reconfigured to support changes in users' needs.

4. Provide cost-effective technologies for energy conservation, indoor air quality, water conservation, waste minimization, etc., that reduce operation and maintenance costs.

5. Develop and implement cost-effective technologies to reduce property damage and loss of function from natural and manmade hazards such as fire, earthquake, wind, flood, and releases of toxic substances.

6. Provide an internationally recognized performance standards system that reflects operations and maintenance costs in initial design and construction of the facility, and promotes acceptance of innovations capable of reducing operations and maintenance costs.

7. Understand how cognitive processes, physiology, ergonomics, human interactions with equipment and environment, and interpersonal relations affect users' requirements for operations and maintenance and the performance of operations and maintenance personnel to provide needed performance while reducing operations and maintenance costs. 
Roadmap for Goal 3: $30 \%$ Increase in Productivity and Comfort

Background:

Industry and government studies have shown that the annual salary costs of the occupants of a commercial or institutional building are of the same order of magnitude as the capital cost of the building. Indeed, the purpose of the building is to shelter and support the activities of its occupants. Improvement of the productivity of the occupants (or for an industrial facility, improvement of the productivity of the process housed by the facility) is the most important performance characteristic for most constructed facilities.

Objectives:

1. Provide information systems and decision-support systems that provide real-time information on users' needs and means to control building services cost-effectively, and to support these needs in an optimum way.

2. Provide automation in techniques for understanding users' needs, facilities operations and management, and service systems controls to support users' productive activities and comfort.

3. Provide high performance construction materials, components and systems that support users' productive activities and comfort.

4. Provide technologies for heating, cooling, ventilation, humidity control, lighting, acoustics, space utilization, furnishings, finishes, etc., that provide a comfortable, stimulating and productive work, residential or recreational environment.

5. Provide technologies and practices to reduce information losses. property damages and losses of worktime and function from natural and manmade hazards such as fire, earthquake, wind, flood and releases of toxic substances.

6. Provide an internationally recognized performance standards system that reflects occupant productivity and comfort in initial design and construction of the facility, promotes acceptance of innovations capable of improving productivity and comfort, and provides for operations and maintenance for productivity and comfort.

7. Understand how cognitive processes, physiology, ergonomics, human interactions with equipment and environment, and interpersonal relations affect users' productivity and comfort. Apply this knowledge to provide productive and comfortable work, residential and recreational environments. 


\section{Background:}

Industrial, commercial, institutional and residential buildings are intended to shelter and support human activities, yet the environment and performance of buildings can contribute to illnesses and injuries for building users. Examples are avoidable injuries caused by slips and falls, legionnaires disease from airborne bacteria, respiratory symptoms which improve when away from work (sick building symptoms) and building collapses from earthquakes or extreme winds. Although data are limited, current evidence suggests that the quality of the indoor environment may be related to sick-building symptoms, infectious disease, allergies and asthma. Sick building symptoms include irritation of eyes, nose and skin, headache and fatigue. If improvements in the quality of the indoor environment reduce days of productive work lost to sick days and impaired productivity, annual nationwide savings could reach billions of dollars. In a 1987 survey of U.S. office workers, 24\% reported dissatisfaction with air quality at the office, while $20 \%$ perceived their performance to be hampered by poor indoor air quality. Complaints about "sick building syndrome" have become sufficiently common that 37 states and territories have designated a contact person for building complaint investigations.

Violence is a safety issue which can be addressed in part by building design, referred to as crime prevention through environmental design. A Department of Justice study released in July, 1994 states that 1 million people will be affected by violent crime while they are at work. These incidents result in 1.8 million lost workdays each year, an average of 3.5 days per crime, and $\$ 55$ million in lost wages, not including days covered by sick and annual leave.

Projections on the growth of computer work suggest that nearly 60 million office and factory jobs will be impacted by computerized systems requiring specialized workplace redesign. These design problems are so pervasive that organizations such as NIOSH, the Human Factors and Ergonomics Society, the American National Standards Institute, and the International Standards Organization have all undertaken efforts to define environmental design criteria to avoid health and performance impairments.

Reductions in illnesses and injuries will increase users' productivity as well as reducing costs of medical care and litigation.

Objectives:

1. Provide information systems and decision support systems that will provide real time information on users' needs and the health and safety characteristics of the building environment.

2. Provide automation in techniques for understanding users' needs, design, construction, facilities operation and maintenance, and service systems controls in order to design, construct, operate and maintain healthy and safe building environments. 
3. Provide construction materials, components, and systems conducive to users health and safety in normal operations and resistant to dangerous behavior in extreme environments or during maintenance and renovation.

4. Provide technologies for heating, cooling, ventilation, humidity control, lighting, acoustics, etc., that provide a healthy and safe work, residential or recreational environment.

5. Provide technologies and practices to reduce risks to users' safety and health from natural and manmade hazards such as fire, earthquake, wind, flood and releases of toxic substances.

6. Provide an internationally recognized performance standards system that reflects users' health and safety in initial design and construction of the facility, promotes acceptance of innovations capable of improving safety and health, and provides for operation and maintenance for safety and health.

7. Understand how cognitive processes, physiology, ergonomics, human interactions with equipment and environment, and inter-personnel relations affect users' safety and health. Apply this knowledge to provide healthier and safer work, residential and recreational environments.

\section{Roadmap for Goal 5: $50 \%$ less Waste and Pollution}

\section{Background:}

Because they shelter and support most human activities, improvement of the performance of constructed facilities provides major opportunities to reduce waste and pollution at every step of the delivery process, from raw material extraction to final demolition and recycling of the shelter and its contents. Examples are reduced energy use and greenhouse gas emissions and reduced water consumption and waste water production. Wastes and pollution also can be reduced in the construction process: construction wastes are estimated at 20 $30 \%$ of the volume of landfills.

\section{Objectives:}

1. Provide information systems and decision support systems to provide real-time information on the waste and pollution implications of alternative materials, components, systems and practices for construction, operation, maintenance, renovation, demolition and waste recycling.

2. Provide automation in techniques for design, construction, operation, maintenance and demolition to avoid waste and pollution and promote reuse of materials.

3. Provide construction materials, components and systems that conserve resources over the life cycle, are adaptable to changes over time in users' needs and activities, and are suitable for recycling. 
4. Provide technologies for heating, cooling, ventilation, humidity control, lighting, communication, water supply and waste handling and treatment, etc., that reduce production of wastes and pollutants.

5. Provide technologies and practices to reduce damages to and harmful discharges from constructed facilities as a result of natural and manmade hazards such as fire, earthquake, wind, and flood.

6. Provide an internationally recognized performance standards system that reflects avoidance of waste and pollution in initial design and construction of the facility, promotes acceptance of innovations capable of reducing waste and pollution, and provides for reduced waste and pollution in operations, maintenance and demolition.

7. Understand how cognitive processes, physiology, ergonomics, human interactions with equipment and environment, and inter-personnel relations affect waste and pollution and apply this knowledge to reduce waste and pollution in the design, construction, operation and removal of constructed facilities.

\section{Roadmap for Goal 6: $50 \%$ more Durability and Flexibility}

Background:

Durability denotes the capability of the constructed facility to maintain (given appropriate maintenance) its initial performance characteristics over the intended service life, and flexibility denotes the capability to adapt the constructed facilities to changes in use or users' needs. High durability and flexibility contribute strongly to the life cycle quality of constructed facilities since they usually endure for many decades.

Objectives:

1. Provide information systems and decision support systems to provide real-time information on the durability and flexibility of construction materials, components and systems.

2. Provide automation in techniques for design, construction, operation and maintenance to improve durability, sense needs for maintenance or repair, and adapt the system for changed users' needs.

3. Provide construction materials, components and systems that are durable and adaptable to changes over time in users' needs and activities.

4. Provide technologies for durable and flexible environmental systems for constructed facilities.

5. Provide technologies and practices to reduce damages from natural and manmade hazards. 
6. Provide an internationally recognized performance standards system that reflects durability and flexibility in initial design and construction of the facility, promotes acceptance of innovations, and provides for operations and maintenance.

7. Understand how cognitive processes, physiology, ergonomics, human interactions with equipment and environment, and inter-personnel relations affect durability and flexibility. Apply this knowledge to provide more durable and flexible work, residential and recreational environments.

\section{HEALTH AND SAFETY OF CONSTRUCTION WORKERS}

Roadmap for Goal 7. 50\% Reduction in Construction Work Illnesses and Injuries

Background:

A major barrier in international competitiveness is the cost of injuries and diseases among construction workers. Although the construction workforce represents about 6 percent of the nation's workforce, it is estimated that the construction industry pays for about one-third of the nation's workers' compensation. Workers' compensation insurance premiums range from 7 to 100 percent of payroll in the construction industry.

Construction workers die as a result of work-related trauma at a rate that is 3 times the annual rate for workers in all other industry sectors (24.1 deaths per 100,000 construction workers, as compared to 7.9 deaths per 100,000 workers in all other industry sectors). Construction workers also experience a higher incidence of nonfatal injuries of varying severity than workers in other industries.

In a recent study in Washington state, the incidence rates of nonfatal injuries in construction during 1988-91 were over 10 per 200,000 work-hours, while the overall incidence rate was 6 per 200,000 work-hours. Overexertion injuries (lifting, pulling, repetitive motion) are the single largest classification of injury in construction accounting for about $24 \%$ of all injuries. Workplace exposures cause lung disease, hearing loss, musculoskeletal disorders and dermatologic conditions among construction workers.

Objectives:

1. Provide management practices, information systems and decision support systems characterizing workplace safety and health hazards and safe work practices.

2. Provide automation to make equipment safer to operate and to reduce workforce exposure to hazardous environments and tasks.

3. Develop construction materials, components and systems supportive of health and safety of construction workforce. 
4. Develop environmental quality practices for the construction worksite, such environmental remediation, supportive of the health and safety of the environmental remediation workforce and the subsequent construction workforce.

5. Reduce vulnerability of incomplete and temporary structures to natural and manmade hazards such as wind, earthquake, fire and toxic substances.

6. Develop and implement standards providing explicit attention to workforce safety performance for construction activities and equipment and for incomplete and temporary structures and equipment.

7. Understand how cognitive processes, physiology, ergonomics, human interactions with equipment and environment, and inter-personal relations affect construction workforce health and safety, and develop and implement improved equipment and work practices.

\section{Roadmap for Removal of Barriers to Innovation}

Background:

The following objectives are presented for removal of the previously described, non-technical barriers to development and implementation of technologies for reaching the C\&B goals.

Objectives:

1. Work with leaders of the construction industry, labor users of constructed facilities and government to develop and implement coordinated private and public sector programs to improve the quality of constructed facilities.

2. Work with Federal agencies and states to develop one-stop processes for regulatory approvals with mechanisms for timely resolution of appeals.

3. Establish a nationally and internationally recognized system for evaluation and acceptance of innovative construction products and services.

4. Encourage construction industry participation in studies under the auspices of private sector organizations and the National Economic Council to recommend national and state legislation bounding liabilities and susceptibility to litigation for producers of products and services.

5. Use Federal construction projects as low risk test beds for innovations. (Note: Executive Order 12902 requires Federal agencies that construct at least five buildings per year to designate at least one building to be a showcase highlighting advanced technologies, energy efficiency practices, and water conservation.) 
6. Work with construction community organizations, insurance and financial institutions, Federal agencies and organizations of states to draft model agreements, total quality management and partnering programs and model legislation supporting teamwork in reaching project objectives, in place of adversarial actions when problems arise.

7. Increase private sector and Federal investments in research, development and deployment for beneficial construction technologies. The Advanced Technology Focused Program at NIST should be used for cost sharing of high risk, high market potential construction research. Federal construction agencies (VA, GSA, DOJ, etc.) should develop a budget line item for the costs of special technical studies needed to incorporate advanced technologies in construction projects. Experiences show these costs often are recouped in savings from the first project in which the technologies are used.

\section{Timeline for Construction and Building R\&D Program}

FY94 Form C\&B Subcommittee

CERF Whitepaper on "Innovation in the Construction Industry"

Report on budget rational and preliminary plan for $C \& B$

FY95 CERF Private sector Strategic Planning Workshop

$C \& B$ forms working groups to focus plans

Flagship projects for seven technology thrusts planned

NSTC strategic and operating plan for $C \& B$ published

Private sector plan published

National Science Foundation (NSF) expands infrastructure renewal program NIST initiates high performance construction materials program NIST's Advanced Technology Program (ATP) initiates first focussed program on construction

Many innovative technology demonstration projects underway

Measures of improvement in construction and building industries identified

FY96 Program report for FY 95

Benchmark for $C \& B$ goals defined

Initiate U.S. system for acceptance of innovative products and services NIST's Manufacturing Extension Partnership (MEP) program promotes safe construction practices through its centers

Department of Energy (DOE) expands Global Change deployment program NIST expands R\&D program in high performance materials and construction automation

Seven technology thrust multi-agency/private sector flagship projects launched

FY97 Program report for FY 96

R\&D plan for FY 99

Standardization of advances of FY 95

Demonstration of FY 96 technology advances

General Services Administration (GSA) sets aside funds for demonstrating new technology in Federal buildings 
Department of Housing and Urban Development (HUD) Technical Suitability

of Products program expanded to include certification and testing

International recognition of U.S. system for acceptance of innovative

products and services

ATP focussed program in construction

MEP tech transfer in construction

FY98 Program report on FY 97

R\&D plan for FY 00

Standardization of advances of FY 96

Demonstration of FY 97 technology advances

Education and training of new construction practices

ATP focussed program in construction

MEP tech transfer in construction

Process for approval and acceptance of innovative products and services demonstrated

FY99 Program report on FY 98

R\&D plan for FY 01

Standardization of advances of FY 97

Demonstration of FY 98 technology advances

Education and training of new construction practices

ATP focussed program in construction

MEP tech transfer in construction

FY00 Program report on FY 99

R\&D plan for FY 02

Standardization of advances of FY 98

Demonstration of FY 99 technology advances

Education and training of new construction practices

ATP focussed program in construction

MEP tech transfer in construction

Information on the results of new technology deployment available on video and $C D$ ROM

FY01 Program report on FY 00

R\&D plan for FY 03

Standardization of advances of FY 99

Demonstration of FY 00 technology advances

Education and training of new construction practices

ATP focussed program in construction

MEP tech transfer in construction

FYO2 Program report on FY 01

$R \& D$ plan for future years

Standardization of advances of FY 00

Demonstration of FY 01 technology advances

Education and training of new construction practices

ATP focussed program in construction

MEP tech transfer in construction

All flagship projects completed 
FY03 Program report on FY 02

Standardization of advances of FY 01

Demonstration of FY 02 technology advances

Education and training of new construction practices

ATP focussed program in construction

MEP tech transfer in construction

$C \& B$ goals achieved

\section{PLAN FOR DEPLOYMENT}

Barriers to the acceptance of new technology include the lack of knowledge of what is available, the benefits to be gained, and the risks involved in initial uses of new technologies. A key part of this multi agency program is the showcasing of new technologies and methods for overcoming barriers. Federal construction and renovation projects provide an excellent showcase for these innovations.

Executive Order 12902 of March 8, 1994, requires that when an agency constructs at least five buildings in a year, it shall designate at least one building, at the earliest stage of development to be a showcase highlighting advanced technologies and practices for energy efficiency, water conservation, or use of solar and other renewable energy. The order also requires that each agency designate one of its major existing buildings to become a showcase to highlight energy or water efficiency and attempt to incorporate solar and other renewable technologies, and indoor air quality improvements. Each agency is required to develop and implement plans and work in cooperation with DOE, and where appropriate, in consultation with GSA and other appropriate agencies to determine the most effective and cost-effective strategies to implement these demonstrations.

Among significant demonstration projects are:

- U.S. Court of Appeals, San Francisco, California. (GSA/NSF) The Ninth Circuit U.S. Court of Appeals, damaged in the 1989 Loma Prieta earthquake is being retrofitted with seismic isolation, additional shear walls and diaphragm strengthening. Friction Pendulum System bearings used for base isolation were developed with support from a grant from NSF.

- IBACOS Reference and Laboratory Houses, Pittsburgh, Pennsylvania. (DOE)

IBACOS, an audience of architects, builders, material suppliers and component suppliers, has completed 2 two story, four bedroom houses. One will demonstrate new technology that will be commercially available in $1-3$ years such as wall construction, heating, ventilating and air quality systems plumbing and energy efficient shell/panel concepts.

- Exemplary Buildings (DOE)

Four highly efficient passive solar residences are being built in California, Kentucky, Virginia and Arizona. These buildings will use about half the energy of typical residences. 
- Walnut Creek National Wildlife Refuge Learning Center, Prairie City, Iowa. (DOI/NIST)

A complex group of environmentally sustainable buildings will be earth bermed, double glazed, have natural lighting, have R30 insulation, and a specifically constructed wetland septic system.

- High Strength Concrete Bridge, Texas. (FHWA)

The bridge will be built from 13000 psi concrete rather than the usual 6000 psi material which is expected to save $20 \%$ on construction costs, require lower maintenance and provide longer seismic life.

- EPA Headquarters, Waterside Mall, Washington D.C. (EPA) The building is being retrofitted with a real-time environmental monitoring system which communicates through a proprietary local area network. Being considered as part of the retrofit are gas absorption cooling, desiccant cooling.

- Flaw Detection Instrument for Concrete. (NSF, NIST)

This instrument currently undergoing application investigations is based on the principle of evaluating the echo response to an imposed impact. The instrument detects flows, voids and the location of reinforcing bars.

- Connecticut Road Industry Surveillance Project. (NIOSH)

This is designed to prevent lead toxicity in bridge workers. Results have shown a continuous drop in blood lead levels from 36 $\mathrm{ug} / \mathrm{dl}$ in 1991 to nearly $10 \mathrm{ug} / \mathrm{dl}$.

- Highway Innovative Technology Center. (HITEC, FHWA, Private Sector) HITEC, a service center of the Civil Engineering Research Foundation supported by FHWA evaluates products for use in any aspect of the highway system. HITEC expedites the introduction and use of new products, establishes product performance benchmarks, fosters public-private sector collaboration, reduces duplication by relying on existing research, testing, and evaluation facilities, and reduces overall evaluation implementation costs.

- Best Practices for Construction Safety. (NIOSH/Center to Protect Workers Rights)

A project on the development of guidelines for industry best practices for construction safety is in its second year as part of a joint construction initiative between the Center to Protect Workers Rights and the National Institute for Occupational Health and Safety. The completion and dissemination of these guidelines int he summer of 1995 will help to meet the milestone for the health and safety of construction workers.

Details of these and other demonstration projects are given in Appendix 3. 
Meeting the C\&B goals for better constructed facilities and health and safety of construction workers requires a long-term deployment strategy for application of innovative technology.

Potential, high profile deployment activities are proposed for Federal agencies responsible for $R \& D$ and for construction, or for funding or assisting for general types of construction:

- Residential

- Commercial and Institutional

- Industrial

- Utilities and Public Works

Proposed deployment projects for FY95 and FY96 are listed in Appendix 3. All of these projects are worthy of funding and will further the C\&B goals. Among the most important are:

- Manufacturing Extension Partnership (MEP). (NIST, with input from NIOSH, HUD, DOE, and EPA).

This will include construction technology as part of the outreach effort at many of their Manufacturing Technology Centers.

- National Building Product Testing, Evaluation and Approval System. (HUD, DOE, NIST, and private sector).

This system will include the testing and certification of all new and innovative building materials and products used for all types of construction, and will incorporate features of the current HUD "Technical Suitability of Products Program" for evaluation and acceptance of materials, components, and structural systems used for HUD-FHA residential construction.

- PlantSTEP Consortium to Build Information Exchange Technology for Process Plants (NIST).

Eleven companies will raise the capability of U.S. firms to compete in the world process market by making sure that they and all U.S. firms can share information seamlessly.

- Golden Gate Federal Building, San Francisco, California (GSA). This will demonstrate the viability of BACnet as an open system communication protocol for Energy Monitoring and Control Systems (EMCS). Open systems facilitate the introduction of advanced technologies and protect owners from being trapped in an obsolete, closed system.

- CFC Conversion Demonstration (DOD).

This will demonstrate the use of environmentally safe refrigerants in commercial size refrigeration and air conditioning systems.

New technologies developed in both the private sector and in government are already available or with minimal additional work can be available for use within the next two years. Many of these technologies are listed in Appendix 3. They are classified in the technology groups used in the 
roadmaps. Agencies planning a new building or a building renovation will consider these technologies for showcasing. Involvement of private sector contractors in the design and construction will help in expanding the use of a particular technology. In most cases effort should be made to measure and publicize the advantages of using the new technologies.

\section{BUDGET PRIORITIES}

The summaries of agencies' budgets for C\&B RD\&D for FY94 and FY95 are shown in Table 2 .

TABLE 2

FEDERAL CONSTRUCTION RD\&D BUDGET SUMMARY

$(\$ M)$

\begin{tabular}{||l|c|c||}
\hline \multicolumn{1}{|c|}{ Agency } & FY 94 & FY 95 \\
\hline USDA & 7.5 & 7.8 \\
\hline DOC (NIST) & 13.8 & 16.9 \\
\hline DOC (NOAA) & 0 & 0 \\
\hline DOD & 17.4 & 17.7 \\
\hline DOE & 87.8 & 135.4 \\
\hline HHS (NIOSH) & 15.4 & 15.4 \\
\hline HUD & 1.5 & 1.5 \\
\hline DOI & N/A & N/A \\
\hline DOJ & N/A & N/A \\
\hline DOL (OSHA) & N/A & N/A \\
\hline DOT & 0 & 0 \\
\hline VA & 0 & 0 \\
\hline EPA & 0 & 0 \\
\hline FEMA & N/A & N/A \\
\hline GSA* & 0 & 0 \\
\hline NASA & 188.4 & 252.7 \\
\hline NSF & 0.0 & 64.0 \\
\hline
\end{tabular}

GSA does not recognize the category R\&D, but does conduct studies at the national and local level that involve technology assessment, application and deployment.

N/A Budget data not available. 
Not all agencies known to have programs relevant to $C \& B$ have been able to participate; N/A (not available) is entered where relevant activities are known to exist but budget data have not been provided. None the less, the total of Federal RD\&D for construction ( $\$ 254$ million for FY 1995) evidently is substantially less than $0.1 \%$ of new construction put in place ( $\$ 470$ billion for 1993.)

FY 95 showed substantial expansion of programs in construction and building:

DOE is planning major expansion and initiatives in programs to deploy emerging and underutilized new technologies through a series of Climate Change Action Plans including collaborative programs to enhance incorporation of efficiency technologies in retrofit applications (Rebuild America), demonstration and market pull programs for efficient appliances and equipment, and cooperative financing of States to improve building codes and other Federal agencies to enhance Federal buildings.

NSF for deterioration science, renewal engineering, advanced materials for infrastructure and large scale processing techniques.

NIST for high performance construction materials and systems, environmentally sensitive construction and one-time supplemental funds for studies of performance of constructed facilities in the Northridge earthquake.

FY 96 plans show a reduction of construction and building RD\&D for DoD and enhancement for DOE and NIST:

DOE programs will include cooperative programs with HUD and additional emphasis will also be placed on new building system design and construction techniques, windows, lighting and equipment technologies.

NIST plans to expand its efforts in automated construction processes and facility management.

The relation of each participating agency's program for FY96 to the C\&B program is described in Appendix 4.

Are planned Federal RD\&D efforts adequate to meet the C\&B goals? The Subcommittee has reviewed Federal plans and studies of private sector RD\&D [3] to arrive at the findings shown in Table 3 . In no subdivision of any area of work (technical studies, removal of barriers or deployment) is the level of effort perceived to be adequate to meet the goals. Substantial plans and programs are progressing for Environmental Quality, but greater progress and complementary work in other areas are necessary to meet goals. Private and public sectors are collaborating in a comprehensive plan for High Performance Construction Materials and Systems, but corresponding funding for RD\&D is lacking. The National Earthquake Hazards Reduction Program is making substantial progress for earthquake risk reduction, FEMA and NIST have significant activities for fire risk reduction, but these are insufficient to meet $C \& B$ goals, and there is not yet a national program for wind risk reduction. 


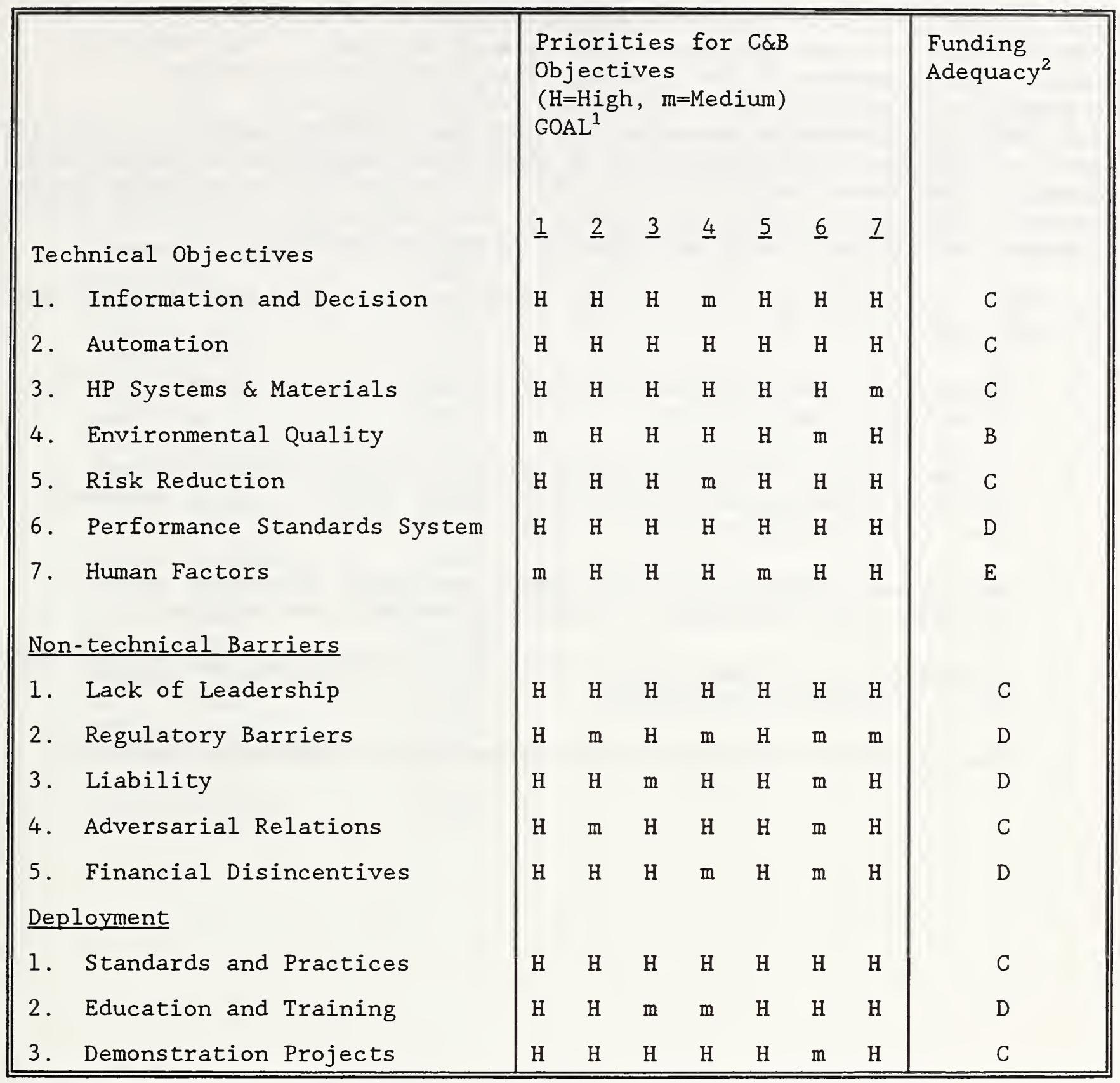

1 1. construction and delivery time

2. operation, maintenance and energy

3. productivity and comfort

4. occupant illness and injury

5. waste and pollution

6. durability and flexibility

7. construction work illness and injury

2 A: R\&D planned and funded to meet goals as scheduled

B: Substantial plans and funding but not adequate to meet goals

$C$ : Some plans and funding, but far short of meeting goals

D: Severely limited plans and activities

E: Very few plans and activities 
The Subcommittee is working with the private sector to prepare a comprehensive, private and public plan to meet C\&B goals. This work will improve the assessment of the adequacy of ongoing work and provide a community-wide perspective of priorities for planned studies. The Subcommittee's present perspective of priorities is shown in Table 3 . All goals are important for the quality of constructed facilities supporting U.S. economic development and quality of life. To achieve each effectively, most technical objectives are of high priority, most non-technical barriers must be removed, and all deployment activities must be implemented.

For FY96, the following priorities are recommended for maximum progress toward the C\&B goals:

- Showcase and demonstration projects to speed application of beneficial technologies and practices.

- Automation and information technologies to improve the quality of decisions in design and construction and to improve quality and reduce time, costs and injuries in the construction process.

- Performance standards and conformance assessment procedures to facilitate the acceptance of beneficial products and services.

- Understanding of human factors affecting accidents on construction sites and in constructed facilities.

- Risk reduction technologies for extreme winds, earthquakes and fires. 
This report is the result of dedicated participation in meetings of the Construction and Buildings Subcommittee and written contributions by the following people:

$\begin{array}{ll}\text { Thomas Anderson } & \text { CTI } \\ \text { Ken Chong } & \text { NSF } \\ \text { Margaret Chu } & \text { EPA } \\ \text { John Deponai } & \text { DOD } \\ \text { Louis Divone } & \text { DOE } \\ \text { David Eakin } & \text { GSA } \\ \text { David Engel } & \text { HUD } \\ \text { Marilyn Fingerhut } & \text { NIOSH } \\ \text { Andrew Fowell } & \text { NIST } \\ \text { Robert Fuller } & \text { HUD } \\ \text { William Hakala } & \text { NSF } \\ \text { Thomas Hamilton } & \text { FPL } \\ \text { Murray Hirshbein } & \text { NASA } \\ \text { Bruce Kinzey } & \text { DOE } \\ \text { Melvin Myers } & \text { NIOSH } \\ \text { Michael O'Connor } & \text { DOD } \\ \text { Thomas Pasko } & \text { FHWA } \\ \text { Arthur Rosenfeld } & \text { DOE } \\ \text { Thomas Rutherford } & \text { DOD } \\ \text { Lloyd Siegel } & \text { VA } \\ \text { Richard Wright } & \text { NIST }\end{array}$




\section{REFERENCES}

[1] National Research Council. 1986. Construction Productivity: Proposed Actions by the Federal Government to Promote Efficiency in Construction. Washington, DC.

[2] Civil Engineering Research Foundation. 1994. A Nationwide Survey of Civil Engineering Related R\&D. Washington, DC.

[3] Robert McManamy, "CII Benchmarks Savings," Engineering News Record, Vol. 233, Number 7, August 15, 1994.

[4] "Energy-Environmental Connection," Ed. by Jack Hollander, Chap.8

"Energy-Efficient Buildings" by A.H. Rosenfeld and Ellen Ward, Island Press. 1992. 


\section{Innovation in the U.S. Construction Industry:}

An Essential Component for America's Economic Prosperity and Well-Being

A Construction Industry White Paper

Presented by the Civil Engineering Research Foundation April 28, 1994

Based on a joint session held April 5, 1994, in Washington, D.C., involving the White House Office of Science and Technology Policy; the Subcommittee on Construction and Building, Committee on Civilian Industry Technology of the National Science and Technology Council; and civil engineering construction leaders from industry, academe, and the public sector.

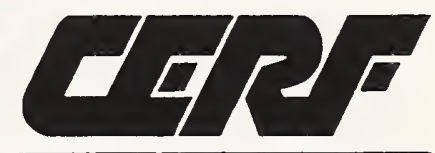

1015 15th Street, N.W., Suite 600 Washington, D.C. 20005 


\author{
INNOVATION IN THE U.S. CONSTRUCTION INDUSTRY: AN ESSENTIAL \\ COMPONENT FOR AMERICA'S ECONOMIC PROSPERITY AND WELL-BEING
}

\title{
A CONSTRUCTION INDUSTRY "WHITE PAPER"
}

\section{Overview/Objective}

In this "white paper" leaders in the construction industry strongly endorse the Clinton Administration's recognition of the construction industry as one of the principal determinants of the nation's prosperity and well-being, as well as the Administration's focus on Federalprivate sector initiatives to substantially enhance the productivity and competitiveness of the industry, at home and abroad. This paper presents to the Administration an "industry leadership" perspective of methods and means that, if jointly supported and implemented by the public and private sector, promise to transform the construction sector into the hightechnology/high skill sector America requires. These methods and means are prerequisites for effective revitalization of the nation's aging infrastructure, for enabling safe, highly efficient, user-friendly, and affordable constructed facilities (private and public infrastructure and housing) and construction practices that are both environmentally sound and sustainable. The proposed action agenda outlined herein derives from the Civil Engineering Research Foundation's recent construction industry leaders-Federal sector dialogue session with representatives from the White House staff as well as the members of the Construction and Building subcommittee, Committee on Civilian Industrial Technology of the National Science and Technology Council. As noted, this session was initiated by the Civil Engineering Research Foundation (CERF), the research affiliate of the American Society of Civil Engineers (ASCE).

Construction industry leaders are greatly encouraged by the fact that the construction sector has been viewed from the beginning of this Administration as a sector where $\mathrm{R} \& \mathrm{D} /$ innovation is essential and as a sector with the potential to significantly benefit the nation. They are particularly appreciative of the already completed actions the Administration has undertaken to assist the construction sector, including:

- designating buildings and construction as one of five explicit "advanced manufacturing " technologies;

- establishing the subcommittee on Construction and Building within the Committee on Civilian Industrial Technology of the National Science and Technology Council (NSTC); and

- establishing primary contact with the Civil Engineering Research Foundation (CERF) as the means for dialogue with the construction industry.

They likewise recognize both the need and the imperative to act now, in order to respond to the very significant efforts underway in Western Europe and Japan and to benefit both the construction sector and, most importantly, the nation. As in other U.S. industries, 
many fundamental discoveries related to construction and civil engineering have emerged from American universities and laboratories, but have been implemented elsewhere due to pervasive barriers to technology transfer and innovation.

Construction industry leaders look forward to the initiation of a robust construction industry-Federal government cooperative initiative aimed at fundamentally improving U.S. capabilities to encourage and adopt innovation. In this spirit they offer in this "white paper" both as a perspective on the industry and as the outline of a program for change, a program that they believe can play an important role in helping revitalize America's infrastructure, enhance economic prosperity, and improve the health and well-being of all Americans through affordable and environmentally appropriate innovative technologies and processes.

\section{The Impact of Construction in the United States}

Construction and construction-related activities are major players in the U.S. economy, employing over 6 million people and comprising roughly 13 percent of current Gross Domestic Product (GDP). Few Americans realize that it is the nation's largest manufacturing activity! While there are large firms, construction activity in the United States is dominated by hundreds of thousands of small firms. These many firms, in toto, provide the nation with the professional and technical skills and services that enable the creation of constructed facilities and renewal of infrastructure.

Constructed facilities comprise the broad category of man-made facilities that are essential for a modern industrial society to function effectively and provide an acceptable quality of life for its citizens. These facilities constitute the national "infrastructure." The U.S. infrastructure, whether public or private, including utilities, roads, bridges, railroads, ports and airports, homes, schools, hospitals and factories, is held captive to the innovation, or lack thereof, in the design and construction sector. Construction therefore truly impacts all aspects of the U.S. economy! Clearly, constructed facilities enable/provide us with many essential functions, such as:

$\begin{array}{llll}\sqrt{ } & \text { workplaces } & \checkmark & \text { housing } \\ \sqrt{ } & \text { transportation } & \checkmark & \text { recreation } \\ \sqrt{ } & \text { communications } & \checkmark & \text { commerce }\end{array}$

These facilities, in turn, are made possible or are impacted by many factors, including:

$\begin{array}{llll}\sqrt{ } & \text { construction materials/methods } & \checkmark & \text { operations/maintenance } \\ \sqrt{ } & \text { automation/robotics } & \checkmark & \text { renewal engineering } \\ \sqrt{ } & \text { environmental issues } & \checkmark & \text { construction work force skills }\end{array}$

The cost of any manufactured product or service is directly impacted by the construction industry! This occurs at production site facilities, in the national transportation network, in the quality of communications facilities, in sum, at every stage of the production 
process, from creation to disposal. It is clear that the United States cannot afford less than excellence in its constructed facilities as it poises itself to enter the 21 st Century and an increasingly complex and challenging international arena.

Constructed facilities are clearly essential for all aspects of human activity in the United States. The efficiency and the quality of America's constructed facilities must be of paramount concern for they truly determine the quality, efficiency and effectiveness of economic activity and, hence, relative competitiveness in the global marketplace. Moreover, they determine the relative quality of life Americans experience every day, whether at work, at home or at play. The construction sector is, for example:

- a major employer of the nation's work force

- a major consumer of raw materials

- a key to environmental well-being, associated with $1 / 3$ of all energy (2/3 of all electricity)

- a key to the nation's work environment, work productivity, safety and health

- a global competitor with international market share

No other manufacturing sector has as pervasive an impact on U.S. economic activity as construction does.

The industry's fragmentation is well-known! Over 80 percent of firms are very small with less than 10 employees; two-thirds have fewer than five. This factor may be partly responsible for the relative difficulty in the past of introducing technological innovations into practice in construction; this is now being resolved with the creation of the Civil Engineering Research Foundation (CERF) as the industry's "facilitator/coordinator/integrator" for R\&D and innovative technologies. Only a few firms have been capable of conducting significant R\&D. Moreover, no firm in the construction sector has been able to absorb the risk inherent in the pursuit and development of innovation. As a consequence, the construction sector currently lags other business sectors in R\&D investment, as indicated below:

Sector

Electrical/Electronics

Telecommunications

Aerospace

Chemicals

Automotive

Construction

U.S. Average
Annual Industry R\&D Investment (\%)

5.4

4.7

4.1

3.8

3.4

$\underline{0.5}$

3.4 
This can and must change! Innovation in constructed facilities and infrastructure renewal will provide significant national benefits! This will occur because of:

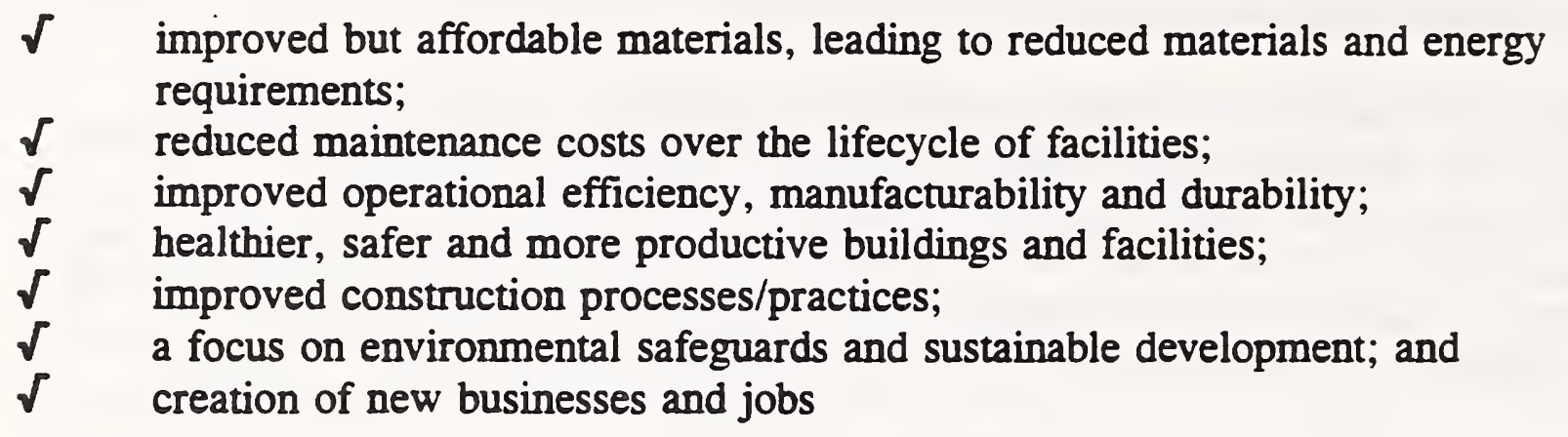

$\sqrt{ }$ improved but affordable materials, leading to reduced materials and energy requirements;

$\checkmark \quad$ reduced maintenance costs over the lifecycle of facilities;

$\checkmark$ improved operational efficiency, manufacturability and durability;

$\sqrt{ }$ healthier, safer and more productive buildings and facilities;

$\checkmark$ improved construction processes/practices;

$\sqrt{ }$ a focus on environmental safeguards and sustainable development; and

$\checkmark$ creation of new businesses and jobs

Innovation in manufacturing processes, materials, design, procurement and costing practices have transformed many U.S. industries, making them more productive as national and global competitors. The construction sector is poised to do likewise.

\section{A Program for Change}

The recent (April 5-6, 1994) initial dialogue between industry leaders and key members of the White House staff, principal Federal agency leaders with construction-related responsibilities, and the members of the National Science and Technology Council (NSTC) subcommittee on Construction and Building (a Committee on Civilian Industrial Technology subcommittee) produced recommendations about methods and means for change that are challenging but achievable from both a technical and an implementation perspective.

The development and use of a process that is capable of encouraging and overseeing innovation in the construction industry is essential. Four components are integral to this process, namely:

- clear and achievable goals;

- appropriate implementation methods and means;

- a viable initial user (customer); and

- incentives and recognition

With respect to goals, construction industry leaders strongly endorse the ambitious goals recently established by the NSTC subcommittee on Construction and Building. These goals include:

- $\quad 50$ percent reduction in project delivery time;

- 50 percent reduction in operations/maintenance costs;

- 30 percent increase in facility comfort \& productivity;

- 50 percent fewer building-related illnesses and accidents;

- 50 percent less waste and pollution; 
- 50 percent reduction in job-related illness and accidents for construction workers

A more detailed industry leaders' perspective on these goals is attached in the form of two enclosures to this "white paper." This perspective notes, among other things, the formidable procedures for construction innovation already in place in Japan and France.

Achievement of these ambitious goals will translate, most importantly, into more affordable constructed facilities, including infrastructure and housing. Timing, however, is critical; the joint establishment (by the NSTC subcommittee and industry leaders) of specific timelines for achievement of these goals, based on the relative priority of each goal and its potential impact, is therefore necessary. Development of both short and longer term timelines, ranging from between two and five years to, perhaps, the end of this decade, appears reasonable. The U.S. construction industry must enter the 21 st Century as a world leader in innovation!

Industry leaders commend the Administration for its active role in establishing and emphasizing specific means for public-private sector cooperation. The growing Advanced Technology Program (ATP) and Manufacturing Extension Program (MEP) of the Department of Commerce (through the National Institute of Standards and Technology), the Technology Reinvestment Program (TRP) and the Corps of Engineers' Construction Productivity Advancement Program (CPAR) provide significant promise for commercial R\&D and "dualuse" technology development. Other means, not currently authorized, appear equally promising and should be given careful attention. These include the "set-aside" of a specified percentage of annual U.S. construction volume for R\&D and diffusion of innovative technologies into wide-spread practice. This procedure is already in use in several European countries.

A fundamentally important aspect of this process is the active involvement of the federal sector as first user/customer. "Proof of concept" is a sine qua non for adoption of innovation in any sector; construction is no exception, indeed is even more dependent, given the required assurances of safety and the specter of liability and risk. The federal sector will truly serve the nation through its unique ability to function in this vital role. In this regard, specific legislation or Executive directives may be essential prerequisites. Specific applications have already been identified. These include, for example, precast concrete moment resisting frames, reinforcement steel bond development and use of composites in construction applications ((for example, fiber reinforced plastic (FRP) bridge decks)).

Incentives and recognition comprise the fourth pillar in this process. As noted, the fragmentation, the current procurement methods and the risk adverse environment that characterizes the construction industry have combined to stifle, if not preclude, an innovative perspective. Suitable recognition is therefore essential to promote a climate for innovation. The Malcolm Baldridge Award should be aspired to-the creation of a construction focused 
award is another possibility, perhaps through the subcommittee on Construction and Building. From a more mundane perspective, suitable incentives must be created, for example, appropriate tax code measures, innovative contract delivery systems, life-cycle costing, consideration of proprietary rights, and pre-qualification for innovative technologies, perhaps in a manner similar to the process now established through CERF's Highway Innovative Technology Evaluation Center (HITEC). Continued dialogue between industry leaders and the Office of Science and Technology Policy (OSTP) staff as well as the subcommittee on Construction and Building may lead to even more innovative approaches with respect to recognition and incentives.

The suggested process is in its formative stages. Much remains to be done; the publicprivate sector dialogue that has framed this "white paper" must therefore be given the highest priority within the industry and the Administration. The proposed process has a clear focus and promises to become a vital component of a larger U.S. industrial policy, a policy that will utilize the nation's excellent talents in research and development to enable successful, commercially profitable construction materials, systems and procedures. By doing so, an iterative process can be generated and sustained, perhaps as depicted below, a process that will truly serve the nation in the years to come.

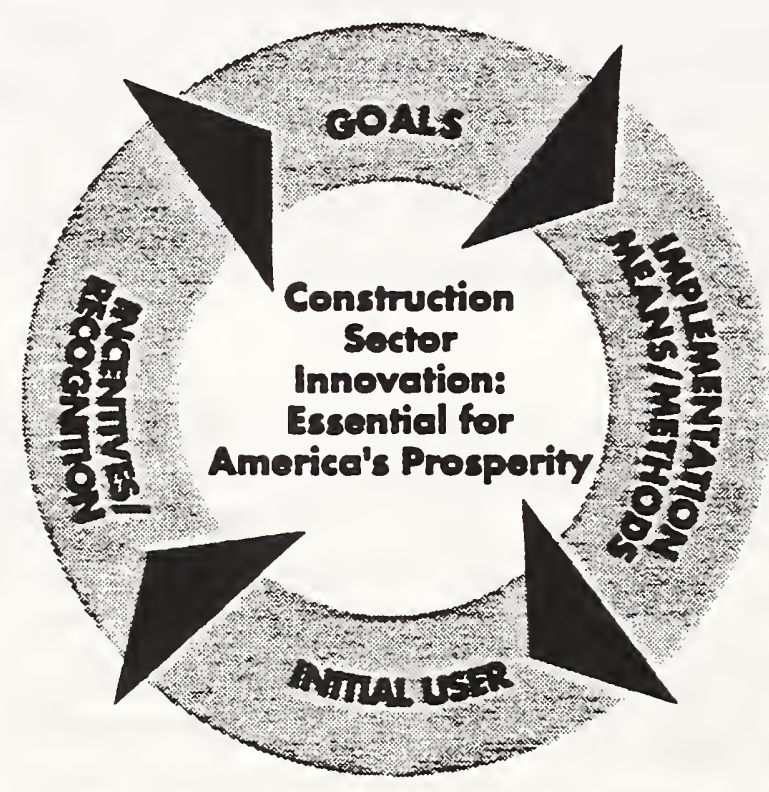


There are, finally, some specific actions that are so important they must be emphasized in this "white paper." These are actions that will empower the process outlined above and, without which, ultimate success will be diminished if not imperiled. They are therefore strongly recommend to the Administration. Specifically, the following actions are recommended:

- reform of Federal procurement practices to explicitly encourage innovation;

- enactment of Federal legislation that provides for the set-aside of a percentage of Federal (or total U.S.) construction funding to promote construction innovation (legislation should include limits on liability);

- $\quad$ create a consensus national "fast track" model (process) for public/private endorsement (approval) of innovation (include code development);

- create tax and other incentives that encourage private sector investment in innovative R\&D and the wide-spread application of such innovation-incentive may be protection of proprietary rights;

- promote the development and use of life-cycle costing in projects and develop standard methodology for application;

- $\quad$ promote the use of new materials, design and construction practices through communication and education regarding innovative R\&D to practitioners, and provide structure and incentives for implementation including the Federal government as first user; and

- identify and work with selected cities/communities/counties/states to incorporate new innovative technologies/practices as a basis for economic development and community revitalization, and obtain Federal waivers and backing as needed (for example, HUD's Empowerment and Enterprise zones).

\section{Conclusions/Recommendations}

The nation's leaders in the construction sector emphatically support the excellent dialogue now emplaced between the industry and the Administration and believe that this dialogue, enabled through Administration leadership, is critical to the continued prosperity and well-being of all Americans. The Administration has "opened the door" as never before to a receptive and committed construction industry leadership. Industry leaders urge expanded dialogue and, most important, the immediate initiation of industry-Federal government cooperative efforts to refine and implement actions suggested herein; joint demonstrations of already developed innovative technologies are recommended as an early cooperative effort, in order to provide high visibility for the benefits derived from such innovation. To use a metaphor that is destined by virtue of innovation to fade rapidly as a real construction sector activity, this "white paper" offers a blueprint for action that the nation cannot afford to see gather dust. The Administration's whole-hearted support, through appropriate legislation and Executive branch actions, will stimulate a construction industry response capable of surmounting the daunting national and global challenges that loom on the threshold of the 21st Century. 


\section{INDUSTRY PERSPECTIVES/INSIGHTS ON CIT SUBCOMMITTEE PROPOSED GOALS FOR THE CONSTRUCTION SECTOR}

50\% Reduction in Project Delivery Time

- Key is "doing it right" the first time; this requires better planning/early goals definition/proper planning and research on the construction process itself

- Requires better integration of design and construction; design/build and design/build/operate have potential

- Performance standards are a must to achieve this reduction

- Requires training, education of work force and demonstrations

- Modify/simplify approval process; too cumbersome and lengthy (in many cases over 20 separate approvals needed)

$50 \%$ Reduction in Operations/Maintenance (O\&M) Costs

Reductions in O\&M costs will result primarily from adoption of life-cycle costing, whereby most suitable materials, systems and environmental considerations can be incorporated. Since initial construction costs are estimated at a mere $2 \%$ of the life-cycle costs associated with a facility, a life-cycle cost perspective (including appropriate research) may significantly reduce O\&M costs

- $\quad 30 \%$ Increase in Facility Comfort \& Productivity of Occupants

- Has received only modest attention so far

- Performance standards needed for indoor air quality

- Will require improved sensing and control systems/individually controllable

- Will also require improved equipment response to control systems

- Requires improved understanding of health and safety implications

- 50\% Fewer Building-Related Illnesses and Accidents

- Need improved health and safety guidelines

- Focus on ergometrics (people) throughout design/construction process

- $\quad 50 \%$ Less Waste and Pollution

- Expand research on evennal use of recyclable materials

- Inadequate information dissemination regarding unsuitable materials

- $\quad 50 \%$ Greater Durability and Flexibility

- improved durability will result from use of performance specifications

- hinges on improved building materials/equipment and test/evaluation programs

- quality, on-time O\&M is a key factor

- requires visible, viable demonstration projects

- inclusion of all affected parties is essential in demonstration projects to obtain "ownership" and support

- must "publicize" both performance expectations and standards.

- use retrofit of public/private facilities to demonstrate potential improvements

- create government/industry partmerships to facilitate demonstrations; consider national/international competition

- explore/use recyclables to gain durability

- view enclosure materials (windows for example) as an asset, not a liability

- ensure building envelope meets performance specifications (not window alone)

ENCLOSURE 1 


\section{PERSPECTIVES ON MOVING INNOVATION INTO \\ THE U.S. CONSTRUCTION SECTOR}

Problem

Develop procedures in the United States that provide incentives for return on construction industry research and development investment. Ensure that the procedures enable efficient transfer of innovation, new technologies, and changed technologies into practice.

\section{Background}

The U.S. practice of separating design and construction into discrete activities with low price as the only selection criteria precludes a return for industry research investment. Companies who invest in research and development are typically penalized because they increase their overhead cost relative to companies who do not invest. Moreover, structural barriers (legal and determination of efficacy) creates risk/reward imbalances which impede effective technology transfer (or preclude such transfer). The U.S. experience stands in sharp contrast to current practices in both Europe and the Far East. Both Japan and France provide instructive insight into processes that appear to function well.

\section{Japan}

$\underline{\text { Process }}$

- Major construction programs which would benefit from research and innovation are announced with desired performance and function delineated (i.e., national breakwater program, national need to reduce earthquake damage, etc.).

- Research is performed by multiple companies which generates diverse innovation/technology.

- Innovation/technology resulting from research is approved for use by committee of industry, government, and academic experts (generally chaired by an academic) which evaluates the companies' research results. (Additional testing and investigation performed by government laboratories, at company expense, when objectivity is required).

- Companies qualify for bidding based on "experience and expertise, "which is demonstrated by research.

- Performance specifications are bid against by prequalified contractors. 
- The companies perform both the design and construction in satisfaction of the performance specifications.

- The most desirable innovations/technologies are transferred to the industry through experience gained on arranged joint ventures.

- An expanding base of companies are prequalified to use a technology/innovation based upon experience rather than research.

0 After extended use of the originally developed technology/innovation, the technology/innovation is standardized or codified and specific qualification is not required for its use.

$\underline{\text { Results }}$

- Prequalification based on expertise stimulates research.

- Design/build allows application of a company's technology/innovation to a project.

- Prequalification based on experience (gained through joint ventures) transfers the technology/innovation.

- Prequalification procurement and design/build delivery system allow a return on industry research investment.

- Evaluation removes efficacy barrier and legal barriers (legal is currently not a significant barrier in Japan).

French

Process

- Minimum performance and feature specifications are used on selected projects.

- Innovation/technology is evaluated and approved by a standing governmentsponsored committee of experts.

- Design/build contractors are prequalified.

- Price and performance are bid.

- Contract is awarded based upon the "best bid" (that bid offering the greatest value based on price/performance). 
- Long term performance of selected items is warranted.

- Operation/maintenance is sometimes included in the bid.

The government also enters into development agreements for innovation with companies which provide exclusive rights, evaluation, and demonstration. Research investment is recouped through demonstration projects and limited exclusive use.

\section{$\underline{\text { Results }}$}

- Best bid selection stimulates research to improve performance.

- Design/build delivery system stimulates innovation by allowing companies to incorporate their innovation into projects.

- Operation and Maintenance (O\&M) component, when used in bidding, quantifies performance over time, yielding a low bid which optimizes the balance between initial cost and life cycle (or a selected time cycle) cost.

- Best bid encourages development of proprietary technology so return on research investment can be achieved.

- Design/build delivery system and development agreements allow a return on research investment.

- Evaluation removes legal (as manifested through insurance requirements) and efficacy barriers.

\section{- Common Characteristics in Japan and France}

- Use of design/build for project delivery.

- Prequalification of bidders.

- Limitations on market use of developed technologies.

- Extended guarantees/warranties on performance. (France - contractual; Japan social.) 


\section{Possible U.S. Procurement Systems}

A. Identified Technology (needing successful transfer)

- Announce significant project(s) whose construction is limited to a defined technology. Announcement to include desired performance and desired features. (Lead time +/-24 months.)

- Project delivery

\section{Design/Build}

Prequalify contractors based on demonstrated expertise, as well as research and development. (Best suited for new technology or where use of modified technology requires development of construction processes.)

- Design, Bid, Build

Selection of A\&E based on team qualification which includes expertise demonstrated by research applying to the requirements of the technology. Contractor selection based on low price. (Best suited where it is a modification of an existing technology so processes do not require extensive development.)

- Prequalify

- Design/Build

Prequalify bidders based on team qualifications and limit most qualified bidders to three (3).

Design, Bid, Build

Prequalify construction bidders and limit number to maximum of five (5) most qualified.

- Evaluate utilization of stipulated technology and provide catastrophic insurance (i.e., \$20 million coverage with $\$ 1$ million deductible - contractor responsible for deductible amount). 
Design/Build Low Bid (if performance fixed or if bid includes O\&M.) Best Bid (if performance and price bid.) Unsuccessful bidders receive stipulated compensation. All bidders receive compensation if no award made.

Design, Bid, Build Low Bidder

- No performance guarantee or warranty. Government assumes risk of the preselected technology performance.

B. Development of various and multiple technologies:

- Announce significant project(s) including performance and features desired (lead time $+/-24$ months).

- Design/Build delivery.

- Prequalify bidders based on team qualifications which includes expertise demonstrated by research applying to the requirements of the project(s).

- Limit bidders to three (3).

- Evaluate technologies utilized by bidders and provide catastrophic insurance (i.e., $\$ 20$ million coverage with $\$ 1$ minimum deductible with contractor responsible for deductible).

- Award

- Low bidder. (if performance fixed or if bid includes O\&M.)

- $\quad$ Best bid. (if performance and price bid.)

- Unsuccessful bidders receive stipulated compensation for bidding.

- Compensation to all bidders if no award made.

- Extended performance guarantee and warranties secured by financial guarantees (bonds) with stipulated penal sum limit (i.e., \$5 million). 
C. Issues

- An open mind approach regarding existing procurement laws would accommodate the suggestions.

- Evaluation should be restricted to life safety and scientific methodology, otherwise good innovations might be precluded. (Some Reflections on Innovation and Invention, George H. Heilmeier: Remarks on Receiving the Founders Award, National Academy of Engineering, Washington, DC, September 29, 1992: "History seems to indicate that breakthroughs are usually the result of a small group of capable people fending off a larger group of equally capable people with a stake in the status quo.")

- Evaluation should be by a panel of experts which includes government, academics and industry. This will enhance technology transfer through exposing experts to innovations and the endorsement for trial use.

- Government's institutional thinking must be changed to that of embracing innovation rather than discouraging it. Otherwise, bureaucrats will always find reasons why new procedures can't possibly be used.

\section{General Observations}

Federal agencies have technical staffs that are capable of evaluating new technology prior to consideration for use and monitoring its performance over time after use. Federal agencies should be participating in technology transfer by encouraging the use of new technology in their projects, or through Federal participation in state and local government projects and selected private projects. Where the new technology is of sufficient magnitude and impact, demonstration projects should be designated and a formalized long term evaluation undertaken. Prior use of a new technology takes major strides in removing the barriers impeding the use of innovation. Successful use on a prior project removes owners' doubts about the risk associated with a new technology, designers' concerns about the standard of care and the contractors' resistance because of unknowns.

All too often in the construction industry we have seen U.S. government supported basic research done at academic institutions in the U.S., but with development and application occurring offshore. The innovation eventually finds its way back to the U.S. and is accepted for use after years of use overseas. This is the challenge we, as civil engineering/construction professionals in the public and private sector must join forces to overcome.

COMCABIOSTPSStephen

ENCLOSURE 2 
Ongoing projects/milestones (o), anticipated projects/milestones ( $*$ ) are identified for agencies involved. Gaps as yet unfunded (非) are also listed. When listed the dates are anticipated completion dates.

\section{Roadmap for Goal 1. 50\% Reduction in Delivery Time}

\section{Background:}

Reduction in the time from the decision to construct a new facility to its readiness for service is vital to industrial competitiveness and project cost reduction. During the initial programming, design, procurement, construction and checkout/startup process, the need of the client for the facility is not being met; needs evolve over time so a facility long in delivery may be obsolete or uncompetitive when it is finished; and the investments in producing the facility cannot be recouped until the facility is operational. The need for reduction in time to project completion is often stronger in the case of renovations and repairs of existing facilities because of interruption of ongoing business. Owners, users, designers and constructors are among the groups calling for technologies and practices reducing delivery time.

Objectives and Milestones:

1. Provide information systems that integrate generic and project-specific information to enable instantaneous controlled distribution and exchange of information and communication of needs for information, and decision-support systems that replicate a complete design cycle from project needs assessment through engineering, construction and trade studies. These systems will be used by owners, designers, regulators, suppliers and contractors to make timely decisions on construction projects. Once information and decision support systems have been developed, tested by users, and educational material prepared, they can be demonstrated through such programs as NIST's Manufacturing Extension Partnership.

The following agency programs relating to information system development for residential, commercial and industrial construction are underway:

- EPA is working with DOD to develop an expert system which will enable designers, constructors, building owners, managers, and end users to make facility decisions from a life cycle perspective.

- DOE's Exemplary Buildings program is developing computer-based information technology to help incorporate passive solar features into building design and specification.

- DOD's military program objectives: Develop innovative concepts, models, methods, and software environments to support real time collaborative facility design efforts. Develop stochastic, 
analytic, probabilistic solution techniques for nonlinear dynamic systems and techniques to break the computational barrier that presently exists for analyzing the response of large, nonlinear ocean structures.

- DOD's civil works program objectives: Develop new quantitative guidance and procedures for developing and maintaining effective flood protection projects within constraints of the water resources development act of 1986 and other regulatory guidance. Partner construction productivity and reduce construction operating costs.

- $\quad$ NIST is developing STEP application protocols for process plant piping systems. 1998

- NSF supports research in construction processes and optimization.

- DOE is modernizing DOE-2 the national building energy simulation program, so that it will run under CAD programs now used for building design.

- NSF funds research in corrosion monitor using intelligent chips, protective coatings, smart paint, and hypermedia fatigue investigator for continuous monitoring and condition assessment of infrastructures.

Planned programs include:

* NIST will extend information technologies to include conceptual design and maintenance phases of process plant life cycle. 1999

* NIST will demonstrate and transfer technologies to process plant industries through existing standards bodies and industrial consortia.

* NIST will expand knowledge systems for construction process information and put in place mechanisms for small- and mediumsized construction firms to gain competence in the use of these new technologies.

* NSF will continue to support concurrent design/automation with fast integrated data exchanges.

Gaps:

非 NASA's artificial intelligence program has produced many products to improve the planning and scheduling of complex tasks such as supporting space shuttle operations. Many of these should have value to the construction industry form initial conception through the entire life cycle. 
2. Provide automation in techniques for understanding users' needs, project planning and management, design, manufacturing, materials handling and placement, quality assurance, regulatory review and inspection, and automatic exchange of information among project participants to reduce time for design, construction and commissioning activities and support, to the extent feasible, parallel activities. Automation techniques will include virtual reality, communication protocols, robotics and sensors for automatic gathering and feedback of information.

The following agency programs relating to automation are underway:

- DOD's military program objectives: Develop integrated design/construct environments/tools to coordinate the efforts of geographically dispersed, functionally different sub-teams to obtain input and advice from all players in the facility life cycle, from requirements identification through facility operation and maintenance; advanced computer-based methods for energy analysis and design, cost estimating, structural modeling, and foundations designs in all climates. Develop new design systems needed to construct and maintain DOD's 1.4 billion sq. yds. of permanent pavements at reduced costs. Develop analytical mechanistic pavement models and phenomena theories for prediction of pavement response and behavior of cohesive, granular, and viscoelastic composite pavement materials under moving, vectorthrust dynamic jet-blast and static loadings.

- DOD's civil works program objectives: Develop computer-aided Structural Engineering (CASE) programs to determine the design strength of conduits, floating breakwaters, soil-structure interactions, seismic responses of concrete dams, and structural behavior of sheet piles.

- NASA's existing projects for space robotics should have a direct application to building and maintenance construction. These include rover technology for telerobotic and autonomous vehicles from microrovers to large systems, equivalent to construction vehicles; manipulation including dexterous arms and smart endeffectors; and general telerobotic control technologies to provide remote operation of complex systems.

- NSF supports research in non destructive evaluation, sensors, and construction automation.

- $\quad$ NIST is developing a virtual construction environment for design/construction of process plant structural systems. 1998

- $\quad$ NIST is developing communication protocol for HVAC controls. 1994

- NIST is developing sensors for real time site metrology. 1998 
- DOE's Building America Initiative is designed to demonstrate a systems integration approach to advanced building design, manufacture and delivery.

- HUD is researching the use of innovative site and land use planning to improve housing affordability.

- FHWA is developing sensors systems for bridges and developing robotics for special uses such as removing lead-based paints from bridges.

- NASA's space remote sensing program is developing technology (including acquisition and analysis of high resolution and multispectral data) that could be used to evaluate and select optimal construction sites.

Planned programs:

* NIST will develop wide band telemetry and data acquisition systems. 1999

* NIST will demonstrate efficacy of construction site utility robotics. 2002

* NIST is preparing to demonstrate Building Automation and Control Networks (BACnet) in a GSA building. 1999

* NSF will support research in construction material handling robotics and micro-tunneling.

Gaps :

非 Facilities management automation lacks attention

3. Develop and implement cost-effective high performance construction materials, components and systems, where high performance includes characteristics promoting reduction in project delivery time as well as high performance of the constructed facility in its service life. Technologies promoting reduction in project delivery time include: materials and components that rapidly can be procured, fabricated, delivered and installed; systems and components supportive of ready reconfiguration to support changing requirements; and sensing, assessment and quality assurance technologies providing real time evaluation of properties relative to those specified.

The following agency programs relating to the development of high performance materials, components and systems are underway:

- DOD's military program objective: Develop/adapt smart materials and environmentally compatible advanced materials technologies for 
infrastructure applications, including airfields and pavements. Develop new flood grout repair materials for rapid runway repair. Develop rapid runway repair device that exploits advances in thermal stabilization.

- $\quad E P A$ is developing as part of its pollution prevention/indoor air quality research program fiber-based alternative materials for structural and interior uses which are superior to existing materials.

- DOE's Advanced Residential Buildings research targets the energy and cost improvements that are possible through the incorporation of industrialized manufacturing processes and advanced materials into residential housing construction.

- FPL is developing processing technology for products that are lighter than traditional materials, more resistant to wind and earthquake loading, easier to handle, and/or quicker to install.

- FHWA is building and assessing the performance of a bridge built of FRP (fiber reinforced plastics).

- FHWA, NIST, Army Corps of Engineers and other agencies are working with CERF and industry in a program called CONMAT to identify needed research in infrastructure materials.

- FHWA is sponsoring research to resolve high performance concrete design and forming problems encountered in the specification of bid documents.

- NSF supports research in high performance construction materials, maintenance, life cycle performance and non destructive evaluation

- NIST is developing, in collaboration with industry, an integrated knowledge system for high performance concrete.

- NIST is developing methods for measurement of inplace properties of high performance concrete for use in Quality control and quality assurance systems.

4. Provide technologies for prompt environmental assessment of a project site and rapid abatement of environmental hazards identified.

The following agency programs are underway:

- $\quad$ EPA is developing a Life Cycle Assessment data base on the Internet which will be specific for the building industry to enable users to evaluate environmental impacts of materials.

5. Develop and implement technologies for reduction of risks that natural and manmade hazards will slow project delivery by damaging project 
documentation, the project site or the incomplete constructed facility. Hazards to be mitigated include: fires, floods, wind, earthquake and releases of toxic substances.

The following agency programs are underway:

- NIST is developing methods for industry to evaluate the impact of smoke from large fires in facilities on the local community for use in planning and response decisions

- NOAA is doing research to reduce the vulnerability of our Nation's populace and property to severe weather including hurricanes by improving the ability to forecast when and where these events will occur.

- $\quad$ EPA is developing technology for building radon free buildings and schools, and has carries out extensive studies on the control of radon in existing or new houses and schools. The technology developed for large buildings has been applied to a new hospital and two schools. Efforts will be expanded to develop regional radon training centers to effect implementation of radon free buildings .

- EPA is evaluating novel methods for preventing soil gas entry in houses and schools.

- DOD's military program objective: Develop analytical simulation and modeling techniques to reduce time and cost of certification of safe performance of large complex facilities, floating facilities and geotechnical systems subject to dynamic loading.

- DOD's civil works program objective: Develop advanced methods for predicting the stability and functional characteristics of complex coastal structures when subjected to a host of adverse conditions such as overtopping, runup, wave transmission, and breakup.

- NSF funds research in the mitigation of earthquakes, wind and floods and develop knowledge base for innovative structural control techniques and use of smart and high-performance materials.

- NSF is developing practical manuals for seismic retrofit and rehabilitation of building structures of all types located in moderate and high risk regions.

- NSF is developing engineering analysis techniques and design tools for prestresses/precasted structural systems to be developed in seismic regions.

6. Provide an internationally-recognized performance standards system that supports rapid acceptance of the project design and construction by 
regulatory authorities, and supports rapid acceptance of design, construction, review, inspection, commissioning, and other innovations capable of speeding project delivery. Subsequent acceptance by the code organizations and authorities will be necessary.

The following agency program is underway:

- DOD's military program objective: Develop criteria for mitigation of thermal bridges, moisture migration and air leakage in metal buildings in cold regions.

- DOD's civil works program objective: Develop improvements in design of bushings, water hammer analysis, and corrosion reduction and other electrical/mechanical problem areas.

- NIST is developing a framework for expressing and analyzing fire safety performance requirements for buildings as a nationally accepted alternate to the current requirements. 1995

Planned Programs:

* NIST will develop and demonstrate a prototype computer aided design system for fire hazard models which will allow architects and engineers to evaluate and optimize innovative building designs and new material applications against fire safety performance criteria, thereby providing better analysis for review by authorities having jurisdiction. This system will allow for reducing construction costs while increasing the level of safety. 1998

Gaps :

\# FHWA should develop a bridge design code/specification for composites.

7. Understand how cognitive processes, physiology, ergonomics, human interactions with equipment and environment, and inter-personal and inter-group relations affect performance of project personnel and equipment and relations with persons and organizations affecting project approval. Use this knowledge to develop practices improving project qualities and accelerating project delivery.

The following agency program is underway:

- NSF is sponsoring research on the ways the economic and social needs of society are served or limited by civil infrastructure and how infrastructure management effects the economic, social, and geographic organization of society.

- NSF supports research in cognitive processes, and human interactions with equipment 
Gaps :

\# NASA's artificial intelligence program has produced many products to improve the planning and scheduling of complex tasks such as supporting space shuttle operations. Many of these should have value to the construction industry form initial conception through the entire life cycle.

非 NASA's artificial intelligence program has produced knowledge-based tools designed to extract information and identify anomalies in the performance of systems (e.g. fault detection). This is very broad-based technology that could be applied to monitor the operations of buildings.

2. Provide automation in techniques for understanding users' needs, facilities operations and management, condition assessment and adaptive control to support high quality operations and minimize waste in operations and maintenance.

The following agency programs are underway:

- $\quad$ NIST is developing communication protocol for HVAC controls. 1994

- $\quad$ NIST is developing fault detection diagnostic and optimization techniques for HVAC controls. 2001

- Virtually all DOE building programs aim to improve energy efficiency through one means or another. Portfolio includes lighting, appliances, equipment (e.g., HVAC system), building shell (e.g., advanced insulation, windows), other.

- DOD military program objective: Develop models and mechanisms for worker task assignments, task automation, and institutional knowledge capture, storage, and retrieval.

- NSF is sponsoring research to evaluate, extend, and enhance the life of facilities and structures that would otherwise continue to deteriorate.

3. Develop and implement cost-effective high performance construction materials, components and systems where high performance includes efficiencies in operations and maintenance as well as fit-for-purpose performance in service. Qualities for efficiency in operations and maintenance include: damage tolerance, durability and resistance to soiling, energy efficiency, low emissions of pollutants, and systems, components and materials that are self-assessing and/or are readily reconfigured to support changes in users' needs.

The following agency programs are underway:

- DOD military program objective: Develop lightweight surfaces for reuse that are capable of carrying 1-million-pound aircraft over 
weak soils; that extend pavement life by 5 years (25\%), and reduce maintenance costs by $\$ 72$ million $(20 \%)$. Evaluate new paving materials under freeze-thaw conditions. Develop corrosion resistant coatings and cathodic protection devices.

- FPL is working to develop improved adhesives and finishes for wood from renewable (non-petroleum) sources.

- FPL is working with the Forest Service fire laboratories to develop a structural ignition assessment model for structures on the wildland/urban interface that are susceptible to wildland fires.

- NIST is developing measurement methods and performance data to facilitate the acceptance of composites in structural applications in constructed facilities.

- DOE's Building Envelope Program is supporting near-term development of CFC-free high $R$-value insulation for new and retrofit applications.

- DOE Lighting Research is developing high-efficiency lamps with greatly extended useful lifetime.

- NSF supports fundamental research in high performance materials with desirable designed properties.

4. Provide cost-effective technologies for energy conservation, indoor air quality, water conservation, waste minimization, etc., that reduce operation and maintenance costs.

- EPA is researching the use of air cleaners to reduce indoor air impacts from emission sources.

- NIST is developing design software for indoor air quality and moisture migration.

- $\quad$ NIST is developing evaporative and condensation heat transfer data and design information for use with replacement refrigerant mixtures. 1995

- NIST is developing refrigeration cycles/hardware for natural fluids. 2000

- Virtually all DOE building programs aim to develop new technologies that conserve energy.

- DOD military program objective: Develop technologies and operational procedures for efficient, cost-effective heat distribution systems; improve energy efficiency of boilers and central heat plants; provide cost-effective options for thermal energy recovery and loss reduction. 
- DOE is studying filtering of indoor air to reduce airborne infectious disease. Adding filtration is far more cost effective than adding more outside air.

- NSF supports innovative methods to mitigate natural and man-made hazards.

5. Develop and implement cost-effective technologies to reduce property damage and loss of function from natural and manmade hazards such as fire, earthquake, wind, flood, and releases of toxic substances.

- DOD military program objective: Develop cost-effective methods for evaluating the seismic vulnerability of existing facilities and upgrading them in accordance with PL 101-614. Develop technologies to solve electrical power quality problems. Develop technologies to ensure the structural reliability, functional performance and extension of facility life for critical waterfront facilities.

- DOD civil works program objective: Reduce damage from earthquakes by advancing state of the art knowledge of earthquake hazard assessment, seismic design, and remediation of infrastructure, and by developing technical capabilities to improve rapid responses to earthquake induced life threatening emergencies.

- NIST is developing a basic wind load assessment procedure for incorporation into ASCE Standard 7.

- NIST is developing the scientific understanding, engineering technology, measurement methods, and performance data to enable US industry to develop the next generation of general purpose fire sensing and suppression systems capable of identifying and controlling fires reliably and with minimal damage.

- NIST is developing methods to measure smoke particle deposition on surfaces as a means of quantifying smoke damage in structures. 2000

6. Provide an internationally recognized performance standards system that reflects operations and maintenance costs in initial design and construction of the facility, and promotes acceptance of innovations capable of reducing operations and maintenance costs.

- NIST is quantifying moisture transport properties for building materials. 1996

- DOD civil works program objective: standardize technology used in planning, design, construction, operation, maintenance and rehabilitation of Corps projects built on rock formations. 
- DOE Office of Codes and Standards works aggressively to establish and improve standards related to all aspects of building energy use.

- FPL research on the physics of moisture movement in wood buildings is establishing the basis for standards for moisture protection and ventilation, directly impacting the ability to maintain target energy efficiency levels.

- HUD is researching the use of innovative site and land use planning to improve housing affordability.

Planned Programs:

* NIST will develop seismic standards for design and construction of existing and new lifeline structures. 2002

* NIST will develop draft interim performance criteria for affordable housing. 1997

Gaps :

非 More stringent standards will be needed for advanced building appliances.

7. Understand how cognitive processes, physiology, ergonomics, human interactions with equipment and environment, and interpersonal relations affect users' requirements for operations and maintenance and the performance of operations and maintenance personnel. Use this knowledge to provide needed performance while reducing operations and maintenance costs.

- DOE is conducting field research into the effects of scotopic (optimum spectra) lighting in office work areas.

- NSF supports research in cognitive processes, ergonomics and behavioral sciences.

The following educational programs support more efficient operations and maintenance for users, owners, designers, constructors and operating and maintenance personnel.

- DOE Wall, Roof and Foundation Research supports the operation of the Building Envelope Research Center as a National User Facility, available to industry for testing of new construction practices and materials.

- DOE Windows Research supports a nationally accepted window energy performance rating and labeling program, which currently certifies over 5,000 products. 
- DOE's Active Solar Space Conditioning program is establishing and implementing industry-wide testing and performance rating procedures to enhance consumer acceptance of the technology.

- In cooperation with the California fire service NIST is developing homeowner self-help technology for enhanced fire protection of residential construction. 1996

- NSF's research centers and education coalition support different facets of educational programs including new curricula development.

Gaps :

非 An operation and maintenance training program and nationallyrecognized training certification program for commercial buildings should be developed.

\section{Roadmap for Goal 3: $30 \%$ Increase in Productivity and Comfort}

\section{Background:}

For a commercial or institutional building the annual salary costs of the occupants are of the same order of magnitude as the capital cost. Indeed, the purpose of the building is to shelter and support the activities of its occupants. Improvement of the productivity of the occupants (or for an industrial facility, improvement of the productivity of the process housed by the facility) is the most important performance characteristic for most constructed facilities.

Objectives and Milestones:

1. Provide information systems that integrate generic and project-specific information to enable instantaneous controlled distribution and exchange of information and communication of needs for information, and decision-support systems that provide real-time information on users' needs and means to control building services cost effectively, and to support these needs in an optimum way. Early introduction of information systems can provide the stimulus for subsequent introduction of new technologies as they become available.

- NSF supports research in integrated data exchange and concurrent design.

Gaps :

非 NASA's artificial intelligence program has produced many products to improve the planning and scheduling of complex tasks such as supporting space shuttle operations. Many of these should have value to the construction industry from initial conception through the entire life cycle. 
非 NASA's artificial intelligence program has produced knowledge-based tools designed to extract information and identify anomalies in the performance of systems (e.g. fault detection). This is very broad-based technology that could be applied to monitor the operations of buildings.

2. Provide automation in techniques for understanding users' needs, facilities operations and management, and service systems controls to support users' productive activities and comfort.

- NASA sensor research and development program encompasses a wide range of technologies for low cost, accurate and robust sensors for applications such as vibration, temperature, chemical species, etc. While the focus of this work is primarily on earth observing, planetary science and human tended/occupied space laboratories applications the technology is applicable to terrestrial measurements.

- $\quad$ NIST is developing communication protocol for HVAC controls. 1994

- NIST is developing fault detection diagnostic and optimization techniques for HVAC controls.

- HUD is researching methods to improve accessibility for the disabled in rehabilitated housing.

Gaps :

\# Research is needed on all aspects of efficiency of work performance of facility users as determined by their work environment design. Research is also needed on the effect of facility design on the "customers" who temporarily visit these facilities.

3. Provide cost-effective construction materials, components and systems that support users' productive activities and comfort and are adaptable to changes over time in occupant needs and activities.

- EPA will develop a building materials selection guide to facilitate the use of low-emitting, low-impact, and bioretardent materials.

- DOE Building Materials Research is developing, in the longer-term, materials capable of varying their thermal resistance in response to changes in the external environment.

4. Provide technologies for heating, cooling, ventilation, humidity control, lighting, acoustics, space utilization, furnishings, finishes, etc., that provide a comfortable, stimulating and productive work, residential or recreational environment. 
- DOE Lighting Research is developing advanced electronic controls and improved design tools that will allow optional building lighting to suit varying user requirements.

- DOE Passive Solar Research is developing building design strategies that will provide basic heating, cooling and lighting services at little or no cost.

- DOE Building Envelope Research strives to improve the thermal integrity of the building shell, easing the ability to maintain desired temperature and humidity conditions.

- EPA is developing and evaluating innovative ventilation and air cleaning strategies for control of indoor pollutants. This includes the development of guidance for designers, builders, product manufacturers and the public on the effectiveness of the various approaches.

- DOD military program objective: Develop advanced techniques and technologies for monitoring and controlling air quality in buildings; for improving the efficiency and quality of lighting systems.

- NSF supports research in building systems including HVAC, lighting, etc.

Gaps :

\# Investigation is needed on integrated building systems for various types of facilities. For example, what would be the first cost and life cycle costs for using raised underfloor systems rather than hung ceiling systems for supply and distribution of utilities.

5. Provide technologies and practices to reduce information losses, property damages and losses of worktime and function from natural and manmade hazards such as fire, earthquake, wind, flood and releases of toxic substances.

- EPA will develop after-disaster building management protocols to provide guidance for reducing property damage and loss of function from natural and manmade hazards such as fire, flood, and leaks.

- DOE Indoor Air Quality Research will lead to scientifically sound radon mitigation strategies for consideration in energy codes.

6. Provide an internationally recognized performance standards system that reflects occupant productivity and comfort in initial design and construction of the facility, promotes acceptance of innovations capable of improving productivity and comfort, and provides for operations and maintenance for productivity and comfort. 
- NIST is developing a framework for expressing and analyzing fire safety performance requirements for buildings as a nationally accepted alternate to the current requirements. 1995

Planned Programs:

* NIST will develop and demonstrate a prototype computer aided design system for fire hazard models which will allow architects and engineers to evaluate innovative building designs and new material applications against fire safety performance criteria. This system will allow for reducing construction costs while increasing the level of safety. 1998

* NIST will develop draft interim performance criteria for affordable housing. 1997

7. Understand how cognitive processes, physiology, ergonomics, human interactions with equipment and environment, and interpersonal relations affect users' productivity and comfort. Apply this knowledge to provide productive and comfortable work, residential and recreational environments.

Gaps :

\# Investigations are needed on the optimal indoor workplace design (lighting, noise temperature, workplace layout) with special reference to computerized work systems.

\# Research is needed to develop methods for assessing worker performance during mental work.

\# Research is needed to identify how factors such as indoor lighting and workplace layout affect worker health and performance.

\# Research is needed on the psychological effects of exterior building design, availability of natural light and views inside the building, interior color selection, inclusion of art, type of furniture arrangements (closed offices versus "office landscape"), grouping of conference rooms, lounges, meeting spaces, etc., versus decentralization of such functions, etc., inclusion or exclusion of eating facilities, child day care, services (shoe repair, groceries, etc.) and how these relate to user morale and efficiency of work performance, sick leave, staff turnover, comparative salary levels, etc.

Roadmap for Goal 4: 50\% Fewer Occupant Related Illness and Injuries

Background:

Commercial, institutional and residential buildings are intended to shelter and support human activities, yet the environment and performance of buildings 
can contribute to illnesses and injuries for building users. Sick leave because of airborne respiratory disease averages about one week/year, $2 \%$ of wages in building, about $1 \%$ of GNP. Examples are avoidable injuries caused by slips and falls, legionnaires disease from airborne bacteria, and building collapses from earthquakes or extreme winds. Although data are limited, current evidence suggests that the quality of the indoor environment may be related to sick-building symptoms, infectious disease, allergies and asthma. Sick building symptoms include irritation of eyes, nose and skin, headache and fatigue. If improvements in the quality of the indoor environment reduce days of productive work lost to sick days and impaired productivity, annual nationwide savings could reach billions of dollars. In a 1987 survey of U.S. office workers, $24 \%$ reported dissatisfaction with air quality at the office, while $20 \%$ perceived their performance to be hampered by poor indoor air quality. Complaints about "sick building syndrome" have become sufficiently common that 37 states and territories have designated a contact person for building complaint investigations.

Violence is a safety issue which can be addressed in part by building design, referred to as crime prevention through environmental design. A Department of Justice study released in July 1994 states that 1 million people will be affected by violent crime while they are at work. These incidents result in 1.8 million lost workdays each year, an average of 3.5 days per crime, and $\$ 55$ million in lost wages, not including days covered by sick and annual leave.

Projections on the growth of computer work suggest that nearly 60 million office and factory jobs will be impacted by computerized systems requiring specialized workplace redesign. These design problems are so pervasive that organizations such as NIOSH, the Human Factors and Ergonomics Society, the American National Standards Institute, and the International Standards Organization have all undertaken efforts to define environmental design criteria to avoid health and performance impairments.

Reductions in illnesses and injuries will increase users' productivity as well as reducing costs of medical care and litigation.

Objectives and Milestones:

1. Provide information systems, incorporating generic and project-specific information, and decision support systems, for owners, designers, manufacturers, constructors, users and operations and maintenance personnel that will provide real time information on users' needs and the health and safety characteristics of the building environment.

- EPA's Source Characterization research develops methods to understand, identify and characterize indoor air pollutant sources.

- NIOSH and EPA make available a joint document recommending methods to evaluate operation and maintenance procedures for possible causes of "sick building syndrome" 
Planned Programs:

* NIOSH and EPA are planning collaborative development of protocols to be used by building operators to evaluate potential causes of sick building symptoms.

Gaps :

\# NIOSH and EPA should showcase and make widely available examples of building design, new technologies, and interventions which reduce incidence of illnesses, injuries and violence

2. Provide automation in techniques for understanding users' needs, design, construction, facilities operation and maintenance, and service systems controls in order to design, construct, operate and maintain healthy and safe building environments.

- $\quad$ NIST is developing communication protocol for HVAC controls. 1994

- $\quad$ NIST is developing fault detection diagnostic and optimization techniques for HVAC controls. 2001

- $\quad$ NIST is developing a virtual construction environment for design/construction of process plant structural systems. 1998

- EPA's Exposure Assessment develops methods to monitor and analyze indoor air pollutants.

Gaps :

非 Technology from NASA's ongoing sensor technology programs could likely be used to help monitor and control the interior of buildings (i.e. temperature, contaminants, etc.) Technology for remote sensing from space (including acquisition and analysis of high resolution and multi-spectral data) could be useful in identifying and assessing environmental problems.

\# NASA has developed compact, very accurate accelerator/seismometer technology that can be used to measure the onset of damage and assesses post event damage.

\# Low cost sensors should be developed for particulate and gaseous pollutants to be used in improved building environmental control systems.

非 Better methods need to be developed for measuring indoor concentrations of toxic or irritating chemical and biological substances.

\# Better methods to measure dermal absorption of chemical substances need to be developed, such as patches made from synthetic skin. 
\# Research is needed to develop modern methods to measure and to prevent microbiological contamination in buildings and in ventilation systems.

非 Better objective methods to measure health outcomes are needed for use in studies of sick building symptoms.

3. Provide construction materials, components, and systems conducive to users health and safety in normal operations and resistant to dangerous behavior in extreme environments or during maintenance and renovation.

- DOD military program objective: Develop autonomous heavy equipment for operations in an unexploded ordinance/chemical environment.

- DOE is demonstrating affordable passive strategies for mitigation of radon in high risk areas.

- EPA is developing standard test methods for determining materials' susceptibility to biocontamination and subsequent indoor air pollution and materials deterioration.

- FPL is developing fire growth models to better predict the behavior of wood construction exposed to fire.

- $\quad$ NIST is developing test protocol for determining the relationships between in-use degradation of polymeric materials and changes in their structural and design properties. 2002

- NSF funds research in repair, retrofit and strategies.

Planned Programs:

* NIST is developing science based performance criteria for a new generation of fire resistant materials based on, e.g., surface layer modifications and nanostructure technology. 2005

4. Provide technologies for heating, cooling, ventilation, humidity control. lighting, acoustics, etc., that provide a healthy and safe work, residential, recreational, school or hospital environment.

- $\quad$ NIST is developing design software for indoor air quality and moisture migration.

- DOE is experimenting with very affordable passive strategies for reduction of radon in radioactive areas.

- EPA's Solution research provides engineering and technical solutions for managing pollutant sources, ventilation and air cleaning, building design/operation/demonstration, radon mitigation and technology transfer. 
- DOD military program objective: Develop methods and technologies to detect and diagnose HVAC control and malfunctions; to reduce DOD costs for facility air conditioning while ensuring improved indoor air quality.

- DOE is developing an advanced control system for oil burning furnaces and boilers that will provide early warning of system malfunction or efficiency degradation.

- NIOSH is conducting research to evaluate the effects of cleaning strategies and ventilation upon the prevalence of sick building symptoms.

- NSF supports research in modeling of HVAC, lighting, acoustics, etc., in building systems.

5. Provide technologies and practices to reduce risks to users' safety and health from natural and manmade hazards such as fire, earthquake, wind, flood and releases of toxic substances.

- $\quad$ NIST is developing a basic wind load assessment procedure for incorporation into ASCE Standard 7.

- NIST is developing and validating a method for predicting the burning rate of upholstered furniture incorporating bench scale flammability data. 1998

- In cooperation with the California fire service NIST is developing homeowner self-help technology for enhanced fire protection of residential construction. 1996

- NIOSH is developing methods of identifying and removing sources of Sick Building Syndrome (SBS) particularly those cases involving hypersensitivity responses.

- HUD is researching the nature of radon hazards in residential housing.

- HUD is researching cost-effective methods to eliminate lead hazards in housing

- FPI is developing non-destructive testing methods to assess the residual strength of biologically degraded wood members and to assess strength properties of composite products and products made from recycled materials.

- DOE is developing radon prediction tools to identify high risk radon areas. 
- DOD civil works program objective: Improve safety and economy in design, construction, and operation of earth and rock-fill dams and other water control structures.

- NSF supports research in the mitigation of natural and man-made hazards, NDE, structural control, etc.

6. Provide an internationally recognized performance standards system that reflects users' health and safety in initial design and construction of the facility, promotes acceptance of innovations capable of improving safety and health, and provides for operation and maintenance for safety and health.

- DOE Infiltration and Ventilation Research is developing measurement techniques and promoting improved standards for building indoor air quality.

- NIST is quantifying moisture transport properties for building materials. 1996

- FPL is developing standards for use of wood in many structural applications where it might offer safety on durability advantages, such as in areas prone to earthquakes or high wind loadings. FPL also develops standards for fire safety.

7. Understand how cognitive processes, physiology, ergonomics, human interactions with equipment and environment, and inter-personnel relations affect users' safety and health. Apply this knowledge to provide healthier and safer work, residential and recreational environments.

- EPA's Health Effects research studies the health effects of organic vapors and biocontaminants.

- NIOSH supports research to identify successful physical structures, control technologies, interventions, and administrative procedures to be implemented in design and operation of buildings to reduce opportunities for violence.

- NIOSH and EPA support research to identify deficiencies in building design, construction, operation and maintenance which result in building-related illnesses.

Gaps:

\# Investigations are needed on the optimal indoor workplace design (lighting, noise temperature, workplace layout) with special reference to computerized work systems. 
\# Comprehensive research programs are needed to definitively identify the relationship of factors in the indoor environment to sick building symptoms, asthma, allergies, and transmission of infectious disease.

The following short courses and educational materials support building users health and safety, for users, owners, designers, constructors, regulators and operating and maintenance personnel.

- $\quad$ EPA is developing indoor air quality short courses and student manuals to provide educational materials and curricula supporting building users health and safety.

* DOE's Sustainable Buildings Initiative will carry out R\&D, demonstrations, education and training on the techniques and resulting benefits of an environmentally-sensitive whole-buildings approach to design and construction practices.

Gaps :

\# NIOSH should develop and make widely available guidance documents recommending physical design options, control technologies, and administrative procedures successful in reducing violence in the workplace.

Roadmap for Goal 5: $50 \%$ less Waste and Pollution

Background:

Because they shelter and support most human activities, improvement of the performance of constructed facilities provides major opportunities to reduce waste and pollution at every step of the delivery process, from raw material extraction to final demolition and recycling of the shelter and its contents. Examples are reduced energy use and greenhouse gas emissions and reduced water consumption and waste water production. Wastes and pollution also can be reduced in the construction process: construction wastes are estimated at 20$30 \%$ of the volume of landfills.

Objectives and Milestones:

1. Provide information systems, incorporating generic and project-specific information, and decision support systems, for owners, designers, manufacturers, constructors, regulators, occupants, and operators, to provide real-time information on the waste and pollution implications of alternative materials, components, systems and practices for construction, operation, maintenance, renovation, demolition and waste recycling.

2. Provide automation in techniques for design, construction, operation, maintenance and demolition to avoid waste and pollution and promote reuse of materials. 
- NIST is developing a virtual construction environment for design/construction of process plant structural systems. 1998

- NSF is sponsoring research to extend and enhance the life of facilities and structures that would otherwise continue to deteriorate.

\section{Planned Programs:}

* NIST will demonstrate efficacy of construction site utility robotics. 2002

* NIST will develop wide band telemetry and data acquisition systems. 1999

* NIST will demonstrate efficacy of construction site utility robotics. 2002

Gaps:

非 Technology developed by NASA for remote sensing from space (including acquisition and analysis of high resolution and multispectral data) could be useful in identifying and assessing environmental problems.

3. Provide construction materials, components and systems that conserve resources over the life cycle, are adaptable to changes over time in users' needs and activities, and are suitable for recycling.

- EPA is researching alternative materials to replace particle board and plywood made from off-spec fibers and discarded automobile tires. The tire product is structurally superior to particle board, and is resilient and sound proof in addition to reducing waste through the reuse of tires.

- NIST is developing test protocol for determining the relationships between in-use degradation of polymeric materials and changes in their structural and design properties. 2002

- DOE Advanced Residential Buildings Research targets incorporation of industrialized manufacturing processes and advanced materials into residential housing construction.

- DOE's Building Envelope Research is developing methods of extending the lives of existing roofs which will reduce landfill requirements.

- FPL research on improved methods for grading sawn lumber will reduce waste through more accurate assignment of design properties. 
- FPL research on using recycled wood, fiber materials (e.g., glass), newspaper, plastics, and other materials to produce highstrength composites will help to utilize municipal wastes stored in landfills and to reduce generation of those wastes.

- FPL research will identify possible agents to inhibit decay without toxicological effects. Research will also identify better and less-expensive methods to clean up contaminated treating sites and materials using wood-degrading fungi.

- HUD is researching affordable alternatives to wood for residential construction including the development of technical standards for framing

- DOD military program objective: Establish criteria for recycling construction materials.

- NSF is sponsoring research on the design of effective demolition, the compatibility of repair materials, and the recycling of resources.

4. Provide technologies for heating, cooling, ventilation, humidity control, lighting, communication, water supply and waste handling and treatment, etc., that reduce production of wastes and pollutants.

- HUD is researching new and improved air distribution systems for manufactured housing to reduce energy loss.

- NIST is developing refrigeration cycles/hardware for natural fluids. 2000

- DOD military program objectives: Develop criteria for efficient centralized waste facilities in cold regions. Identify energy technologies based on renewable sources; investigate technologies for increased coal combustion; develop advanced electrical systems technologies to reduce electrical energy consumption.

Gaps :

非 Waste Minimization will develop prototype technologies that generate less waste in building construction and rehabilitation, influence codes and standards to encourage the use of such technologies, and create the Volunteer Sustainable Builder Certification program.

5. Provide technologies and practices to reduce damages to and harmful discharges from constructed facilities as a result of natural and manmade hazards such as fire, earthquake, wind, and flood.

- NIST is developing methods for industry to evaluate the impact of the smoke from large fires in facilities on the local community for use in planning and response decisions. 
- DOD military program objective: Develop environmentally acceptable replacements agents for the current generation of fire suppressants such as Halon 1211, Halon 1301, and dry chemicals.

- HUD is performing research on the affordability, safety and durability of manufactured housing.

Planned Programs:

* NIST will measure the heat transfer characteristics of exterior fires including intensity and duration for typical sources. 2000

6. Provide an internationally recognized performance standards system that reflects avoidance of waste and pollution in initial design and construction of the facility, promotes acceptance of innovations capable of reducing waste and pollution, and provides for reduced waste and pollution in operations, maintenance and demolition.

7. Understand how cognitive processes, physiology, ergonomics, human interactions with equipment and environment, and interpersonnel relations affect waste and pollution. Apply this knowledge to reduce waste and pollution in the design, construction, operation and removal of constructed facilities.

DOE's Sustainable Buildings Initiative will carry out R\&D, demonstrations, education and training on the techniques and resulting benefits of an environmentally-sensitive whole-buildings approach to design and construction practices.

\section{Roadmap for Goal 6: 50\% More Durability and Flexibility}

\section{Background:}

Durability denotes the capability of the constructed facility to maintain (given appropriate maintenance) its initial performance characteristics over the intended service life, and flexibility denotes the capability to adapt the constructed facilities to changes in use or users' needs. High durability and flexibility contribute strongly to the life cycle quality of constructed facilities since they usually endure for many decades.

Objectives and Milestones:

1. Provide information systems, incorporating generic and project-specific information, and decision support systems, for owners, designers, constructors, manufacturers, occupants, and operators, to provide realtime information on the durability and flexibility of construction materials, components and systems.

- NIST is developing, in collaboration with industry, an integrated knowledge system for high performance concrete. 
2. Provide automation in techniques for design, construction, operation and maintenance to improve durability, sense needs for maintenance or repair, and adapt the system for changed users' needs.

- $\quad$ NIST is developing communication protocol for HVAC controls. 1994

- HUD is performing research on the affordability, safety and durability of manufactured housing.

- NSF funds research in computer integrated automation processes.

3. Provide construction materials, components and systems that are durable and adaptable to changes over time in users' needs and activities.

- FPL research on the effect of extreme environmental exposure and chemical treatments and treating processes on the properties of solid and composite structural members is leading to safer design of engineered structures.

- FPL is developing design criteria for the strength of solid and composite wooden structural members and fastening systems to improve their durability in buildings.

- NSF is sponsoring research on how materials and structures break down and wear out. This research involves materials science, chemistry, biology, geotechnical engineering, mechanics, failure processes, and risk and reliability.

- NSF is sponsoring research in the assessment of structure and facility durability and cleanliness. This work involves nondestructive evaluation techniques, improved sensor technologies, "smart" self-correcting materials, and enhanced geographical information systems.

- NSF is sponsoring research on the design of effective demolition, the compatibility of repair materials, and the recycling of resources.

- NIST is developing methods for measurement of inplace properties of high performance concrete for use in quality control and quality assurance systems.

- NIST is developing a micromechanical model of cement pastes for use in predicting modulus of elasticity, crack propagation, and the effects of expansive inclusions. 1999

- NIST is developing reliability-based service life prediction methodology for corrosion-protective organic coatings. 1997

- NIST is developing test protocol for determining the relationships between in-use degradation of polymeric materials and changes in their structural and design properties. 2002 
- DOE Passive Solar Technologies program develops heating, cooling, and lighting characteristics of buildings that are integral to the building itself, thus remaining operative throughout the life of the building.

- DOE Lighting Research is developing high-efficiency lamps with greatly extended useful lifetime.

- DOE is conducting exploratory research for the design of a high efficiency roof with a 30 year life.

- DOD military program objective: Develop low maintenance corrosion resistant coatings and cathodic protection and scale removal technologies to increase the durability of utility systems in all environments. Develop materials to obtain significant increases in durability of waterfront structures.

- DOD civil works program objective: Investigate suitability of a variety of concrete materials and construction practices which may be used to economically construct civil works structures while maintaining or improving overall performance and durability.

- A VA research study produced the "Veterans Affairs Hospital Building System (VAHBS)" to reduce construction delivery time and cost and to control obsolescence, not only of building subsystems, but also of the renovations required because of the dynamic changes in the technology and delivery of health care. Several medical centers have been constructed without increased first cost, but studies have not been made to quantify recognized lifecycle cost savings. Although this VAHBS integrated systems technology has been occasionally used for hospitals by other federal agencies and in the private sector, no active attempt has been made to publicize or deploy the results.

Planned Program:

* NIST will develop science based performance criteria for a new generation of fire resistant materials based on, e.g., surface layer modifications and nanostructure technology. 2005

4. Provide technologies for durable and flexible environmental systems for constructed facilities.

No current or planned programs were identified.

5. Provide technologies and practices to reduce damages from natural and manmade hazards such as fire, earthquake, wind, flood and releases of toxic substances.

- NIST is developing a new, rational method for evaluation of the fire performance of structural materials. 2002 
- FPL is investigating the technical feasibility of high-performance wood structural systems which improve both on-site construction times and resistance to wind and earthquake loading.

- HUD undertaking extensive research on the impact of earthquakes on residential housing including surveys of residential building performance in the Northridge earthquake and improved earthquake resistance for manufactured homes.

- HUD is undertaking research to improve the wind resistant homes.

- NSF supports research in earthquake and wind resistant buildings and structures as well as inflatable dams for flood control.

Planned Program:

* NIST will measure the heat transfer characteristics of exterior fires including intensity and duration for typical sources. 2000

6. Provide an internationally recognized performance standards system that reflects durability and flexibility in initial design and construction of the facility, promotes acceptance of innovations, and provides for operations and maintenance.

- $\quad$ NIST will develop design guidelines for lightly reinforced and partially grouted masonry structures.

7. Understand how cognitive processes, physiology, ergonomics, human interactions with equipment and environment, and interpersonnel relations affect durability and flexibility. Apply this knowledge to provide more durable and flexible work, residential and recreational environments.

Roadmap for Goal 7. 50\% Reduction in Construction Work Illnesses and Injuries

Background:

A major barrier in international competitiveness is the cost of injuries and diseases among construction workers. Although the construction workforce represents about 6 percent of the nation's workforce, it is estimated that the construction industry pays for about one-third of the nation's workers' compensation. Workers' compensation insurance premiums range from 7 to 100 percent of payroll in the construction industry.

Construction workers die as a result of work-related trauma at a rate that is 3 times the annual rate for workers in all other industry sectors (24.1 deaths per 100,000 construction workers, as compared to 7.9 deaths per 100,000 workers in all other industry sectors). Construction workers also experience a higher incidence of nonfatal injuries of varying severity than workers in other industries. In a recent study in Washington state, the incidence rates of nonfatal injuries in construction during 1988-91 were over 10 per 200,000 
work-hours, while the overall incidence rate was 6 per 200,000 work-hours. Overexertion injuries (lifting, pulling, repetitive motion) are the single largest classification of injury in construction accounting for about $24 \%$ of all injuries. Workplace exposures cause lung disease, hearing loss, musculoskeletal disorders and dermatologic conditions among construction workers.

Objectives and Milestones:

1. Provide information systems, available and useful to employers and workers, characterizing workplace safety and health hazards and safe work practices.

- NIOSH is supporting an evaluation of surveillance systems which provide data on fatal and non-fatal injuries in the U.S. workforce, in order to identify gaps and to develop improved systems .

Planned Program:

* NIST plans developing a virtual construction environment for visualization and analysis of the safety of construction operations: 1998

Gaps :

\# A good national surveillance system for nonfatal injuries in the construction workforce could be achieved by expanding the National Electronic injury Surveillance System (NEISS) to include ages 18 to 54. Currently NIOSH and the Consumer Product Safety Commission collaborate to collect occupational injury data from hospital emergency rooms for persons under 18 and over 55.

2. Provide automation to make equipment safer to operate and to reduce workforce exposure to hazardous environments and tasks.

- FHWA is supporting automation of highway construction and maintenance equipment to reduce exposures of construction and maintenance workforce to traffic hazards:

- $\quad$ NIST is developing sensors for real time site metrology. 1998

- NIST is developing a virtual construction environment for design/construction of process plant structural systems. 1998

Planned Programs:

* NIST plans developing sensors; data acquisition, processing and visualization techniques; and control technologies to support development, by industry, of safe and productive construction equipment: 1999 
NIST will demonstrate the efficacy of construction site utility robots. 2003

3. Develop construction materials, components and systems supportive of health and safety of construction workforce.

- NSF is studying innovative materials and connections to reduce needs for manual work in high-risk locations

- FHWA is demonstrating high performance concrete and composite bridge structures that reduce higher hazard site construction activities: $1998 \mathrm{x}$

- NIST in collaboration with industry is developing innovative connections for precast concrete structures that will reduce higher hazard, on-site concreting: 1996

- NIOSH is studying the effects of heat stress from protective clothing.

- DOE Advanced Residential Buildings Research targets the incorporation of industrialized manufacturing processes into residential housing construction.

4. Develop environmental quality practices for the construction worksite, such environmental remediation, supportive of the health and safety of the environmental remediation workforce and the subsequent construction workforce.

- NIOSH is developing data relating to breathing problems such as silicosis and asthma, and methods of controlling welding fumes, asphalt fumes, and lead exposure.

- $\quad$ EPA is not currently conducting construction and building specific environmental remediation research. However, some of the work EPA is pursuing on environmental health and safety and environmental remediation can be applied to construction and building.

5. Reduce vulnerability of incomplete and temporary structures to natural and manmade hazards such as wind, earthquake, fire and toxic substances.

- NIOSH is supporting research to identify successful methods of lead abatement and to disseminate the information widely

- NIOSH is supporting research to establish and evaluate technological controls and good practices for renovation and maintenance of steel structures protected with lead-based paint.

- NIOSH is supporting research to test performance and applicability of existing engineering controls for drywall sanding and roofing kettles. 
- NIOSH is supporting research to develop in vitro assays to evaluate the potential cytotoxicity of human-made fibers that could replace asbestos in construction and industrial applications .

- $\quad$ NIST is developing improved techniques for sensing and extinguishing fires and for modeling fire hazards to guide design of safer construction practices: 1996

- FEMA, USGS, NSF, FHWA and NIST, through the National Earthquake Hazards Reduction Program, are providing knowledge and recommended practices for reducing earthquake risks: 1998

Planned Program:

* NIST, NOAA and NSF, through the National Wind Engineering Program, plan to provide knowledge and recommended practices for reducing wind risks: 1997

Gaps:

非 Improved methods are needed for sampling airborne particulate exposure and dermal absorption among construction workers.

6. Develop and implement standards providing explicit attention to workforce safety performance for construction activities and equipment and for incomplete and temporary structures and equipment.

- NIOSH is assisting OSHA in developing standards for medical surveillance, exposure assessment, and ergonomics.

Planned Program:

* NIST will perform an evaluation of new fire fighting technology. 2002.

7. Understand how cognitive processes, physiology, ergonomics, human interactions with equipment and environment, and inter-personal relations affect construction workforce health and safety, and develop and implement improved equipment and work practices.

- NIOSH is developing data on construction ergonomics and exposure factors affecting construction injuries.

- NIOSH conducts a national program of health hazard evaluations, in which NIOSH medical, engineering, and industrial hygiene staff respond to requests from workers and employers to determine whether a health hazard exists in a particular work setting. 
- NIOSH is conducting surveillance and research studies to ascertain health effects of concern in construction trades unions (carpenters, bricklayers, electrical workers, laborers, roofers, painters, operating engineers, ironworkers, sheet metal workers)

- NIOSH is conducting research to ascertain risk factors for key illnesses and injuries in the construction workforce in order to design preventive strategies.

- NIOSH is conducting hazard surveillance in the construction industry to identify key exposures for prevention/intervention activities.

- NIOSH is developing methods to characterize exposures of construction workers based upon tasks carried out by workers. This approach permits intervention by task and can be widely implemented by workers.

- NIOSH is supporting research to evaluate the ergonomic stresses of construction tasks, including tool use, work practices, reaching and lifting.

- NIOSH is supporting research to control lead toxicity, occupational dermatitis and musculoskeletal injuries in workers involved in bridge and road rehabilitation.

- NIOSH is supporting the development of hearing conservation programs for construction workers.

- NIOSH supports occupational fatality investigations in 15 states in the Fatality Assessment and Control Evaluation (FACE) surveillance system.

- NIOSH supports research to ascertain risk factors for falls and to recommend injury prevention strategies.

Planned Program:

* NIST plans to incorporate technical support and training for construction organizations, including workforce safety and health, in the Manufacturing Technology Centers: 1996

The following NIOSH short courses and educational materials support employers, workers and university teachers in understanding and implementing health and safety objectives in construction.

- NIOSH is supporting worker training programs for lead abatement

- NIOSH supports development of training programs for workers and contractors to disseminate useful knowledge about construction safety and health. 
- NIOSH supports production and dissemination of written materials for workers, contractors, engineers regarding construction safety and health.

- NIOSH supports development of health and safety programs for construction work.

- NIOSH is developing an instructional module for civil engineering faculty to assist them in educating students to understand health and safety issues in construction.

- NIOSH supports development of training programs for apprentice and experienced carpenters to teach them to recognize ergonomic hazards and to implement solutions.

- NIOSH supports programs in the Cincinnati tristate area, West Virginia, Chicago, Connecticut and New York which involve construction workers, employer organizations, and academics in assessing health and safety needs and in developing collaborative projects to address the needs.

- NIOSH works collaboratively with the Center to Protect Workers Rights, the nonprofit research arm of the AFL-CIO' Building and Construction Trades Department, whose 15 unions represent approximately 4 million construction workers in the U.S. and Canada, in a nationally coordinated effort to lead to better health and safety among construction workers.

Gaps:

非 Providing for health and safety of this workforce requires methods different from those used in other industries for several reasons. The worksite changes continuously as construction progresses, weather is an important factor because much of the work is outside, multiple employers are generally involved, and construction work typically employs workers for brief periods of time, after which the worker typically moves to another job and another employer, and episodic, high-level exposures are common. In response to these special needs, the 1990 Congress charged NIOSH to develop a comprehensive prevention program directed at health problems by expanding existing NIOSH activities in areas of surveillance, research and intervention. Although substantial progress has been made in the past few years, much remains to be done. Ongoing projects in safety and health need to be continued and expanded. As better knowledge of risk factors for injuries and illness is ascertained, emphasis needs to be placed on implementation of prevention strategies.

\# Comprehensive surveys of chemical and physical hazards at construction sites and compilation of the information into a job exposure matrix database are needed to provide a foundation for prevention and evaluation of successful interventions. 
\# A demonstration program is needed to evaluate silica exposures among construction workers, to evaluate masonry products for silica content, and to evaluate options for low silica materials in masonry structures.

非 A comprehensive assessment strategy is needed for wood dust exposures among construction workers in order to develop successful interventions.

\section{Roadmap for Removal of Barriers to Innovation}

Background:

Improved technologies alone are not sufficient for improvement of the life cycle quality of constructed facilities and enhancement of the competitiveness of U.S. industry. The improved products and services must be successful in the marketplace and become the ruling technologies in construction practice. In a number of studies, industry has identified the following major nontechnical barriers to beneficial innovations:

1. Lack of leadership

Policy makers in industry and government do not give priority to quality of constructed facilities consistent with their importance to the economy and quality of life. An important symptom of this lack of leadership is the overemphasis on first cost of construction with failure to recognize life cycle benefits possible from improved functionality, efficiency and durability.

2. Regulatory barriers

Individual projects often are severely delayed by a large number of uncoordinated and sometimes conflicting regulatory requirements. Delay raises costs and leaves the need for the facility unfulfilled during the delay.

The introduction of innovative products and services to the marketplace is made more expensive and delayed by the need to get approvals from many local jurisdictions.

3. Liability

Innovators and users of innovations face potentially large liability from real or imputed failures of products to perform over the service life as the customer or other injured party expected.

4. Adversarial relations in construction projects

Participants in each project for a constructed facility (owners, users, designers, manufacturers, constructors, regulators, etc.) often take adversarial positions rather than partnership to achieve project objectives. 
5. Financial disincentives for innovation

Industry and government have underinvested in construction R\&D as compared to other industrial sectors. The large number of design and construction firms and the mobility of their workforces make trade secrets infeasible and patent enforcement difficult. Regulatory barriers noted above slow returns on investments in innovation. The overemphasis on first cost, noted above, is a barrier to products and services requiring increased first cost to achieve reduced life cycle cost. Education and training are required for successful use of an innovation; the innovator often is required to provide the education and training.

The above barriers must be removed to meet each and every $C \& B$ goal previously described. The following objectives and milestones are presented for removal of the barriers.

Objectives and Milestones:

1. Work with leaders of the construction industry labor, users of constructed facilities and government to develop and implement coordinated private and public sector programs to improve the quality of constructed facilities.

- Private/Public consensus plan for research, development and deployment of advanced construction technologies. 3/95

- Budget initiative of the Federal government for FY96. 10/96

2. Work with Federal agencies and states to develop one-stop processes for regulatory approvals with mechanisms for timely resolution of appeals.

- National Economic Council / National Governors Council / Council on Competitiveness joint initiative to streamline regulatory processes. 10/96

3. Establish a nationally and internationally recognized system for evaluation and acceptance of innovative construction products and services.

- A prototype product evaluation program is presently underway for the Highway Innovative Technology Evaluation Center (HITEC) by CERF for the FHWA.

- Develop performance standards for the materials, components and systems of constructed facilities. See various milestones under the C\&B goals.

- Establish a private sector mechanism, drawing on the capabilities of industry, academic and federal laboratories, for evaluation and acceptance of innovative products and services. 9/96 
4. Encourage construction industry participation in studies under the auspices of private sector organizations and the National Economic Council to recommend national and state legislation bounding liabilities and susceptibility to litigation for producers of products and services.

- Participation in focused studies. 6/95

5. Use Federal construction projects as low risk test beds for innovations. (Note: Executive Order 12902 requires Federal agencies that construct at least five buildings per year to designate at least one building to be a showcase highlighting advanced technologies, energy efficiency practices, and water conservation.)

- Cooperative funding of Federal program and research agencies and the private sector for demonstrations of high priority technologies. $10 / 95$

- Issue Executive Order or Presidential Directive authorizing Federal agencies to request and reserve contingency funds to correct failures resulting from unsuccessful innovations. 10/95

6. Work with construction community organizations, insurance and financial institutions, Federal agencies and organizations of states to draft model agreements and model legislation supporting teamwork in reaching project objectives, in place of adversarial actions when problems arise.

- Plan for development of model agreements and legislation, 6/95

7. Increase private sector and Federal investments in research, development and deployment for beneficial construction technologies.

- President's request for a Federal initiative for construction RD\&D. 2/95

- Private sector consensus plan for private sector and government investments in construction RD\&D. 6/95

- Establish a focused program in construction of the Advanced Technology Program as an incentive for private sector investments in $R \& D$ of high economic potential. $6 / 95$

- Establish construction technology transfer components for the Manufacturing Extension Partnership. 10/95

- Inform and educate decision makers on the life cycle benefits and costs of advanced technologies. See various milestones under $C \& B$ goals.

- Federal construction agencies develop a budget line item for special technical studies needed to incorporate advanced technologies in their projects. 


\section{APPENDIX 3: DEPLOYMENT PLANS AND OPPORTUNITIES}

\section{Demonstration Projects Nearing Completion}

U. S. Court of Appeals, San Francisco, California. (GSA/NSF)

The Ninth Circuit U.S. Court of Appeals at 7th and Mission Streets in San Francisco was damaged in the 1989 Loma Prieta earthquake and is now being retrofitted with seismic isolation, additional shear walls, and diaphragm strengthening. When completed the building will be the largest base-isolated structure in the United States. The Friction Pendulum System bearings used for the base isolation were developed with support from a research grant from NSF. The use of these bearings resulted in increased earthquake safety and considerable savings not only in the isolation system itself but also in related costs and construction schedule. The building is scheduled for completion in 1995.

IBACOS Reference and Laboratory Houses, Pittsburgh, Pennsylvania. (DOE)

IBACOS has completed the construction of "Laboratory House A," a 2,200 sq. ft. reference house that has two stories, four bedrooms, two and one-half baths, a full basement and attached garage. A similar model "Laboratory House B" has also been constructed nearby. Modifications for evaluation purposes include more integrated packages that may be commercially available in 1-3 years (i.e. new wall construction systems, heating, cooling, ventilating and air quality systems, supply and waste plumbing distribution concepts, and energy efficient shell/panel concepts, etc. The monitoring and testing of the houses is a cooperative venture between IBACOS (an alliance of architects, builders, material suppliers, and building component suppliers), DOE, Florida Solar Energy Center, the National Renewable Energy Laboratory, and the Lawrence Berkeley Laboratory.

\section{Exemplary Buildings (DOE)}

DOE's Exemplary Buildings are highly efficient passive solar residences. With construction costs funded by others, but using DOE design support, these buildings will utilize about half the energy of typical residences and will be showcased as models of efficient design. Construction is to be completed on four such residences by November 1994, including locations in Yosemite, CA (11/94), Louisville, KY (10/94), Winchester, VA (9/94), and Grand Canyon, AZ (10/94). Two international locations are also currently planned in the near future as part of an International Energy Agency buildings project.

Walnut Creek National Wildlife Refuge Learning Center, Prairie City, Iowa. (DOI/NIST)

A consolidated campus of facilities including a visitor center and parking facilities, an Environmental Education Building, a Research Complex and a Maintenance Facility will be constructed at the Walnut Creek National Wildlife Refuge. The buildings will be earth bermed to 
help insulate and protect from the wind thereby keeping them more comfortable and more fuel efficient. The double glazed windows will have argon gas trapped between the layers, and have a low-E coating on one surface to reflect heat back into the room to reduce heat loss in the winter and reduce solar gain in the summer. The exhibit and administrative work areas will have clerestories to provide natural light during daytime. The roof will be insulated to R-30 and will be covered with a white EPDM membrane which reflects sunlight and ensures that water runoff is cleaner than from a built up roof. Sewage leaving the building will flow through a septic tank where the solids will sink and the liquids flow into a specially-constructed wetland. No chemical additives will be used. Microbes and plants clean the water which can flow from the wetland to the local streams. The complex will have a constructed wetland. Ground breaking is scheduled for September 1994, and the grand opening of the Visitor Center is scheduled for 1996.

New Building Designs

All Federal Agencies have adopted a policy to design all projects in Hard Metric. Rather than using systems and materials that relate to the English system of measurements, all building design calculations, dimensions, specification references, etc., will be in metric units exclusively. This delivery practice will strongly promote the international competitiveness of the U.S. construction industry.

High Strength Concrete Bridge, Texas. (FHWA)

A 13,000 psi concrete bridge is being built by Texas DOT. (Most concrete bridges are built with concrete which has a strength of $6,000 \mathrm{psi}$ ). It is anticipated that the use of high strength concrete designs can save about $20 \%$ on the cost of future construction, and will mean reduced maintenance and longer service life. FHWA is assisting Texas in getting technical help in resolving concrete, design and forming problems in the preparation of bid documents. FHWA is helping to educate and develop the confidence of bridge designers.

EPA Headquarters, Waterside Mal1, Washington D.C. (EPA)

A real-time environmental monitoring system is being installed in Waterside Mall. The system communicates through a proprietary local area network. The system's architecture will permit a wide array of environmental monitoring at interior space, exterior stations and equipment termination ports. The system is expected to improve client services, lease administration, environmental management, and energy management. Mechanical systems are also being upgraded. Under engineering evaluation are a hybridization of desiccant cooling, gas absorption cooling and significantly downsized, but high efficiency, chiller plants. Additional opportunities are being evaluated for waste energy (heat) capture. A battery assisted photo-voltaic DC electrical power system for lighting 50 percent of the Waterside Mall is also being evaluated. More efficient, microprocessor controlled elevators and water saving plumbing fixtures have already been installed. 
Connecticut Road Industry Surveillance Project. (Yale/NIOSH)

The Connecticut Road Industry Surveillance Project is a statewide medical surveillance program designed to prevent lead toxicity in bridge workers. Several studies have confirmed serious risk to workers involved in bridge repair and rehabilitation. Blood lead levels of over $100 \mathrm{ug} / \mathrm{dl}$ have been seen in bridge workers. This project has showr the efficacy for the control of lead poisoning when the Connecticut Department of Transportation incorporated into its contract language, which required medical monitoring and exposure control. Few medical visits occurred before this requirement but there were over 3,000 medical after the requirement. The project showed that these requirements resulted in a continuous drop in blood lead levels from 34 $\mathrm{ug} / \mathrm{dl}$ in 1991 to nearly $10 \mathrm{ug} / \mathrm{dl}$ in 1994. The DHHS objective for the year 2000 is $25 \mathrm{ug} / \mathrm{dL}$.

Composite Reinforced Bridge. (NSF)

A demonstration of the use of a composite grid for the tension reinforcement of a concrete short span bridge is being constructed in the District of Columbia. Dr. Bank of Catholic University is the principal investigator. Composite materials which were developed by the aerospace industries are being adapted to construction projects because of their special characteristics. These include high strength, light weight and corrosion resistance. The use of composites in construction projects could lead to cost savings in maintenance and extend the life of the structure.

Flaw Detection Instrument for Concrete. (NSF, NIST)

An instrument to detect flaws in reinforced concrete structures has been produced and is undergoing application investigations. Dr. Mary Sansalone of Cornell University is the research investigator. The instrument is based on the principle of evaluating the echo response to an imposed impact and referred to as the impact echo technique. The interpretation of the data will detect voids, flaws and location of reinforcement bars in concrete structure. This type of data is essential to the evaluation of the safety of existing structures throughout the country.

Bridge Seismic Resistance Computer Program. (NSF)

A computer program to analyze the seismic resistance of highway bridges has been developed and is being evaluated by bridge engineers throughout the country. The computer program was developed by Dr. Roy A. Imbsen, of Imbsen and Associates at Sacramento, California. The computer program enables bridge engineers to analyze the behavior of new bridges, of steel or reinforced concrete when subjected to earthquake forces. It may also be used to evaluate the safety of repair/retrofit methods which will improve the safety of existing bridges and the piers supporting the roadway deck system. 
Demonstration Projects Proposed for FY95 and FY96

PlantSTEP Consortium to Build Information Exchange Technology for Process Plants (NIST)

In collaboration with NIST a group of major U.S. process owners, engineering firms, equipment suppliers, fabricators, and information technology companies have created a consortium aimed at building a neutral information exchange of process plant data based on the international standard known as STEP, Standard for the Exchange of Product model data. The eleven companies involved have set a goal of raising the capability of raising U.S. firms to compete in the world process market by making sure that they and all U.S. firms can share information seamlessly. The U.S. process and construction industries have a vital stake in STEP. Companies with STEP expertise will have a competitive edge in the increasingly tough global market place. The first results of PlantSTEP will be available in 1995 and all results are scheduled for release in 1996.

Golden Gate Federal Building, San Francisco, California. (GSA)

To encourage the rapid adoption of BACnet within the building industry, NIST, GSA, DOE, Lawrence Berkeley Laboratory, and Pacific Gas and Electric and several energy monitoring and control system (EMCS) manufacturers are planning a BACnet Testbed demonstration project in the 450 Golden Gate Building in San Francisco which is PG\&E's second largest energy demand load in the San Francisco area. The Testbed building will focus on demonstrating the viability of BACnet as an open system communication protocol for Energy Monitoring and Control Systems (EMCS), documenting the energy and operating cost savings that can be achieved through intelligent building control using BACnet. The Project will also facilitate the development and implementation of advanced control concepts involving fault detection, diagnostics, and building system optimization. BACnet will be expanded from HVAC application to the control of all building services, including life safety, security, and transportation. The Testbed Demonstration Project should have a significant positive impact on both domestic and international sales of EMCS by U.S. companies. The installation of BACnet based EMCS throughout the nation could result in an energy cost saving to end users of $\$ 23$ billion per year.

Federal Building, Wilshire Boulevard, Los Angeles, California. (NSF, GSA)

Seismic concerns are being addressed with the planned use of structural frame shock absorption design. Diagonal braced members should effectively off-set framing movements in an earthquake. The building is in the planning stage. 
Federal Building Courthouse, Omaha, Nebraska. (GSA)

A new Federal courthouse is planned to address functional objectives of tenant productivity, energy efficiency, and environmental performance. This project is identified as a GSA energy conservation showcase under Executive Order 12902. The project is in the authorization stage with design to begin in FY 95.

Manufacturing Extension Partnership (MEP): (NIST, with input from HUD, DOE, and EPA)

NIST is planning to include construction technology as part of the outreach effort at many of their Manufacturing Technology Centers. There are currently 35 centers. The number of centers will expand to 45 by the end of FY 94 and to 100 in FY 97. MEP is working with component manufacturers to deploy new technology and remove barriers to the introduction of new technology. MEP is also funding a test project with National Association of Home Builders (NAHB) to examine the advantages and disadvantages of regional (four States) linkage of planning, design, construction, distribution, and installation of windows.

National Building Product Testing, Evaluation and Approval System. (HUD, DOE, NIST, DOE, CERL and private sector)

A National building product approval system to expedite acceptance of new and innovative materials, components, and systems is needed. It should include a way to reduce the liability to owners, builders, developers, and building officials sanctioning utilization in construction; complete evaluation, verification, testing, and certification programs; and methods to evaluate life-cycle costs and benefits, and long-term durability factors. The current HUD "Technical Suitability of Products Program" for evaluation and acceptance of materials, components, and structural systems used for HUD-FHA residential construction will be expanded to include the testing and certification of all new and innovative building materials and products used for all types of construction.

Innovative, High-Tech Manufactured Housing. (HUD)

New industrialized, prefabricated, and affordable housing is needed to supplement current modular, panelized, and manufactured housing. The product should use less wood, be easier to construct, be more energy efficient, have better indoor air quality, reduce condensation problems, be resource sensitive, and remain affordable. This project could take the form of a contest for systems developers to design, construct a prototype, and evaluate a manufactured housing system that will provide wind resistance, fire safety, energy efficiency, etc., at a competitive price. 
Subdivision of the Future.

(HUD)

HUD is planning a Subdivision of the Future which would include innovations in land use, infrastructure and advanced housing systems. (HUD)

Ft. Hood, Texas. (DOD)

Ft. Hood will be a demonstration site for power factor capacitor implementation utilizing state of the art sizing and placement algorithms developed at CERL and the University of North Dakota. Reactive VAR compensation (power factor capacitors) can minimize losses and save energy in electrical distribution networks. Capacitors can be placed at the substation or distributed throughout the electrical network. Distributing capacitors throughout the electrical network is the most effective as it improves distribution efficiency, reduces demand charges, eliminates power factor penalty charges and reduces emissions from the utility company. As a result of the inherent complexities involved, distributed capacitor placement requires computational resources for their correct implementation.

Vandenberg AFB, California. (DOD)

DOD is demonstrating fuel cell technology at 12 military installations. Vandenberg AFB is the first. Fuel cells are electrochemical power generators with the potential for attaining very high electrical energy conversion efficiencies while operating quietly with minimal polluting emissions. Operational characteristics including efficiency, maintenance, and air emissions will be monitored and evaluated at each site.

Ft. Jackson, South Carolina. (DoD)

Chilled Water Storage (CWS) Cooling System: A 2.25 million gallon capacity of chilled water storage cooling system is under construction at Ft. Jackson. The system will shift up to 3 megawatt of electrical demand from the onpeak to offpeak periods, thereby saving over $\$ 300 \mathrm{~K} /$ year in electrical demand cost for Ft. Jackson. Due to the favorable condensing condition during the night and the steady operation of chillers during the charging process, $\mathrm{kW} /$ ton ratios of the chillers with CWS cooling system are expected to improve significantly (resulting in energy conservation as well as demand shifting). The system will be ready for 1995 cooling season, and USACERL will monitor the performance of this system.

CFC Conversion Demonstration. (DOD)

A cold storage plan in Ft. Jackson is planned to be converted from R-12 (CFC) to R-134a (HFC) refrigerants. Due to the stratospheric ozone layer destruction potential, CFC refrigerants are to be phased out from the Army air conditioning and refrigeration (AC/R) systems by year 2000 according to the DOD policy. The conversion of an $A C / R$ system from $C F C$ 
to non-CFC refrigerants or replacement of a CFC AC/R system with an HCFC/HFC system is the major option to phaseout CFC refrigerants from the Army $A C / R$ systems. USACERL monitored the performance of an R-134a (HFC) chiller at Ft. Leonard Wood that replaced an old R-11 (CFC) chiller. The performance of the replaced $\mathrm{R}-134 \mathrm{a}$ chiller turned out to be excellent compared to the old R-1l chiller. The conversion of an R12 cold storage facility at Ft. Jackson will be completed by spring of 1995, and USACERL will monitor performance of the converted system with R-134a refrigerant.

High-Efficiency, High Intensity Sulfur Lamp. (DOE)

DOE has developed a high-efficiency sulfur lamp ("S-lamp") of high intensity that is to be demonstrated in early FY95. The lamp is used in combination with "light tubes" that are designed to distribute the light from a relatively few high-intensity sources to various locations in buildings. The light tubes themselves consist only of glass and therefore never require replacement, barring breakage, so that maintenance costs are greatly reduced. A demonstration system has been installed in the Smithsonian Air and Space Museum and is scheduled to be opened October 1994. The light tube/S-lamp combination is anticipated to eliminate difficulties associated with changing lightbulbs over aircraft that hang in the building. Another system is to be installed in the main entrance to the DOE Forrestal building in the near future.

Health Study of Painters. (NIOSH)

A study at Johns Hopkins University funded by NIOSH and the National Cancer Institute found that painters experienced an elevated risk of lung cancer and lymphatic malignancies and several other malignancies including Hodgkin's disease. This project is a follow-up with part of the cohort from that study to determine the incidence of Hodgkin's disease.

Job Assessment Protocol for Ergonomic Hazard Evaluation. (NIOSH)

Despite improvements in personal ergonomic monitoring equipment, few of these devices have proven sufficiently durable for construction workers. Video tape methods hold promise for exposure assessment in construction work, but until the advent of computerized image analyses, most analysis was done manually and required a high degree of technical skill. For this project, new hybrid video tape-computer image analysis systems will be adapted for use in a state-of-the-art hazard assessment protocol.

Cumulative Trauma Disorders in Carpenters. (NIOSH/Greater Cincinnati Health Center)

One of the issues related to work-related musculoskeletal disorders is cumulative trauma. This project is characterizing these disorders in carpenters, conducting ergonomic analyses of carpentry tasks that lead to these disorders, and developing recommendations to decrease exposures to cumulative trauma. 
Reducing Musculoskeletal Disorders Among Construction Workers. (NIOSH/CPWR)

Time lost injuries add a high cost to construction work. Among these are work-related musculoskeletal disorders. This project is defining and identifying the magnitude of these disorders among construction workers, identifying the risk factors associated with these disorders, building awareness within the industry of these disorders and how to prevent them, and developing training and other intervention programs to prevent these disorders.

Lead in Construction. (NIOSH/California Public Health Foundation/IL DOH/WA DLI/CT DOH/NJ DOH)

Five projects will provide important preliminary data on lead exposures, compliance with contract language, medical monitoring, and take-home exposures for workers and their family members in the construction trades. This group of workers was not previously covered under the OSHA Lead Standard for general industry, but are now newly included under the OSHA Interim Final Rule on Construction. The California Painters' Project will evaluate the effectiveness of an intervention to educate workers and monitor the effectiveness of the program by documenting changes in blood lead levels both prior to and post intervention. The other four projects cover a variety of issues concerning lead in construction (e.g compliance with contract language for bridge and steel superstructures, lead certification training protocols, and exposures among painters). These projects will provide insight into the nature and magnitude of lead exposures among construction workers.

\section{Technologies Ready for Deployment}

The following unfunded deployment projects and new technologies ready for deployment are classified in the technology groups used in the roadmaps.

1. Information and Decision Technologies

1. Fire Data Management System (NIST) Demonstration of the accessibility of fire data for use by fire safety engineers through the Fire Data Management System. FDMS (Fire Data Management System) provides platform-independent storage, retrieval, and exchange of fire data. This data includes benchscale and real-scale fire test results, results from available fire models as well as a variety of supplemental information including details on organizations, personnel, products evaluated and their related properties, and test method descriptions. Distribution of a CD-ROM FDMS generated from the centralized database is planned. The CD-ROM database will be distributed with each new installation of the HAZARD (a fire hazard analysis program) software) As a consequence to including a CD-ROM FDMS implementation as part of HAZARD, direct access to objects in the database will be available to CFAST, FPETOOL, and other modules within the HAZARD suite. (NIST, industry). 
2. Automation in Design, Construction and Operation

1. Integrated Computer-Based Delivery System (DOD) Integration of the life cycle of real property facilities through graphic and textual use of computers for planning, design, construction, operation, and disposal of buildings. Typical modules are: Geographic Info. Systems (GIS) - to determine a facility's relationship to the surrounding natural and built environments, (2) Computer Aided Design (CAD) with cost/benefit analysis to support design and construction of new facilities and repair, renovate, and expand existing ones.

2. Computer Assisted facility Maintenance Management (DOD) Breakdown maintenance and repair is expensive and disruptive, Facility Maintenance Management Systems that rely on condition assessment and degradation algorithm to optimize maintenance and repair work can both reduce maintenance cost and increase facility condition. Maintenance Management systems exist for water navigation structures, roads, railroads, paint, and low slope roofing. These systems are ready for use today. Integrated maintenance management systems for building and

transportation/utility systems are near completion and need to be tested and demonstrated in the near future.

3. Bridge Sensors and Network Monitoring (FHWA) Every year bridges collapse because of fatigue, coating deterioration, corrosion, oxidation, overloading, inadequate cathodic protection. Nondestructive testing, a network of instruments, sensors and monitors, and research on the causes of deterioration and degradation of materials and connections are needed. Defenseoriented electronics research and private industry development need to be utilized.

4. Smart tagged composites CERL and the Society of Plastics Industry Composite Institute are evaluating advanced composite materials involving active and passive tagging. Tagging involves embedding micron-size sensor particles into materials such as composites, concrete structures, or adhesive layers. These embedded particle sensors generate measurable signatures which can be correlated with internal stress, strain, temperature, voids, chemical degradation, etc.

5. Civil Infrastructure: Performance Assessment and Life Prediction (NSF). Many infrastructure systems, including bridges, experience severe corrosion which is compounded by fatigue cracking caused by heavy traffic loads. Through the Engineering Research Center in Advanced Technology for Large Structural Systems at Lehigh University, integrated research including large-scale testing is being conducted to build laboratory and in-service knowledge base to improve infrastructure maintenance and prolong the service life. 
3. High Performance Materials, Components, and Systems

1. Truss-Frame House Framing System (USDA). This is a prefabricated framing system incorporating roof and floor trusses, and wall studs connected together with steel truss plates; shipped to the site and erected at 24" o.c. on foundations. This innovative house framing system needs an approval, acceptance, and marketing strategy.

2. Hardwood and Wood Composite Building Materials (USDA). Hardwoods are seldom used as framing, structural lumber, roof trusses or glue-laminated members; engineering properties were not generally published, so engineers and builders have not specified their use. Composite wood structural members made from wood fibers and particles are available, but many engineers and builders are not familiar with their use or properties. Testing, research and marketing are needed.

3. Advanced Composite Materials for Structures (NSF, DOD) Jointly sponsored research with Society of Plastics Industry Composite Institute to develop composites of graphite and fiberglass reinforced resins, and active and passive tagging systems, which involve embedding micron-size sensor particles into materials is needed. These sensors interact with their host structures and indicate measurable signatures of internal stress, strain, temperature, voids, \& degradation.

4. New Reinforcing Bar Configurations (GSA, U. of Kansas, NSF) New reinforcing bar configurations developed through the University of Kansas will improve concrete strength and durability.

5. Composite and High Performance Steel Bridges (FHWA) The industry needs a composite bridge code and specifications to be able to use these structures in public works projects. Applicable design procedures and material testing and research are needed. High strength and fatigue and corrosion-resistant steel members and connections need to be developed for high performance steel bridges.

6. Steel Framing (private industry and HUD)

7. Stress Skin Panels (private industry and DOE)

8. Composites used for bridges (FHWA) The "Stealth " bridge built of composite materials in California has demonstrated the use of the material for bridges. A composite building (bridge) design standard is needed for industry to use in designing and presenting to the public works sector. A set of design procedures, material tests, and property/construction specification specifications are needed. 
9. Advanced Window Technologies (DOE) Includes the development, testing, and demonstration of "super-windows," advanced spectrally-selective, thin-film windows, and electrochromic windows.

10. GAX Heat Pump (DOE) DOE's GAX Absorption Heat Pump is on the verge of commercialization for the residential and light commercial markets. The non-CFC technology is estimated to reduce energy consumption by $40 \%$ relative to competing technologies. Contracts with Carrier and Phillips Engineering are underway to commercialize the heat pump, with the first commercial units expected in late 1996 or early 1997. Initial agreement has been obtained from six major gas utilities to support a National GAX program covering technical and market participation. Current development efforts include shortening the development schedule, improving initial quality and lowering cost of the units.

11. Improving the Performance of Oil Combustion Equipment DOE is beginning efforts to deploy the Flame Quality Indicator (FQI) as a device for monitoring the performance of residential oil combustion equipment. The FQI will help detect the presence of excess air during the combustion process which degrades the overall efficiency of the furnace or boiler. Additional laboratory and field testing is needed to demonstrate the effectiveness and durability of the technology.

12. Super Insulation Products DOE is developing superinsulation products with the potential of two to four times the thermal performance of the best conventional foam insulations. The current focus is upon powder evacuated panels that can be used in refrigerators and freezers. DOE is currently working with a number of insulation and appliance manufacturers to further refine these products. Initial prototype refrigerators will be completed in 1995 and field testing will be undertaken to evaluate the energy performance and aging characteristics of this technology. Additional research will be required to extend this technology for insulating buildings.

13. Light Weight Masonry Units (DOD) Masonry units that are half the weight but meet strength criteria have been developed. Full-scale prototype tests need to be conducted to determine the impact that the light weight units have on construction productivity. It has been estimated that these units may improve productivity by 25 to 30 percent at no or little increase in material cost.

14. Antifreeze admixtures for concrete (DOD) The U.S. spends about $\$ 800$ miliion a year to protect fresh concrete from freezing.

Recent government research has shown that much of this expense and drain on nonrenewable energy resources is unnecessary. Antifreeze admixtures have been developed that, when added to a concrete mix, are capable of protecting concrete from freezing while allowing it to gain full strength without requiring heat. 
15. Roller Compacted Concrete (DOD) Roller compacted concrete (RCC) is a method of producing durable and economical concrete pavements. RCC differs from conventional concrete pavements in that it is consolidated by compaction from heavy, roller equipment. Savings of as much as $40 \%$ can be realized by the use of RCC rather than conventional concrete pavements.

16. Surface treatments to Minimize Concrete Deterioration (DOD) Freezing and thawing, penetration of salts, weathering, chemical attack, and erosion cause concrete surfaces to deteriorate. Surface treatment of the concrete with a material more resistant to these forces than concrete can slow or even eliminate the rate of deterioration. Various surface treatments have been evaluated with emphasis on materials that can reduce or prevent damage to concrete from cycles of freezing and thawing, the major contributing cause of non-air-entrained concrete failure. The test data for surface treatment materials indicate wide differences in the effectiveness of these materials for protecting concrete or minimizing concrete deterioration. Criteria have been established for use as guidance in the selection of concrete scalers.

17. High-Performance Blended Cement System (DOD) A high-performance blended cement system was evaluated under the CPAR program to provide guidance on its use by the military and private sector. Concretes made with this cement were found to exhibit rapid strength gain and superior durability which allows construction and repairs to be accomplished in less time with longer service life. The Air Force claimed a savings of $\$ 7$ million at Barksdale AFB by using this cement for concrete runway repair at night and allowing operation during the day. Likewise, the Charleston Airport Authority was able to keep their airport open during pavement replacements with savings of over $\$ 100$ per minute of airport operation time.

18. Microtunneling for the Installation of Underground Utilities (DOD) Microtunneling is a remotely controlled, laser-guided, pipejacking system that can be used to install $10 \mathrm{in.} \mathrm{to} 10 \mathrm{ft}$. diameter pipelines through a variety of ground conditions ranging from soft clay to rock. It can be used up to $100 \mathrm{ft}$. below the water table without dewatering. The system has been used to install concrete, steel, centrifugally spun cast polyester resin, fiberglass-reinforced, PVC, and vitrified clay pipe. Lengths of up to $1500 \mathrm{ft}$. at a time can be installed in a single pass. slurry and auger systems are offered with typical production rates of 30 to $60 \mathrm{ft}$. per day, although rates of $200 \mathrm{ft}$. per day have been demonstrated under ideal conditions. The slurry system has enhanced capabilities for applications below the water table. Both systems have been used successfully in Europe, Japan, and the United States. Microtunneling systems are currently marketed by five companies; one Japanese, two German, one United Kingdom-U.S.joint venture, and one U.S. Approximately 30 machines had been 
purchased by U.S. contractors by mid 1994. Microtunneling can be quite cost-effective when compared to open-cut construction when pipelines are to be installed in congested urban or environmentally sensitive areas, at depths greater than $15 \mathrm{ft}$., in unstable ground, or below he water table. The system has been used primarily for sewer line construction. Potential applications include environmental remediation work, such as a proposed horizontal cutoff below a contaminated site or waste plume.

4. Environmental Quality

1. Dewatering Water Treatment Sludge (DOD) Development and demonstration of mechanical, chemical, and natural freezing sludge dewatering systems. Typically, sludge contains only $1 \%$ to $2 \%$ solids of clays, organic sediments, colloids, bacteria, algae, various metals, and other particles. Freezing beds have been developed for waste water treatment plants, and a mechanical system has been developed in conjunction with the Electric Power Research Institute. The final dewatered product could be used as fill, a fertilizer, or a building product.

2. Alternative Rubber Particle Building Products(EPA) Research and demonstration of systems to grind up rubber tires for a fiber matrix which can be used to fabricate building panels. This would be a structural material with acoustic properties to be used for wall, floor, and ceiling panels.

3. High-Pressure Water Asbestos Removal (GSA) High-pressure water systems appear to be effective in rapidly removing sprayed-on asbestos coatings from surfaces which now require hand scraping. Research and development need to be coordinated to identify benefits and problems associated with wet systems, such as clean up, surface damage (spilling, etc.), and other application issues. Development of an inventory and conducting a cost impact study are considered important.

4. Ice (Thermal) Storage is being considered by GSA for peak load shedding.

5. No-flush and Low-flush Bathroom Fixtures and Gray Water Storage Distribution are being considered by GSA for water conservation.

6. Energy Efficient and Environmental Building Systems (DOE, NSF) Design techniques and demonstrations for waste minimization, recyclable and recycled materials, advanced building systems analysis and modeling, passive and active solar systems, integrated controls, and operations automation and diagnostics.

7. Lead Based Paint Abatement (DOD) Lead based paint, a major health and environmental hazard, was used to protect most infrastructure facilities constructed prior to 1980. The development and 
demonstration of cost-effective techniques for removing lead based paint from wood, metallic, and gypsum substrates, and making the resulting waste non-hazardous by complying with TCLP criteria is required.

8. Low temperature hot water district heating systems (DOD) Due to improved materials and methods, low temperature hot water (LTHW) is now widely regarded as the most efficient means of district heating. High temperature water and steam systems are more costly to build and operate than LTHW systems. Studies on military bases have shown that heat loses from the LTHW systems are only $35 \%$ of those from comparable high temperature water systems. Technologies for using low temperature hot water at temperatures of $200^{\circ} \mathrm{F}$ or lower should be demonstrated in the U.S. At those temperatures, it becomes possible to use nonmetallic flexible piping systems. Such systems eliminate corrosion problems and greatly reduce installation and maintenance costs.

5. Risk Reduction Technologies

1. Radon-Free Building Technology (EPA) Continued extensive studies and development of radon control systems for existing or new residential construction, schools, hospitals, and commercial buildings. Demonstration projects using a soil depressurization system for the control of radon in existing detached dwelling units.

2. Water Mist (NIST, GSA, USFA, DOJ, U.S. Park Service) In cooperation with industry, demonstration of the use of water mist for suppression of fires in residential buildings including dormitories or prisons. This technique controls fire without extensive water damage.

3. Computational fluid dynamics modeling (NASA, NIST, GSA, Army, Navy) The use of computational fluid dynamics modeling can provide data on smoke movement and smoke layer development in high bay areas to enable decisions on fire detection and suppression in these spaces to be made. Different fire sizes, fuel types, forced air flow, temperature stratification effects and many other factors should be addressed. A design guide for high bay spaces should be produced. Large spaces, such as those found in warehouses, historical buildings, atriums, and aircraft hangars, represent some of the most difficult fire protection challenges since they are frequently of historical significance, contain large quantities of fuel, have unique geometries, and/or present special life safety problems. Accurate detector activation predictions are important in these large spaces, as timely detection of a fire is more difficult due to the distance heat and products of combustion must travel to reach sprinklers and detectors. Since fires frequently grow at an exponential rate, an increased time to detection results in larger fires at the time of detection and larger fires to be suppressed by, e.g., an automatic 
sprinkler system. Even a modest uncertainty in the prediction of the activation time may lead to a large uncertainty in the fire size used to predict the hazard, a central element of many fire protection analyses.

4. Smoke Detector and Sprinkler Citing (NIST, USFA) Demonstration of the improved performance and lower cost achieved by using new design techniques for siting smoke detectors and sprinklers in areas with complex ceilings.

5. Earthquake Resistant Connections (NIST, ASCE, NSF) Demonstrate retrofit and new construction standards and practices for earthquake resistant connections for welded steel frame structures.

6. Seismic Design and Retrofit Electrical Power Guidelines (NIST, ASCE, NSF, Industry) Demonstrate nationally applicable seismic design and retrofit guidelines for electrical power distribution systems.

7. Seismic Design and Retrofit Masonry Guidelines (DOD, NSF, NIST) Through a long-term coordinated research program on reinforced masonry buildings, analytical techniques and design guidelines are developed to demonstrate new building design for improved seismic performance.

8. Fatality Assessment and Control Evaluation for the Construction Industry (NIOSH) The Fatality Assessment and Control Evaluation (FACE) program reduces fatal occupational injuries through a program of case-based surveillance, on-site investigation, and prevention activities particularly a series of informational hazard alerts. FACE is now focused on deaths in confined spaces, falls, and electrocutions. The proposed activity would begin a similar FACE program that is targeted to the construction industry. This would enlarge and broaden existing coverage of the construction industry. On site investigations of fatalities would be conducted after state agencies and associations voluntarily notify NIOSH of traumatic occupational fatalities resulting from targeted causes of death in the construction industry. The purpose of the investigations would be to use a case series design to identify factors contributing to these fatalities and to develop recommendations for preventing similar deaths. Multiple source surveillance systems would be used by participating states to identify all traumatic occupational fatalities occurring within the state. Data collected would be used by both NIOSH and the states to prioritize, develop, and evaluate traumatic occupational injury research and prevention programs. Publications and ALERTS would be disseminated after a number of similar incidents are investigated.

9. National Traumatic Occupational Fatality Database and Census of Fatal Occupational Injury (NIOSH) NTOF and CFOI are parallel 
systems for injury fatality surveillance. The Census of Fatal Occupational Injury was designed by the Bureau of Labor Statistics to use a variety of source documents to compile data for all fatal work injuries. The sources include death certificates, workers' compensation records, coroner and medical examiner reports, Occupational Safety and Health Administration (OSHA) reports, and other reports. The Census will contain fatalities of private wage and salary workers, government employees, and the self-employed. For 1992, the Census reported the construction industry to have one of the highest percent distribution of fatalities.

Epidemiologic analyses of the new data obtained for 1992 would provide information concerning the source of injury, state, worker characteristics, occupation, industry, and estimates of incidence rates.

6. Performance Standards System

1. Approvals System (Federal, State and local government) Implementation of a system for one-stop local, state and federal regulatory approvals for construction projects with a mechanism for timely resolution of appeals. This would be styled on the successful one-stop-shop for helping small business export licensing.

2. Design-Build Contracting (GSA) Associated performance based requirements coupled with contractor selection based on offered value encourages the use of latest technologies and quality features.

3. Improvement in Trade-Controlling International Construction Standards (NIST) The aim will be to recognize leading technologies and U.S. practices and products, in international standards and trade.

7. Human Factors

1. Attitude and Behavioral Change Successful innovation typically requires changes in organizations and in attitudes and behaviors of people as well as technology. USC has developed a theory and software system, named "ACTION" based on this notion in the context of manufacturing. An adaption of ACTION for the integration for the integration of the design and construction processes should be showcased in a highly visible construction project. 


\section{APPENDIX 4: AGENCIES' PROGRAM SUMMARIES}

\section{THE FOREST PRODUCTS LABORATORY CONTRIBUTION TO THE CONSTRUCTION AND BUILDING PROGRAM}

The USDA Forest Service Forest Products Laboratory (FPL) conducts research to more efficiently utilize our timber resources in all types of products but with particular emphasis on the use of wood in construction. The research program addresses the needs of both the wood products and building industry by finding new ways of building with less material. Research includes developing models to predict the demand for wood products in various types of construction, technology for processing, product properties, engineering performance and the relationship between product properties and building system performance. In addition, research scientists participate in developing national standards for testing methods, materials and design. FPL data are often used in the development of building codes.

Research is describing improved process technology to produce lumber and panel products, performance of wood products and systems in fire; moisture flow in the exterior shell of wood frame buildings; performance of various wood finishes; structural performance of lumber, panels and other engineered wood products; performance of timber in transportation structures such as bridges; performance of wall, floor and roof systems; and the performance of structural adhesives and mechanical fasteners.

Nationally, scientists contribute to technical committees of industry association, professional societies and standards organizations.

Internationally, FPL scientists work closely with scientists in many countries through technical exchanges and cooperative research. In addition, scientists participate in the development of international testing and material standards as well as providing advice in the development of foreign standards to facilitate the acceptance of U.S. products.

The new research proposed by FPL addresses priority research needs for construction identified by the Subcommittee on Construction and Building. The first involves the increased use of recycled materials in construction. Pressures on the timber resource coupled with increased cost of landfilling is prompting new emphasis on recycling of wood and fiber products. Research being proposed at FPL will develop process technology for creating building products, evaluate the performance of this new family of products from recycled wood and fiber (including the development of new evaluation standards); and conduct studies of the economics of the new technology.

A second area of proposed research involves development and promotion of environmentally friendly technologies for the construction industry. Public concern for the environment is forcing our society to evaluate the environmental consequences of processing and manufacturing technologies used to produce or dispose of construction materials. Adhesives are critical to composite wood products. FPL research will be accelerated to develop wood adhesives from renewable resources that are environmentally benign. 
Preservatives are used extensively to increase the service life of wood structural member - yet most preservatives are toxic to humans as well as target pests. FPL research will be accelerated to identify alternative methods to inhibit decay without toxic effects and to identify better and less expensive methods to clean up contaminated sites using wood-degrading fungi.

\section{USDA ONGOING PROGRAM RELATED TO C\&B GOALS}

\section{Topic}

Engineered Wood Fiber

Design Criteria

Wood Performance Standards

Wood Structural Systems
C\&B Goals Addressed

$\begin{array}{lllllll}1 & 2 & 3 & 4 & 5 & 6 & 7\end{array}$

$\mathrm{X} X$

$\mathrm{X}$

$\mathrm{X}$

$\mathrm{X}$

$\mathrm{X}$

$\mathrm{X}$

$\mathrm{X} \quad \mathrm{X}$ 
THE NATIONAL INSTITUTE OF STANDARDS AND TECHNOLOGY CONTRIBUTION TO THE CONSTRUCTION AND BUILDING PROGRAM

The National Institute of Standards and Technology (NIST) conducts nationally recognized programs in major aspects of construction and fire research.

The building research program works cooperatively with other public and private organizations to improve the usefulness, safety, and economy of constructed facilities and to increase the productivity and international competitiveness of the construction industry. It develops technologies to predict, measure, and test the performance of construction materials, components, systems, and practices. Its programs include structural engineering, materials, mechanical and environmental systems, and computer integrated construction. NIST is studying structural and fire safety systems performance in the January 17, 1994, Northridge, California, earthquake to improve the seismic performance of buildings, public works, and utilities. NIST research supports environmentally sensitive construction to meet users' needs and exploit the most advanced thinking in design and engineering while using energy efficient and environmentally sound processes and materials. In cooperation with industry, NIST is developing measurement methods to define the performance of advanced building environmental systems.

NIST also contains the foremost fire research laboratory in the United States. The fire research program was established by the Federal Fire Prevention and Control Act of 1974 to reduce the human and economic costs of unwanted fires by providing scientific and technical knowledge on all aspects of fire for the fire protection community. It investigates the scientific principles that govern the phenomena of fire, provides the knowledge base for fire safety, develops the underlying technical support for new safety standards, and generates the engineering methodology to support the practice of fire protection engineering. The fire research program is designed to provide to fire protection engineers, fire investigators, fire service organizations, product manufacturers, state and local officials, standards developers, fire safety educators, and fire researchers the methods of measuring the fire properties of materials, such as ignitability, rate of heat release, flame spread, smoke, and toxicity; engineering tools; and predictive methods to assess the adequacy of performance of fire protection features. These methods will be used increasingly in performance-based standards to reduce costs of fire safety, fire investigation, and litigation.

The new activities proposed for the NIST program will address priority R\&D needs of the construction industry identified by the NSTC Subcommittee on Construction and Building as essential to the nation's growth. The first involves modernizing construction by providing the technical basis for integrated automation and robotics in the construction process, supporting industry's development of automated constructed facilities, and reducing injuries to the construction workforce. NIST's leadership in knowledge systems for construction process integration will be expanded to provide a practical framework for quality improvement of constructed facilities, and put in place mechanisms for small- and medium-sized construction firms to gain competence in the use of these new technologies. 
NIST will also provide the technical information, data and measurement methods needed to enhance the reliability of constructed facilities. NIST-developed infratechnologies will lessen the risks of fire, wind and earthquakes, speed new, safer products to market, and reduce the time and costs associated with the incorporation of such technologies into practice. NIST will assist U.S. industry with the tools needed for performance-based codes and standards, and will work to improve performance tools for reducing the regulatory burden of prescriptive codes on industry and society, and supply the technical basis for next generation sensing and suppression technologies. It will provide world leadership in new technologies for risk and hazard reduction. This program responds to Congressional mandates in fire safety and earthquake hazard reduction, and to a potential mandate in wind engineering proposed in NIST's pending reauthorization legislation for FY 1995.

NIST will strengthen its environmentally sensitive construction program to provide technologies for reducing operation and maintenance costs, building related illnesses and injuries, waste and pollution. NIST will complete an indoor air quality (IAQ) computer aided design (CAD) model for use in predicting indoor air pollution, and will prepare a methodology for predicting the life-cycle performance of building materials, components, and systems using new environmentally sensitive technologies for heating, cooling and other building systems.

NIST ONGOING AND NEW PROGRAMS RELATED TO C\&B GOALS

Topic

High Performance Construction

Materials and Systems

Automation for Construction

and Constructed Facilities

Earthquake and Wind Risk

Reduction

Fire Safety Research

Environmentally Sensitive

Construction
C\&B Goals Addressed

$\begin{array}{lllllll}1 & 2 & 3 & 4 & 5 & 6 & 7 \\ X & X & X & X & X & X & X \\ X & X & X & X & X & X & X\end{array}$

$\begin{array}{lllllll}X & X & X & X & X & X & X\end{array}$

$\begin{array}{lllllll}\mathrm{X} & \mathrm{X} & \mathrm{X} & \mathrm{X} & \mathrm{X} & \mathrm{X} & \mathrm{X}\end{array}$

$\begin{array}{llllllllllll}X & X & X & X & X & X & X\end{array}$ 
DEPARTMENT OF DEFENSE CONTRIBUTION TO

THE CONSTRUCTION AND BUILDING PROGRAM GOALS

\section{Civil Works Research \& Development Program}

The mission of the Civil Works (CW) R\&D program is to provide solutions to common and specialized problems encountered within the overall CW Program. The focus is on high priority problems that significantly impact the execution of current or planned CW projects. The R\&D is highly applied research utilizing products and techniques developed by industry and universities and adapting them to $C W$ needs. Six sub-areas of the overall CW R\&D program are relevant to the Goals of the $C \& B$ Sub-committee. They are materials; coastal structure evaluation and design; flood control structures; repair, evaluation, maintenance \& rehabilitation; construction productivity; and earthquake engineering.

\section{Military Research \& Development Program}

In the early 1990's, DOD initiated the Reliance program to eliminate redundant military research and development ( $R \& D$ ) programs and capabilities and to increase interdependence among the military services for Civil Engineering Science and Technology (S\&T) R\&D. The R\&D mission scopes of five Civil Engineering Reliance focus areas are directly related to the seven Construction \& Building Sub-Committee goals. The five focus areas are Conventional Facilities, Airfields \& Pavements, Fire Fighting, Ocean \& Waterfront Facilities/Operations, and Critical Airbase Facilities/Recovery.

Conventional Facilities R\&D encompasses S\&T required to effectively revitalize and operate its aging infrastructure to ensure that DOD has effective strategic power platforms, homes for the forces, and training and working bases to support the National Military Strategy. FY2000 goals are to reduce facilities acquisition, maintenance, and repair costs by $15 \%$ compared to 1990 levels and to reduce energy consumption by $20 \%$ compared to 1985 baseline.

Airfields and Pavements R\&D encompasses S\&T required to provide the requisite aircraft launching and recovery platforms, roads, railroads, and other operating surfaces required for force projection. DOD has an $\$ 85 B$ investment in 40,000 miles of roads, 450 airports and heliports, and 3,500 miles of railroads within the U.S. The S\&T scope is to develop technologies to reduce the construction and maintenance costs while increasing service life and military reliability. The research areas include construction materials and equipment, design, construction, maintenance, repair, phenomenology modeling of pavements using recycled and waste materials, military unique aircraft pavement design, tracked vehicle wearing surfaces, and thermal effects for VTOL/STOL aircraft. Included are airfields, roads, railroads, and contingency and assault landing strips in all climatic regions of the world. FY2000 goals are to reduce pavement construction and maintenance costs by $20 \%$ and to extend pavement life by $25 \%$.

Fire Fighting R\&D encompasses S\&T required to develop advanced fire fighting agents required by the military services to effectively combat aircraft, 
shipboard, fixed and mobile weapons systems, facility and hazardous material fires at military installations worldwide. FY2000 goals are to reduce ozone depletion for streaming agents and flooding agents by development of floroiodocarbon compounds; to increase biodegradability of fire fighting foam; and to improve fire detector/suppression systems.

Ocean \& Waterfront Facilities/Operations R\&D encompasses S\&T required to reduce the Navy's $\$ 1.6 \mathrm{~B}$ backlog of infrastructure deficiencies by developing materials and methods for enhancing the durability of waterfront structures, by developing diagnostic technologies for large complex ocean facilities, and by providing improved analysis and design concepts for large underwater ocean engineering projects. FY2000 goals are to increase service life of pier repairs from 3 to 15 years; to improve ocean mooring capabilities by $80 \%$; and to validate non-destructive testing improvements for crane lift components.

Critical Air Base Facilities/Recovery R\&D encompasses S\&T supporting the survivability, recovery, and sustainment of mission critical air base facilities. This includes rapid runway repair, damage assessment, and rapid repair of structures and utilities. FY2000 goals are to develop or adapt emerging technologies to improve airfield operating surfaces and to reduce recovery and repair times for critical airbase facilities by $30 \%$.

\section{PROJECTED FY96 PROGRAMS RELATED TO C\&B GOALS}

$\underline{\text { Topic }}$

CW R\&D (Cat "A", except as noted) Materials

Coastal Structures

Flood Control Structures

Repair, Eval., Maint, Rehab

Construction Productivity

Sub Total:

Earthquake Engineering (Cat "B")

CW Sub Total:

$\frac{C \& B \text { Goals Addressed }}{125345667}$

$\begin{array}{lllllll}X & X & - & X & - & X & - \\ X & - & - & - & - & - & - \\ X & - & - & - & - & - & - \\ - & X & - & - & - & - & - \\ X & - & - & - & - & - & -\end{array}$

Military R\&D (Cat "B")

Conventional Facilities

Airfields and Pavements

Fire Fighting

Ocean \& Waterfront Facilities

Critical Airbase Facilities

Military Sub Total:

$\begin{array}{lllllll}X & X & X & X & X & X & - \\ X & X & - & - & - & - & - \\ - & - & - & - & X & - & - \\ X & X & - & - & - & X & - \\ X & - & - & X & - & - & -\end{array}$




\section{THE DEPARTMENT OF ENERGY CONTRIBUTION TO THE CONSTRUCTION AND BUILDING PROGRAM}

The Department of Energy (DoE) conducts a comprehensive program that seeks to increase the energy efficiency in the nation's stock of residential and commercial buildings. This program supports research, development, and commercialization of advanced technology and promotes the expanded use of currently available energy-efficient technologies and practices.

The DoE program is built upon an integrated strategy that moves along three major fronts: Codes and Standards, Market Conditioning, and Research and Development. The Codes and Standards strategy seeks to eliminate the most energy wasteful appliances, equipment, and building practices from the market in an effort to achieve the maximum energy efficiency that is both tecinnologically feasible and economically justifiable. The Market Conditioning strategy is designed to encourage buyers to select products that are more efficient than required by energy codes and standards. This is achieved by developing partnerships with industry and utilities to accelerate the commercialization of new, energy-saving and renewable energy technologies; and by educating consumers and buyers on the benefits of enhanced energy efficiency in new products. For the federal sector, many of these activities are conducted through the Federal Energy Management Programs; these programs provide direction and assistance to federal agencies in planning and implementing measures that improve the energy efficiency of the federal infrastructure. The Research and Development strategy is designed to achieve the maximum technical potential from advanced energy conversion processes and new materials applicable to buildings.

Although portions of all three elements of the overall DOE strategy support the goals of the Sub-committee on Construction and Building, the Research and Development activities, as complemented by Deployment activities under the Climate Change Action $\mathrm{Plan}$, provide the most direct linkage to these goals. In general these activities involve improved building design tools that recognize the interactions of various building subsystems and the development of new materials, energy-saving equipment, and improved construction techniques.

The DOE's research program is carried out under three major areas: 1) the building envelope, 2) equipment and appliances within that envelope, and 3 ) as an integrated system that reflects the interactions of each the building's components with each other. The major research programs under these three broad areas are highlighted below.

\section{Building Envelope}

The DOE conducts several major research programs that are concerned with improving the quality of the building envelope. Building Materials Research is developing new insulations for use both building envelopes and appliances. These products will exhibit very high thermal resistance, and will now require the use of ozone-depleting chemicals in their manufacture as most current insulating materials do. Advanced materials will also be capable of varying 
thermal resistance in response to changes in the external environment. Wa1l, Roof, and Foundation Research is directed primarily at establishing the thermal and mechanical properties of construction materials including new, high performance insulation. The program supports the operation of the Building Technology Research Center at the Oak Ridge National Laboratory as a National User Facility, available to private industry for testing of new construction practices and materials. Windows Research is focused on improving the energy performance of window, doors, and skylights through improvements in glazing, supporting framing, and the design tools used to engineer, construct, and specify fenestration products. The DOE expects to develop a new generation of high performance windows exhibiting high thermal resistance and dynamically variable optical properties.

As part of the Department's envelope research program, the Indoor Air Quality program supports research on the impact of energy efficiency measures on the health and comfort provided by the indoor environment. Striking a balance between higher energy efficiency from increased air-tightness and the quality of the conditioned space is the overall objective of the research. Elements of this program include the development of a high-risk radon prediction tool, research into advanced ventilation systems for residential buildings, and support of the technical foundation for improved industry consensus standards on indoor air quality, infiltration, and ventilation.

\section{Building Equipment}

Building equipment research involves lighting, heating and cooling, advanced appliances, and several programs dealing with solar-related building equipment. Lighting Research is being directed at the development of advanced light sources as replacements for conventional incandescent and fluorescent lamps. These new lamps represent efficiency improvements of 30-40 percent when compared to the best existing fluorescent technology, and in some designs utilize more environmentally friendly materials as replacements for the mercury used in current lighting systems. On another front, the development of advanced electronic controls and improved design tools will allow lighting system designers to optimize building lighting to suit varying user requirements and the availability of natural daylighting. The DoE also supports research on advanced lighting fixtures and on the impact of new lighting technology on building occupant productivity and comfort.

Heating and Cooling R\&D is currently focusing on the development of thermallyactivated heat pumps for residential and small commercial applications, and on high efficiency absorption chillers for cooling commercial buildings. These technologies rely on the direct combustion of natural gas as an energy source, eliminating the inefficiencies and atmospheric pollution associated with electricity production. The department's program also is carrying out research that will support a nationally accepted system for establishing thermal distribution system efficiency.

Industry efforts to eliminate ozone-depleting chemicals are being supported by Advanced Refrigeration activities that establish the compatibility of new refrigerant alternatives with equipment materials and lubricants, and test the thermodynamic properties of totally-new refrigerant mixtures. 
Solar-related building equipment research is being undertaken on two fronts: Active Solar Space Conditioning, and Building-Integrated Photovoltaic systems. Both of these program efforts are designed to lower the cost of utilizing solar energy. Active solar research is directed at achieving a 40 percent reduction in system installed costs through a combination of strategies to improve market acceptance of this technology, and the establishment and implementation of industry-wide testing and performance rating procedures that will serve to further improve consumer acceptance of active solar systems. Building integrated photovoltaic systems such as improvements in code requirements, and gaining acceptance of electric utilities for the operation of building integrated photovoltaic.

\section{Building Systems Integration}

A major new activity in $\mathrm{DOE}^{\prime}$ s research portfolio dealing with building systems integration is DOE's Building America Initiative, a project designed to demonstrate a systems engineering approach to advanced building design, manufacture, and delivery. This would lead to a fundamental restructuring of the buildings industry. Through support for the formation and development activities of industry consortia representing a broad range of materials and equipment manufacturers and home builders, the DOE expects to achieve greatly improved energy performance, cost, and delivery for the nation's next generation of residential buildings. The program will not only seek to develop methods of optimally integrating various components and systems in new homes, but also attempt to lower institutional barriers to the application of manufacturing industry techniques such as just-in-time inventory control and automated quality control that can be used to dramatically lower costs in the construction and energy-related operation of homes. This initiative will be enhanced by the Climate Change Action Plan's proposed activity with respect to upgrading residential building standards. The CCAP effort recognizes the need for standards to provide greater design flexibility to take advantage of the benefits of more integrated design.

Advanced Residential Buildings research targets the energy and cost improvements that are possible through the incorporation of industrialized manufacturing processes and advanced materials into residential housing construction. To accelerate the adoption of products stemming from this research, the Climate Change Action Plan will create state-wide programs and demonstration centers that will showcase advanced energy efficiency and solar techniques, advanced materials, and other energy-saving technologies in the residential sector. These activities will directly support the C\&B goals of reduced delivery times, reduced costs and maintenance, and increased productivity and comfort.

Passive Solar Technologies have the potential to substantially reduce energy requirements for heating, cooling and electric lighting. Efforts are underway to identify design strategies that capitalize on the potential benefits of passive solar energy including the use of core daylighting techniques, passive cooling, thermal storage, and integration of passive solar technologies with mechanical ventilation and electric lighting systems. 
The Department of Energy's Exemplary Buildings program teams with the building industry to design, construct and monitor several buildings applying passive solar and solar integration concepts, and then promotes replication of successful strategies. New computer-based control and information technology has given rise to the concept of improving energy performance in all phases of a building's life cycle; from initial design and specifications through construction, commissioning and operation.

Commercial Buildings Research is supporting the development of design tools based on "expert systems" that can imbed life cycle energy considerations into existing and new computerized commercial building design methods. Research is also being carried out focussing on advanced diagnostic technologies to support building commissioning, operation, and maintenance. Under the Climate Change Action Plan, DoE will initiate government industry (EPA, industry, and utilities) collaborative to accelerate the introduction and widespread use of advanced lighting, heating, and cooling equipment for commercial buildings.

\section{Utilities Technologies related to Buildings}

Several utilities technologies have particular relevance to reducing the $\mathrm{CO} 2$ emissions from buildings. One component of the photovoltaic (PV) program is researching methods for integrating $P V$ systems into residential and commercial buildings. For example, PV systems that double as electrical generators and lightweight roofing material are being developed. Other efforts include the building of manufacturing homes with PV power, engineered loads, passive solar design, and solar hot water built in.

Geothermal heat pumps (GHP) offer the potential of highly efficient, costeffective heating, cooling and hot water for buildings. DOE is conducting research to find ways to reduce installation costs and increase the performance and, therefore, increase the marketability of the GHP technology. The focus of the technical research effort involves developing advanced concepts for constructing improved heat exchangers and confirming their performance.

\section{DOE PROGRAMS RELATED TO C\&B GOALS}

$\underline{\text { Topic }}$

Building Envelope Research

Building Equipment Research

Building Systems Integration

Codes and Standards

Federal Energy Management Programs

Utilities Technologies--Buildings

Other Deployment/Analysis Activities
C\&B Goals Addressed

\begin{tabular}{lllllll}
1 & 2 & 3 & 4 & 5 & 6 & 7 \\
\hline$X$ & $X$ & $X$ & $X$ & $X$ & $X$ & $X$
\end{tabular}

$\begin{array}{lllllll}0 & X & X & X & X & X & x\end{array}$

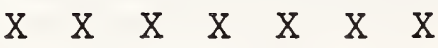

$\begin{array}{lllllll}X & X & X & X & X & X & X\end{array}$

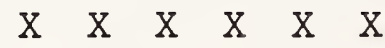

$\begin{array}{lllllll}0 & X & X & X & X & X & x\end{array}$

$\begin{array}{lllllll}0 & X & X & X & X & X & X\end{array}$ 
NATIONAL INSTITUTE OF OCCUPATIONAL SAFETY AND HEALTH'S CONTRIBUTION TO THE CONSTRUCTION AND BUILDING PROGRAM

The National Institute for Occupational Safety and Health (NIOSH) gains it principle authority from the Occupational Safety and Health Act of 1970 from which it conducts nationally recognized research programs in occupational safety and health. These programs include research in the construction industry as well as places of employment most of which are in industrial, commercial, and institutional buildings.

NIOSH identifies the causes of work-related diseases and injuries and the potential hazards of new work technologies and practices. With this information, NIOSH determines new and effective ways to protect workers from chemicals, machinery, and hazardous working conditions. Creating new ways to PREVENT workplace hazards is the job of NIOSH.

Construction Safety and Health

Prevention of occupational disease, injury, and death in the construction industry poses unique problems. Workers in these industries face everchanging work environments, which are affected by factors such as weather, worksite conditions from site preparation involving deep excavations to confined spaces, or buildings several stories high, and multi-employer situations where interaction between contractors and individuals is in continual flux. In addition to the activities normally associated with construction, construction workers are also involved in rehabilitation or demolition of buildings, reconstruction at disaster sites, and the clean-up at hazardous waste sites. Work under these constantly-changing conditions presents a wide variety of potential hazards, many of which are unknown when they are encountered in the course of construction work.

NIOSH has established a core group of professionals with an understanding of and sensitivity to the unique circumstances of the hazards faced by construction workers. At NIOSH, the premises for the National Research Program for Occupational Safety and Health in Construction are:

1. Broad Focus: The prevention focus in construction needs to be broadened beyond the traditional focus on employers and workers to also consider the roles of the owner, the design engineer, the means and methods engineer, the primary contractor, and the self-employed.

2. Cohort Continuity: Depending on employer records is problematic for conducting epidemiological research because construction workers routinely change employers several times a year, thus, a different approach is needed. Union records offer a different approach because of an opportunity for tracking workers over their career that is independent of employer records.

3. Task-based Approach: Within the dynamics of the construction site certain tasks remain constant. These tasks include those performed by the different trades such as wiring or plumbing. A focus for research, thus, 
lies with investigating the exposures associated with tasks from which presumptive standards (like OSHA's interim lead standard) can be recommended.

4. Qualified Persons: Ancillary to the focus on presumptive standards, is the need to design training programs that can assure an adequate supply of qualified persons in safety and health on the worksite.

5. Construction Planning: The Critical Path Method (CPM) is an instrument that can be used to integrate the planning and implementation of preventive actions. CPM provides a plan for construction activities or tasks against which presumptive standards and expert knowledge can be integrated. It also offers an opportunity for planning for occupational safety and health between the different subcontractors who concurrently operate on the construction site.

6. Construction Design: Innovations in the onset use of computer-aided design and construction may provide instruments for safety and health interventions into the means and methods used in construction.

7. Innovation Deployment: National and international coalitions need to foster the exchange of safety and health information, to identify interventions that are shown to be efficacious, and to encourage their effective deployment.

The threat to the health of construction workers covers a broad range of problems, which include serious injuries such as fatalities from falls, cancer such as mesothelioma, musculoskeletal disorders such as back injury, lung diseases such as silicosis, neurotoxic disorders such as those that arise from lead poisoning, hearing loss, and dermatological disorders such as dermatosis. One research task for NIOSH is to determine the risk factors for each problem that has been identified, and another is to demonstrate interventions such as protections or preventive services to reduce the risks as efficacious. A system of surveillance monitors progress and trends and to identify health problems that require preventive action.

\section{NIOSH PROGRAMS RELATED TO C\&B GOALS}

\section{Topic}

Construction Workforce

Safety and Health

Building Occupant

Safety and Health
C\&B Goals Addressed

\begin{tabular}{lllllll}
\hline 1 & 2 & 3 & 4 & 5 & 6 & 7 \\
& & & & & & $X$
\end{tabular}

X X 


\section{General}

The building technology research mission of HUD is to conduct research and analysis on the production and supply of housing and the physical and technical aspects of community development. To the extent resources are available, HUD addresses all physical, structural, developmental technology, regulatory, and related issues needed to support its commitment to ensure decent, safe, and sanitary housing in a suitable living environment for all Americans.

The Department's research goals are to:

- advance the Department's policy priorities

- effectively integrate other Administration priorities affecting the built environment with the programs and objectives of HUD.

\section{Advancing the Department's Policy Priorities}

Although all the Department's policy priorities raise technical, structural and developmental research issues, the following three have the most extensive research requirements:

\section{A. Expand Housing Opportunities for Low and Moderate Income Families}

1. The Department engages in research and policy analysis to expand affordable housing opportunities by reducing the initial and operating cost of housing and to expand the affordability of new and rehabilitated housing supplied by both the private and publicly-assessed market. To accomplish this goal, the Department undertakes research and related regulatory and policy analysis in the following areas:

a. reducing the cost of producing, rehabilitating and operating a home or dwelling unit through:

- new and innovative technologies and construction methods;

- reform of codes, standards and product evaluation and acceptance systems; and

- methods to accelerate technological transfer and acceptance of innovation.

b. reducing the cost of land for development through:

- land and development requirements; 
- land development technologies; and

- zoning and land regulation reform.

c. reducing the cost of residential infrastructure

d. eliminating or reforming duplicative or excessive regulatory requirements that unnecessarily raise the cost of both private market and publicly assisted housing and limit housing opportunity (barriers to affordable housing).

2. The Department undertakes research to improve the substance and administration of Departmental standards and requirements affecting the structure and land development including:

- HUD Minimum Property Standards;

- Section 8 Housing Quality Standards; and

- HUD Manufactured Housing Construction and Safety Standards.

3. The Department engages in research to assure that new and rehabilitated for low- and moderate-income families housing also adequately protects health \& safety.

4. The Department undertakes research to assure that the interests of consumers, especially special users (elderly, disabled) are adequately and cost-effectively considered in the construction and rehabilitation of housing.

5. The Department undertakes research to improve the quality and design of affordable housing.

6. The Department undertakes research the impact of code, technical standards, building and environmental regulation on the housing \& development process.

\section{B. Empower Communities}

The Department conducts technical, developmental and related regulatory research to assist in the redevelopment of communities including research on:

1. The impact of environmental regulations and policies on central city redevelopment, low-income families and urban housing markets;

2. The impact of locational, developmental and housing actions on environmental risks to low-income families (environmental justice).

3. Technologies for affordable rehabilitation including providing for historic preservation in the rehabilitation process; 

4. Urban infrastructure technical needs;
5. Metropolitan, regional and community planning;

\section{Open Housing Markets to Minorities}

Many development regulations have the potential to restrict access by minority and low-income families to areas of economic growth, housing, and job opportunities. The Department conducts ensure equitable access to jobs and housing including:

1. cost impacts of development regulation;

2. reform of planning and developmental regulations to assure balanced growth that accommodates jobs and housing opportunities, transit, envirormental protection and urban amenities;

3. expanding residential mobility through zoning and land use reform;

4. development of tools for metropolitan, regional and State planning;

\section{SUPPORT OTHER ADMINISTRATION OBJECTIVES}

The Administration has a number of important policy goals that can have a significant impact on housing construction and the overall development process. These include: 1) increased energy efficiency, 2) environmental protection (lead, radon, toxic lands, global warming, wetlands, endangered species), 3) disaster mitigation (earthquakes, floodplain, hurricanes), and 4) historic preservation. In this regard, the Department's mission is to conduct research that will permit, to the fullest extent possible, the integration of these other objectives into the programs of the Department with the least a negative impact on housing affordability and urban redevelopment.

Research includes, but is not limited to:

1. ensuring that HUD-assisted housing meets high levels of energy efficiency without endangering housing affordability;

2. working to assure that carbon emissions from new and existing housing are reduced so as to limit the dangers of global warming (President's Global Warming Initiative);

3. developing effective standards to limit future disaster damage and costs (earthquakes, hurricanes) in both HUD-assisted and privatemarket housing;

4. improving the indoor air quality of housing;

5. limiting waste in residential construction and maximizing the use of renewable and recyclable materials; 
6. assuring that HUD programs operate in a manner fully consistent with principles of environmental justice; and,

7. assuring that in providing for wetlands and endangered species protection and other environmental objectives, an adequate supply of land for affordable housing is available.

8. assuring that HUD and State and local housing and community development programs support the Administration goal of sustainable development. 
The Department of the Interior manages a significant inventory of the unique physical assets which include 38,000 buildings, 30,000 recreational facilities and 1,700 bridges, water supply systems and other infrastructure facilities such as research laboratories and hatcheries. The maintenance activities of the DOI land management Bureaus (Bureau of Land Management, National Park Service, United States Fish and Wildlife Service) and the corrosion research at the U.S. Bureau of Mines support the Department's objectives and the Department's mission as steward of the Nation's national and cultural resources.

There is high potential benefit from research directed at extending the life of structures which are exposed to corrosive environmental conditions. An examples of such structure are the many bridges that are in coastal regions which are exposed to salt spray, precipitation, fog, high winds, solar radiation, and other factors that contribute to a harsh environment for materials such as metals and organic coating. Other geographical areas of concern are those in which salt is routinely used to improve winter driving conditions. The U.S. Bureau of Mines (USBM) is involved in research in partnership with state DOT's and private industry to improve the performance of steel reinforced concrete bridges and other structural materials in coastal environments; and to develop a fundamental understanding of bridge corrosion control using thermal spray coatings. Analysis of runoff from metal samples, studies of the long-term adherence of zinc coatings to concrete, and electrochemical modeling will be used to evaluate coatings applied to coastal bridges which give cathodic protection to the structures. In addition, research is being performed to develop chloride sensors that may be used in bridge structures to determine the level of chloride inside of reinforced concrete.

The USBM is also developing TRIP (TRansformation Induced Plasticity) steels as smart materials for stress/strain monitor in infrastructure applications such as bridges, buildings, and underground mines. Work is being done with industry and state DOT's to instrument limited number of bridges on the interstate highway system. In the future, the use of TRIP steel monitors will be rooted as a means to monitor the structural integrity and safety of a network of bridges over a much broader geographical area. Instrumentation and networking of the data to central locations may also be initiated with the cooperation of state and federal DOT agencies and industry.

\section{DOI PROGRAMS RELATED TO C\&B GOALS}

Topic

Corrosion Research

TRansformation Induced Plasticity
C\&B Goals Addressed

\begin{tabular}{lllllll}
1 & 2 & 3 & 4 & 5 & 6 & 7 \\
\hline & & & $X$ & $X$ & \\
$X$ & & & $X$ & $X$ &
\end{tabular}


The U.S. has approximately 3.9 million miles of surfaced roads, which carry one-third of the ton-miles of domestic freight and nearly $90 \%$ of passengermiles travelled. High-performance airports are central to long-distance public transportation. Public expenditures for construction and maintenance of the highway system are approximately $\$ 80$ billion per year. Obtaining the best life-cycle performance from street, highway and runway pavements is thus of great importance not only to users, but also to government at all levels. Infrastructure expenditures for other modes of transportation are smaller, but still very substantial. For example, U.S. railroads spend about $\$ 5$ billion each year on maintenance of way and structures, while making non-equipment capital investments of nearly $\$ 3$ billion.

The development of technological alternatives in the defense and consumer sectors have produced a rich inventory of materials, structural design concepts, and innovative tools and techniques, awaiting only the effort to develop specific applications to transportation infrastructure, demonstrate their effectiveness and long-term viability, and, often, reduce costs to a competitive level. Examples include composite materials, innovative structural design concepts, new approaches to corrosion protection and control, structural composites and adhesives, and new pavement mixtures.

There is great potential benefit from research directed toward high performance construction materials, automated tools and devices, design concepts and construction methods for renewal of transportation infrastructure. The focus of this work should be not only new construction, but also renewal, rehabilitation and maintenance of existing facilities. Examples of major opportunities include high performance concrete and steel, innovative composites, and computer-aided design and automated construction and maintenance tools. In addition to economic and performance benefits, innovative methods will yield construction processes less damaging to the environment.

Transportation infrastructure is also a rich field for application of nondestructive inspection and testing devices, valuable both during and after the construction process. These offer benefits in terms of safety, infrastructure lifetime, and optimized maintenance practices. One concept long discussed but little used to date in transportation is that of "smart structures"--roads, bridges, runways, tunnels, etc., with a network of embedded sensors that can continually provide detailed information as to the structure's condition throughout its lifetime, under normal as well as abnormal' circumstances.

Many technical advances already exist that are absent or not widely applied in the United States. Impediments include uncertainties as to long-term benefits and life-cycle costs, and differing ways of funding capital versus maintenance/renewal activities. An important component of R\&D in this area is demonstration and evaluation, conducted over a long timeframe and with comprehensive consideration of overall benefits and life-cycle costs. Development of appropriate testing devices is a necessary element of the demonstration and evaluation process. 


\section{DOT PROGRAMS RELATED TO C\&B GOALS}

\section{Topic}

Hi Performance Materials

and Systems

concrete

steel

composites

aluminum

asphalt

Automation for Construction

bridges

pavements

tracks

airports

waterways

Resistance to Disaster

seismic

wind

water

man-made

Network Safety Monitoring

bridge instrumentation

ground motion

non-destructive evaluation

Environmental

waste generation

construction effects

operations

clean up
$C \& B$ Goals Addressed

$\frac{1}{X} \frac{2}{X} \frac{3}{X} \leq \frac{5}{X} \quad \frac{6}{X} \frac{7}{-}$

$X x-x-x$

- $-\quad-X X X$

$X X X-X-$

$-X--X-X$ 


\section{GENERAL SERVICES ADMINISTRATION CONTRIBUTION TO THE CONSTRUCTION AND BUILDING PROGRAM}

The General Services Administration (GSA) has a history of showcasing innovative building technologies. Demonstration projects were formally recognized in the 1970 's to initiate and to emphasize national programs within the agency. In the 1980's, GSA initiated an advanced technology buildings program that featured both new construction and retrofit projects. Innovative technology applications are continuing in the 1990's in order to better understand emerging technologies and new delivery methods. Throughout this period of over twenty years, GSA's showcasing efforts were internally driven to improve the performance of its quarter billion square foot building inventory.

In the 1970's, GSA developed a series of theme oriented demonstration projects. The application of high-rise firesafety standards, addressing areas of refuge, smoke control, and building automation interface became a principal focus for the Federal Building, in Seattle, Washington. The theme of environmental protection was pursued on the Federal Building in Saginaw, Michigan, providing active and passive solar systems, reuse of site materials, and energy-efficient systems. The Norris Cotton Federal Building, in Manchester, New Hampshire, served as GSA's first energy conservation demonstration project: The Manchester project was intended to serve as a "laboratory" for numerous energy efficient building systems/features, with each floor featuring different technologies. Energy conservation themes were continued in the early 1980's with GSA's support of the Department of Energy's Solar Demonstration Program, resulting in forty active solar demonstration projects. These early innovative technology projects served to redefine many GSA design policies and criteria.

In the mid 1980's, GSA initiated its Advanced Technology Buildings Program which resulted in five showcase projects, involving both new construction and retrofit. New construction projects included the Federal Building East, in Portland, Oregon, the Federal Records Center, of Overland, Missouri, and the Federal Building in Long Beach, California. Retrofit projects included the Mart Building, of St. Louis, Missouri and the Terminal Annex Federal Building, in Dallas, Texas. While previous showcase projects focused on a single performance themes, the advanced technology projects addressed innovation for many building functions. Occupant productivity and space flexibility were principal concerns, resulting in raised flooring throughout the buildings, modular power distribution systems, integrated telecommunication systems, and the use of systems furniture. Energy conservation features were also addressed with heat recovery concepts, energy efficient lighting, occupancy sensors, and thermally efficient building envelopes. The Portland and Overland projects also featured environmental concerns with the continuous monitoring of indoor air pollutants using built-in diagnostic centers. These building technology applications served to influence GSA design criteria to the standards used today.

In the $1990^{\prime} \mathrm{s}$, GSA is pursuing a number of innovative technologies. Similar to the comprehensive focus of its Advanced Technology projects, the new 
Federal Building Courthouse, in Omaha, Nebraska, is planned to address functional objectives of energy efficiency and environmental performance. This project is now in the authorization stage, with design to begin in Fiscal Year 1995. The Omaha project will serve to satisfy the new construction showcasing requirements of Executive Order 12902 as well as support the environmental concerns of Executive Order 12873.

Also underway are a number of individual technology applications addressing various performance issues. The U.S. Court of Appeals, in San Francisco, California will demonstrate the retrofit application of Base Isolation structural systems. This historically significant structure is being protected from seismic events by cutting its columns at the foundation and installing shock-displacing isolators: Construction is underway, with completion expected in 1995. Seismic concerns are also being addressed with the planned use of structural frame shock absorption design for the Federal Building at 11000 Wilshire Boulevard, in Los Angeles, California: Diagonal bracing members with elastic shock absorbers should effectively off-set framing movements in an earthquake. Other technologies are awaiting match-ups to planned projects. There is interest in applying the new reinforcing bar configurations (developed through the University of Kansas) which should improve concrete bonding characteristics. The BACnet protocol for building automation systems (developed through the National Institute of Standards and Technology) is another technology being considered, allowing communication between different control subsystems and advanced control/monitoring functions. A further technology interest is an improved method to remove asbestos fire-proofing in existing buildings: A pulsed high-pressure water technique offers the promise to remove coatings much faster than current manual methods. Still other technologies are being considered.

GSA is also pursuing new delivery methods/practices. One of the most significant changes in GSA design policy is to develop all projects in HardMetric. Rather than using building systems and materials that relate to the English system of measurements, all building design calculations, dimensions, specified performance and size requirements, etc., will be in metric. GSA's exclusive use of metric should offer a significant market for such product lines, which should indirectly support product compatibility/competitiveness between U.S. manufacturers and foreign markets. Another significant delivery practice being pursued is Design-Build contracting: Associated performance based requirements, coupled with contractor selection based upon greatest value offered, encourages the use of latest technologies and quality features. Although only in the investigative stage at this time, another delivery practice being considered is the use of integrated computer-aided design/facilities management systems: Should this technology evolve to reach its potential, information developed during design would be carried into and expanded upon during construction, and ultimately used and further expanded for building operations.

GSA's construction programs will continue to offer an opportunity to explore innovative building technologies. Through such initiatives, GSA will support the deployment objectives of the National Science and Technology Council, as well as realize its own goals of doing things better, faster, cheaper, and smarter. 
The U.S. EPA indoor air quality research contributes most directly to the construction and building program. EPA's research on life cycle assessment methods and guidance also directly contributes to construction and building. Other EPA research on the identification, characterization, prevention, control and remediation of environmental pollution contributes indirectly to the goals of programs on construction and building.

The indoor air quality research and other environmental research activities are reported and described mostly under the Committee on Environment and Natural Resources of the National Science and Technology Council. Activities which contribute to the built environment described here focused on indoor air quality research and showcasing or demonstrating "green" building techniques and strategies.

\section{INDOOR AIR PROBLEM STATEMENT}

Indoor air pollution in residences, offices, schools, and other buildings is widely recognized as one of the most serious potential environmental risks to human health. The U.S. Environmental Protection Agency's (EPA'S) report Unfinished Business and the Science Advisory Board's Reducing Risk report rank indoor air pollution as one of the highest health risks meriting EPA attention.

Concern about indoor air exposures stems from the following: (1) most people spend more than 90 percent of their time indoors; (2) indoor concentrations of many pollutants (e.g., chemicals, microorganisms, aeroallergens, particles, fibers, radon) are often substantially higher than outdoor concentrations; and (3) persons who are potentially more biologically susceptible (e.g., small children, the elderly, the infirm) are likely to spend most of their time indoors. Indeed, the majority of peoples' exposure to some pollutants (e.g., particles, NO2, formaldehyde, radon, asbestos) is indoors, so that indoor air concentrations of these pollutants, combined with time spend indoors, are the best single predictor of human exposure.

The carcinogenic effects of some indoor air pollutants (e.g., asbestos, environmental tobacco smoke, formaldehyde, radon) are relatively well characterized, and policy responses have been (or are currently being) developed to reduce the risks posed by these pollutants. In contrast, the noncancer effects (e.g., neurologic, pulmonary, reproductive/developmental, immune system) associated with many air pollutants at the levels typically encountered indoors, both individually and in combination, are not well understood.

The available scientific evidence indicates that there are many documented, suspected, and potential health risks associated with indoor air pollution. This evidence, although fragmented and uneven, has led many groups to conclude that indoor air pollution is one of the most serious environmental risks to human health. 
Yet, while we have considerable information about many indoor pollutants, their sources, and their associated health effects, we know little about the relative magnitudes of the potential risks associated with indoor environments. Research is needed to identify, characterize, and compare the health risks associated with exposures to indoor air pollutants so that risk assessors and risk managers can make informed decisions to protect public health.

Characterizing these risks is a very complex task involving many different factors: pollutants, sources, and building environments; exposure scenarios; health endpoints; confounding factors (e.g., thermal comfort, odor, job stressors); and solution approaches.

EPA's indoor air research strategy emphasizes the quantitative evaluation of indoor exposures and associated health effects as the bas is for relative risk assessment of important pollutants and pollutant mixtures. The first step in this evaluation is to pose the key scientific questions that need to be answered before the environmental risks posed by indoor air pollution can be viewed in proper perspective.

\section{RESEARCH PROGRAM DESCRIPTION}

The Office of Research and Development (ORD) indoor air research program is divided into four major research areas: source characterization (e.g., developing and validating test methods and models for indoor pollutant sources); exposure assessment (e.g., studying indoor air quality in large buildings); health effects (e.g., conducting laboratory, clinical, and field studies of health effects associated with indoor exposures to chemical and biological pollutants); and solutions (e.g., developing and evaluating the effectiveness of different indoor air quality control techniques).

\section{(1) Source Characterization}

Research devoted to source characterization and pollutant transport should quantify the multiple pollutant emissions from indoor sources under different environmental conditions (e.g., ventilation, temperature, humidity). These data should be used in validated indoor air models to apportion the contributions of both indoor and outdoor sources to indoor pollutant levels. EPA anticipates the private sector to study the emissions from individual sources/products, while the public sector research efforts will focus on standardizing methods to quantify chemical emissions, developing new methods to measure microbial emissions, and studying pollutant transport. EPA research is also devoted to investigating the feasibility of using responsebased tests (human, animal and/or in vitro) to evaluate the acceptability of emissions from indoor sources.

(2) Exposure Assessment

Quantifying indoor pollutant exposures is a very complex task, requiring reliable monitoring methods and standardized protocols for 
collecting data on environmental factors as well as on human perceptions. Research is especially needed to develop low-cost screening techniques for the physical, environmental, and comfort parameters that influence occupant health, comfort, and productivity. In addition, standardized protocols for diagnosing indoor air quality problems need to be developed and validated in different indoor environments. Field studies are needed to assess: spatial and temporal variabilities in levels of pollutants, both individually and in combination; the relationship between indoor exposures and occupant perceptions; and the influence of occupant activities, building characteristics, and indoor and outdoor pollutant sources on the indoor environment. These studies should be coordinated with related research efforts, such as the proposed National Human Exposure Assessment Survey (NHEXAS).

\section{(3) Health Effects}

Research devoted to indoor air health effects similarly must be coordinated with ongoing studies of the health effects associated with ambient air toxins, especially pollutant mixtures. In addition, several avenues of research need to be pursued to relate indoor exposures to documented health signs/symptoms and then to longer-term disease or tissue damage are to be coordinated.

One goal of the research is to develop methods to assess signs/symptoms, exposure/dose/response models for key contaminants and contaminant mixtures established. Factors to be considered in developing these methods and models are the impact of environmental variables such as temperature and lighting level; psychological variables such as stress; exposure scenarios that cover concentration, duration, and repeated exposures; and impacts on sensitive subpopulations. Methods for assessing disease/damage to the respiratory, immune, and nervous systems are also targeted, so that relationships to "sick building" signs/symptoms can be evaluated.

\section{(4) Risk Assessment}

The overarching goal of indoor air research is to identify, characterize, and compare the health risks associated with exposures to indoor air pollutants to enable a comparative risk assessment of indoor pollutants and pollutant mixtures. Indoor air risk assessments are conducted to address pollutant sources, emission rates, indoor concentrations, exposures, and health effects to both the general population and sensitive subgroups. Both cancer and noncancer health effects should be evaluated. One step toward this goal is to assess the relative contributions of particles, volatile organic compounds (VOCs), and biocontaminants to indoor air health effects. 
(5) Solutions to Prevent and Mitigate Pollution

Research devoted to preventing and mitigating indoor pollution risks focuses on the three basic techniques for achieving good indoor air quality: source control to prevent/reduce contaminant emissions and transport (e.g., entry of soil gases); effective energy-efficient ventilation approaches to dilute or displace contaminated indoor air with clean(ed) outdoor air; and air cleaning techniques to remove both gaseous and particulate contaminants. This research should include evaluating work practices and control options. Both standardized measurement protocols and models for indoor air quaiity for comparing the cost and effectiveness of innovative indoor air quality control approaches in different building types and climatic zones. In this area of indoor air research, public sector efforts encourage private sector involvement, especially in pollution prevention research devoted to developing and testing "clean products."

Major planned outputs for the FY 1996 indoor air research program include:

Information on the factor influencing the growth, dispe:sal, and control of biocontaminants that will provide the scientific basis for guidance on cleaning indonr surfaces and operating and maintaining ventilation systems.

Data from an interagency intervention study on the relationship between ventilation rates and occupant complaints that will contribute to efforts to determine ventilation rates which optimize indoor air quality and energy efficiency.

Information on the health effects of exposures to indoor pollutant mixtures, including effects on biologically susceptible populations.

III. Showcasing and Demonstration of "green" building technologies.

EPA construction and building deployment activities focuses on promoting sustainable design, construction, operation and renovation of facilities. The Energy star Buildings Program for commercial and EPA facilities acquisition and management are described below:

\section{(1) The Energy Star Buildings Program}

The EPA Energy Star Buildings Program is a voluntary energy efficiency program, in which participants agree to make a series of investments in their commercial buildings that will result in substantial reductions in both energy use and cost. These efficiency investments in better lights, fans, insulation and air-conditioning systems not only reduce energy costs and greenhouse gas emissions, but they also create jobs.

A group of 24 organizations have committed to take the lead in EPA's Energy Star Buildings Program by completing a "showcase" efficiency upgrade in their headquarters or other building over the next year. 
Over the next twelve months, these Energy Star Showcase Buildings participants will demonstrate the profitability and environmental benefits of a wide variety of energy efficient technologies for their buildings. These Energy Star Showcase Buildings participants will reduce their energy bills up to $50 \%$, and earn returns of $20-40 \%$ on invested capital.

These showcases will also demonstrate the potential of EPA's voluntary partnerships, Green Lights and Energy Star Buildings, to save the Nation \$28 billion annually and reduce pollution by 120 billion pounds if adopted fully nationwide. EPA will use these showcase buildings as successful examples in marketing the Energy Star Program in 1995.

The President's Climate Change Action Plan projected an outlay of $\$ 34$ million for FY 96 combined DOE-EPA buildings Program. EPA's share of that was $\$ 15$ million.

\section{(2) EPA's "Green Buildings" Initiatives}

For several years EPA has been implementing portions of the agenda identified in its Green Buildings vision and Policy Statement. These efforts will accelerate as we proceed with new construction and renovation projects. The following is a partial listing of projects already implemented, projects currently underway, and potential future projects:

Nationwide Initiatives:

- CFC and Halon Removal - EPA has replaced chillers containing CFC's at most of its laboratories with more energy efficient and non-CFC chillers; this process will be completed by the end of 1997. Halon fire suppression systems have been replaced at all of its laboratories except one, which will have a replacement system in place by the end of 1995.

- Green Lights - EPA is continuing to carry out audits of its facilities, and will have installed Green Lights systems in 500,000 square feet of its facilities by the end of FY 1994. New facilities are being designed and built with Green Lighting.

- Energy Conservation - EPA has completed audits on more than $10 \%$ of its facilities pursuant to E.0. 12902. EPA's laboratory at Ann Arbor has been identified as one of the first Showcase retrofit facilities. EPA Facility Standards are currently being updated to require energy and water conservation to be incorporated in new facilities.

Specific Projects:

- Research and Administration Facility at RTP - Numerous strategies are being pursued to incorporate "green" principles in this new 1,000,000 SF facility including atrium design to enhance daylighting and minimizing exterior surface, exterior window shading to reduce heat gain, use of indigenous plant materials to reduce water consumption, selection of environmentally preferable materials, green lights, centralized fume hood exhaust system to reduce make-up air requirements, location of electrical 
equipment to minimize effect of EMF's, and the use of a modular design which will allow efficient reuse of spaces when functions change.

- Central Regional Laboratory for Region 3 - Some of the "green" principles incorporated in the design include: reuse of a previously built upon site with existing infrastructure, use of environmentally preferable materials, well insulated exterior envelope, building configuration to maximize daylight in laboratory rooms, high efficiency HVAC equipment, building HVAC automation controls, green lighting.

- Atlanta Federal Center - EPA is working with GSA to incorporate a number of features which will significantly increase the efficiency of this facility over a conventional design.

EPA PROGRAMS TO C\&B GOALS

Topic

Indoor Air Quality

Energy Star Buildings

Showcasing

Facilities Initiative
$\underline{C \& B \text { Goals Addressed }}$

\begin{tabular}{lllllll}
\hline & 2 & 3 & 4 & 5 & 6 & 7
\end{tabular}

$\mathrm{X} X$

$\mathrm{X} \quad \mathrm{X} \quad \mathrm{X}$

$\mathrm{X} \quad \mathrm{X} \quad \mathrm{X}$ 


\section{THE NATIONAL AERONAUTICAL AND SPACE ADMINISTRATION'S CONTRIBUTION TO THE CONSTRUCTION AND BUILDING PROGRAM}

Though NASA does not have programs focused specifically on Construction and Buildings research and technology (R\&T), technology developed for aeronautics and space applications can have significant value toward improving the planning, design construction and operations of buildings and other civil structures to make them less costly, safer and more productive elements of the national infrastructure. For over three decades NASA developed technology has been applied widely to benefit the overall U.S. economy and society as a whole. Similar benefits can be realized for construction and buildings.

Key areas of NASA R\&T that may be relevant to the technical goals and objectives of the Subcommittee on Construction and Building include: robotics, remote sensing, sensors and life support, materials and NDE/NDI, planning and scheduling, advanced computational analysis. In all of these areas NASA has on-going aeronautics and space R\&T programs that can serve dual-use applications within the scope of construction and building.

NASA is a leader in the development of artificial intelligence and robotics technology. Current work in artificial intelligence includes complex task scheduling that has been applied to space shuttle operations and extensive work in system monitoring, analysis and diagnosis. The latter activity is focussed on propulsion systems and space system "health monitoring," but the technology can also be applied to construction scheduling and optimized building operations. In robotics, NASA has been developing technology for autonomous rovers for several years, including terrestrial applications.

NASA's robotics program encompasses telerobotics systems and operations technology to enable tasks to be performed in space to reduce the requirement for astronaut extravehicular activity (EVA). This includes the areas of task planning; vision systems and proximity sensing to avoid collisions; precise and dexterous manipulation; development of technology for surface rovers including, mobility, stability and mechanical design; and operator feedback. The program has a strong basic research and applications content involving industry and universities. This program has application to teleoperated/autonomous construction vehicles and robotics construction equipment, tools, etc. Recently NASA developed an advanced version of a small teleoperated rover to be used to assess hazardous situations.

NASA's science sensor/instrument research and development program encompasses a wide range of technologies for accurate and robust sensors including technology focused on advanced fabrication methods for small, low cost devices and integrated sensor systems.

While the emphasis of this work is primarily on earth observing planetary science and human tended/occupied space laboratories applications, the technology is applicable to terrestrial measurements. Technology from NASA's on going sensor technology programs could likely be used to help monitor and control the interior of buildings. Technology for remote sensing from space (including acquisition and analysis of high resolution and multi-spectral data) could be useful in identifying and assessing environmental problems as 
well as the general area of infrastructure by enabling site characterization, resource assessment (water, vegetation, etc.) and overall better municipal and regional planning.

Other sensor applications includes, small very accurate accelerometers to monitor motion of structures, enabling better damage assessment from normal degradation with age or disasters such as earthquakes. NASA has produced devices with a very wide dynamic range that could be used as part of an overall "structural health monitoring" system. NASA's program in life science and life support technology include areas of water and air purification and monitoring focused on enabling astronauts to live and work safely and productively in space. Much of the technology that will be used to monitor chemical contaminants and biological agents for applications such as the space station will likely be useful for monitoring buildings as well. Air filtering and revitalization (e.g., CO2 removal) technology may also be useful.

NASA's Commercial Remote Sensing program, in particular, is unique in the government in the manner it works with the commercial sector to develop remote sensing applications. The program was started in 1986 with the strategic objective to establish U.S. economic preeminence in value-added products derived from remote sensing and related information technologies by conducting collaborative research in technology and application programs with private firms, government agencies and universities. Uses include resource management, agricultural monitoring, mapping, general infrastructure support (e.g., city planning, road and pipeline construction, vehicular traffic projections, etc.) and media, including education and news coverage.

NASA has been actively developing advanced materials for several decades. The agency has been a leader in the development of light alloys, in particular aluminum and polymer composites for airframe applications. NASA has placed an emphasis on reducing the cost of component design and fabrication through understanding material process fundamentals, material characterization and failure mechanisms and by incorporating material models into accurate analysis and innovative structural design capability. The development of polymer matrix composites analysis and durability methods including low cost composite processing methods such as filament winding, resin transfer molding and automated tow placement. Composites can readily reduce the weight of many components by $20 \%$ to $40 \%$ with a comparable increase in structural properties and cost savings of $25 \%$. NASA is also a recognized leader in the NDE/NDI among the aerospace community.

In the general area of computational methods NASA has been a national and world leaser in many areas including fluid mechanics, structural analysis, thermal analysis and optimization. NASA has had focused programs in these areas for well over a decade and has established worldwide recognition as a leader in these fields. The very strong emphasis in this area has been driven by the very high cost and long time - often over a decade - to develop a new aircraft, spacecraft or space vehicle. Typically, the computational problems faced by the aerospace community can overwhelm even the most powerful computing system. As an example, to date there has not been an end-to-end system level analysis of a complete aircraft gas turbine engine. As a result, 
much of the effort at NASA has been to develop computationally efficient methods that often take on a hierarchical structure that enables a progressive analysis from relatively simple to very detailed.

More specifically, NASA has a strong program focused on computational structural mechanics with particular emphasis on analysis of composite structures. NASA has also developed computational fluid dynamics codes that can be directly applied to external flows around buildings.

Specific applications of NASA R\&T are cited in this plan where NASA technology can contribute to the goals and objectives of the Subcommittee on Construction an Building. As both the plan and NASA R\&T evolve additional applications will be identified and included in the Construction and Building program plan.

\section{NASA PROGRAMS RELATED TO C\&B GOALS}

Topic

Advanced Sensing

Knowledge Systems

Construction Robotics

Remediation of Sites

Earthquake
C\&B Goals Addressed

$\begin{array}{lllllll}1 & 2 & 3 & 4 & 5 & 6 & 7 \\ \mathrm{X} & & \mathrm{X} & \mathrm{X} & & & \\ \mathrm{X} & \mathrm{X} & \mathrm{X} & & & \\ \mathrm{X} & \mathrm{X} & & & & \end{array}$

X $\quad \mathrm{X}$

$\mathrm{X}$ 
NSF is the largest federal supporter of fundamental Civil Infrastructure Systems-related research. For example, it provides for approximately 65 percent of total federal funding for basic civil engineering research. NSF provides almost all of the small amount of fundamental CIS-related research on institutional effectiveness and productivity.

NSF's new focus builds on a broad array of fundamental research related to civil infrastructure systems, totaling approximately $\$ 45$ million in FY 1994. At the core of this effort is support for individual investigators and small multidisciplinary research groups at universities and colleges. Through its various Directorates, NSF supports a broad range of research on civil

infrastructure that enriches the knowledge base and underpins the development of new CIS technologies.

Academic and industrial research over the last decade have spurred numerous advances, e.g., in new materials, structural systems, automated construction, ground improvement, development of underground space, prefabricated

assemblies, corrosion inhibition, opto-electronic communication, understanding of public decisions, management, location and citing, and public finance. Yet much innovative research remains to be done. New discoveries in areas that cross disciplinary boundaries may offer radically different and valuable ways of improving the infrastructure and providing new infrastructure services.

NSF's breadth of mission allows it to focus on areas of commonality for all aspects of civil infrastructure system problems and to bring to bear any and all relevant fields of knowledge in finding practical solutions. Through its close ties to the academic community, NSF can mobilize the nation's intellectual resources to attack the challenges of infrastructure renewal. In supporting CIS research and education, NSF has the following goals:

- Enrich the science and engineering knowledge base that can advance the understanding, assessment, and intelligent renewal of civil infrastructure systems;

- Encourage the integration, transfer, and application of knowledge that will contribute to the intelligent renewal of the infrastructure, and

- Integrate research with education and training to produce the next generation of engineers, scientists, and others who will design, build, and use the civil infrastructure systems of the future.

A new strategy to achieve these goals emerged from an in-house task group, established in early 1992 to study CIS research issues. As a base for the study, in April 1992 NSF organized a workshop on CIS research to determine the need for a national focus on such research and to develop the basis for a broad-based, interdisciplinary CIS research program. Forty experts from academe, industry, professional practice, and federal agencies recommended that NSF establish a multidisciplinary CIS initiative to conduct fundamental 
research on materials, infrastructure components, and systems integration, including the transfer of research results to appropriate users.

This strategy focuses on the optimal performance of systems, in addition to understanding the individual components. Focusing on the performance of individual components in separate systems results in incremental improvement in some areas but does not substantially improve the performance of the overall system. The new strategy emphasizes systems integration at all levels and specifically addresses the need to develop new scientific and engineering knowledge in the following four key areas:

- DETERIORATION SCIENCE examines how materials and structures break down and wear out. Most construction materials are dynamic, with their properties evolving over time through changing conditions. Through research in materials science, chemistry, biology, geotechnical engineering, mechanics, failure processes, and risk/reliability, we can improve our understanding of deterioration and design, build, and maintain structures that are more durable, safer, and more environmentally sound.

- ASSESSMENT TECHNOLOGIES determine how durable, safe, and environmentally benign our structures and facilities are. Current methods are relatively primitive and unreliable, prompting conservative, often costly decisions. Research in this area can lead to nondestructive evaluation techniques, improved sensor technologies, "smart" selfcorrecting material, and enhanced geographical information systems.

- RENEWAL ENGINEERING extends and enhances the life of civil infrastructure systems and components that would otherwise continue to deteriorate. Many facilities designed for transportation, energy production and distribution, waste management, water supply, work and recreation, and communication have aged by the elements or rendered obsolete by technological progress. It would be too costly and disruptive to simply replace these vast webs; rather, we must renew them. However, we must focus research on other aspects of the process as well, such as new approaches in designing effective demolition, the compatibility of repair materials, recycling of appropriate resources, novel sensors that monitor wear, and so on. Due to the vastness of the challenge, the emphasis cannot be on the exotic, rather, it must fit the economics of real-world situations.

- INSTITUTIONAL EFFECTIVENESS AND PRODUCTIVITY recognizes the importance of those factor affecting the decision processes underlying the provision and management of civil infrastructure on the economic and social productivity of society. We must seek to understand, for example, the management and pricing of public infrastructure, public participation in decisions and variability in user needs and benefits, as well as the role of entrepreneurs in effecting urban change. Such research reveals the barriers to the most effective construction and replacement of civil infrastructure investments ont he productivity of American business and on the economic and social well-being of the American public. 
These four strategic areas reflect the complexity and multidisciplinary character of today's forefront research. They also illustrate the need to cooperate across fields of research to address national concerns.

Knowledge Transfer: An Essential Part of the Overall Strategy

It is not enough to foster the discovery and integration of new knowledge for renewal of civil infrastructure systems. NSF must also help the nation derive maximum value from these discoveries by aggressively promoting "knowledge transfer." To ensure this, NSF will support the following activities:

- Research on the barriers to innovation and knowledge utilization;

- Proof-of-concept experiments;

- Human resources and educational programs;

- Workshops and seminars; and

- Information services and networks.

NSF's knowledge transfer activities build working relationships at the research project level between academe, industry, and other potential users. This strategy is particularly effective when there are close working relationships and people exchanges, e.g., when university-trained researchers and professionals move to industry and vice versa. NSF actively promotes collaborative research among university and industry investigators.

NSF's Small Business Innovation Research (SBIR) and Small Business Technology Transfer (STTR) programs are also important components of the knowledge transfer strategy. These programs move new knowledge to the market place by supporting exploratory research to prove the technical feasibility of an idea.

\section{NSF PROGRAMS RELATED TO C\&B GOALS}

\section{$\underline{\text { Topic }}$}

- Deterioration Science

- Assessment Technologies

- Renewal Engineering

- Institutional Effectiveness and Productivity
C\&B Goals Addressed

$\begin{array}{lllllll}1 & 2 & 3 & 4 & 5 & 6 & 7\end{array}$

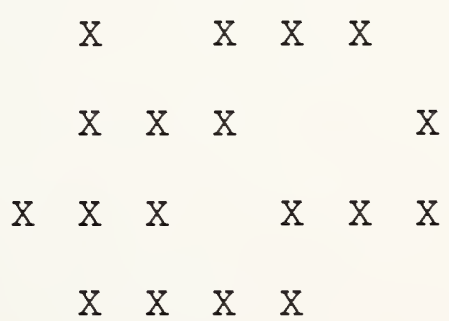






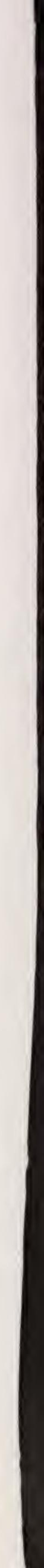

